Margit Hempel, Markus Kötter und Jutta Rymarczyk

\title{
Fremdsprachenunterricht in der Grundschule in den Bundesländern Deutschlands
}

Eine Bestandsaufnahme des Status quo und seiner gewünschten Weiterentwicklung

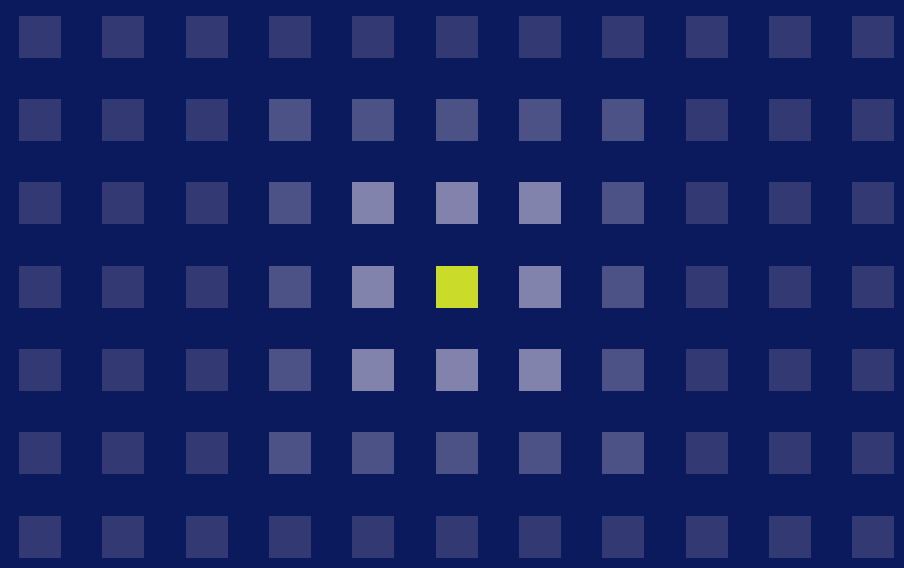




\section{Margit Hempel, Markus Kötter und Jutta Rymarczyk Fremdsprachenunterricht in der Grundschule in den Bundesländern Deutschlands}

Die Studie zum Fremdsprachenunterricht in deutschen Grundschulen bietet einen Überblick über Bundesländergrenzen hinweg in eine heterogene Bildungslandschaft, die von erheblichen curricularen Unterschieden und Widersprüchen geprägt ist. Neben dieser Bestandsaufnahme zeigen die Autoren auf, welche bildungspolitischen und fachdidaktischen Ausgestaltungen Fachleute aus Hochschulen, Landesinstituten und Schulen als sinnvoll und wünschenswert erachten. Ihr Meinungsbild erlaubt es, bundesländerübergreifende Konzepte für die qualitative Weiterentwicklung des frühen

Fremdsprachenunterrichts zu entwickeln, daraus resultierende Im- plikationen für Lehreraus- und Fortbildung zu beleuchten und so letztlich eine Basis für nationale Mindeststandards für den Fremdsprachenunterricht in der Grundschule zu bieten.

\section{Die Autoren}

Margit Hempel ist Wissenschaftliche Mitarbeiterin in der Fremdsprachendidaktik an der Universität Duisburg-Essen.

Markus Kötter ist Professor für die Didaktik der englischen Sprache an der Universität Siegen.

Jutta Rymarczyk ist Professorin für englische Sprache und ihre Didaktik an der Pädagogischen Hochschule Heidelberg. 
Fremdsprachenunterricht in der Grundschule in den Bundesländern Deutschlands 

Margit Hempel / Markus Kötter /

Jutta Rymarczyk

\section{Fremdsprachenunterricht in der Grundschule in den Bundesländern Deutschlands}

Eine Bestandsaufnahme des

Status quo und seiner gewünschten

Weiterentwicklung

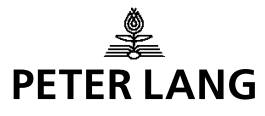




\title{
Bibliografische Information der Deutschen Nationalbibliothek
}

Die Deutsche Nationalbibliothek verzeichnet diese Publikation in der Deutschen Nationalbibliografie; detaillierte bibliografische Daten sind im Internet über http://dnb.d-nb.de abrufbar.

Die frei zugängliche digitale Publikation wurde ermöglicht mit Mitteln des BMBF-Projektes OGeSoMo der Universitätsbibliothek Duisburg-Essen. In diesem Projekt wird Open Access für geistes- und sozialwissenschaftliche Monografien gefördert und untersucht. Informationen und Ergebnisse finden Sie unter www.uni-due.de/ogesomo.

ISBN 978-3-631-74402-4 (Print)

E-ISBN 978-3-631-74845-9 (E-PDF)

E-ISBN 978-3-631-74846-6 (EPUB)

E-ISBN 978-3-631-74847-3 (MOBI) DOI 10.3726/b16457
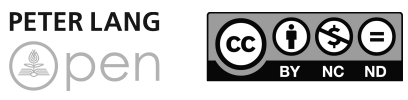

Open Access: Dieses Werk ist lizensiert unter der Creative Commons

Lizenz Namensnennung - Nicht kommerziell -

Keine Bearbeitungen 4.0 International (CC BY-NC-ND 4.0).

Den vollständigen Lizenztext finden Sie unter:

https://creativecommons.org/licenses/by-nc-nd/4.0/deed.de

(C) Margit Hempel / Markus Kötter / Jutta Rymarczyk, 2017

\author{
Peter Lang GmbH \\ Internationaler Verlag der Wissenschaften \\ Berlin \\ Peter Lang - Berlin · Bern · Bruxelles · New York \\ - Oxford $\cdot$ Warszawa $\cdot$ Wien \\ Diese Publikation wurde begutachtet. \\ www.peterlang.com
}




\section{Danksagung}

Eine Publikation wie dieses Buch bedarf stets der Unterstützung, der Hilfe und des Zuspruchs vieler Beteiligter. Ihnen allen möchten wir an dieser Stelle herzlich danken. Wir bedanken uns bei der Deutschen Gesellschaft für Fremdsprachenforschung (DGFF) für die Möglichkeit, im Rahmen ihres 26. Kongresses 2015 in Ludwigsburg ein sogenanntes Freies Format mit zwei Working Sessions zum Thema „Fremdsprachenunterricht in der Grundschule in den Bundesländern Deutschlands" abgehalten haben zu können. Wir danken Herrn Ministerialdirektor Püls, seines Zeichens seinerzeit zudem Vorsitzender der Amtschefkommission „Qualitätssicherung in Schulen“ der KMK, Herrn Ministerialrat Wolfgang Schumacher, seinerzeit KMK-Fachvertreter für den Bereich Sprachförderung und Mitglied der AG „Fremdsprachen in der Grundschule“ sowie unseren Kolleginnen und Kollegen Otfried Börner, Stefanie Frisch, Isabel Martin, Claudia Polzin-Haumann, Christiane Reissner, Jana Roos, Michaela Sambanis und Ella Schramm für Impulsbeiträge im Rahmen dieses Freien Formats. Ein weiteres herzliches Dankeschön gilt all jenen, die uns im Vorfeld der Tagung bei der Erstellung der Fragebögen als Informantinnen und Informanten zur speziellen Situation in ihren jeweiligen Bundesländern unterstützt haben, namentlich Heidi Barucki (BB), Carmen Becker (NS), Ottfried Börner (HH), Daniela Elsner (HE), Gaby Engel (NW), Cornelia Fenner (TH), Stefanie Frisch (RP - jetzt NW), Jutta Heyer (TH), Martina Kankowski (SH), Adelheid Kierepka (SA), Annika Kolb (BW), Renate Krüger (TH), Isabel Martin (BW), Alexandra Papa (BY), Claudia Polzin-Haumann (SL), Katrin Reichel-Wehnert (SN), Jana Roos (BB), Bianca Roters (NW), Michaela Sambanis (BE), Katja Schmidt (MV), Anja Steinlen (BY), Beate 
Vogel (HB). Besonders danken wir aber jenen Expertinnen und Experten aus ganz Deutschland, die zum einen unsere Working Sessions durch ihre Anwesenheit und ihre kritische Begleitung mit geprägt haben, und die uns zum anderen dadurch unterstützt haben, dass sie entweder im Laufe der Sessions oder im Anschluss daran unsere Abstimmungsbögen bearbeitet, teils ihre Urteile ergänzend kommentiert, und durch beides entscheidend zum im Buch dargelegten Urteil zum Fremdsprachenunterricht in der Grundschule in Deutschland aus der Sicht der Fachwelt beigetragen haben. Wir hoffen, ihnen allen mit dieser Publikation nun auch unsererseits etwas zurückgeben zu können - und vor allem natürlich, gemeinsam die Forschung und Praxis zielführend weiterentwickeln zu können.

Essen, Heidelberg und Siegen im Herbst 2017 


\section{Abstract}

Der frühe Fremdsprachenunterricht ist seit über einer Dekade in Deutschland etabliert und dennoch existieren - weitgehend bedingt durch die Kulturhoheit der Länder - noch immer erhebliche curriculare Unterschiede und teilweise Widersprüche in den 16 Bundesländern. Aufgrund der zentralen Prämisse des Bildungsföderalismus differieren die bildungspolitischen Entscheidungsprozesse und führen so zu unterschiedlichen Implementierungen und Ausgestaltungen des Fremdsprachenunterrichts in der Grundschule. Die vorliegende Studie versucht zum einen, einen Überblick über diese heterogene Bildungslandschaft zu vermitteln, indem sie den Status quo des Fremdsprachenunterrichts in der Grundschule mit seinen Unterschieden und Gemeinsamkeiten über die Bundesländergrenzen hinweg aufgezeigt. Zum anderen geht sie aber über die bloße Bestandsaufnahme hinaus: Auf der Basis der ermittelten Ergebnisvielfalt wurden für die Grundschule ausgewiesene Fachdidaktiker, Vertreter von Landesinstituten und Lehrkräfte befragt, welche der bildungspolitischen und fachdidaktischen Ausgestaltungen sie als sinnvoll und wünschenswert erachten. Die Resultate dieser Befragung erlauben es, mögliche bundesländerübergreifende Konzepte und konkrete Vorstellungen für die qualitative Weiterentwicklung des Fremdsprachenunterrichts in der Grundschule zu entwickeln, daraus resultierende Implikationen für Lehreraus- und Fortbildung sowie bildungspolitische Voraussetzungen zu beleuchten und so letztlich eine Basis für nationale Mindeststandards für den Fremdsprachenunterricht in der Grundschule zu bieten. 
In spite of the fact that foreign language teaching (FLT) has been made compulsory at primary level in Germany more than a decade ago, there continues to be considerable variety in the 16 federal states not only with regard to the curricula but also concerning their implementation. Thus, the first part of this twofold survey reveals the diversity of the different states with reference to the curricula, current practice and specific requirements. The second part of this survey, however, goes beyond the documentation. It presents ideas and concepts researchers, (political) decision makers and practitioners have developed building on the findings of the first part of the survey in regard to specific requirements, national standards, assessment, teaching approaches, teacher qualification and training. Based on these ideas, issues that have to be addressed in the future in order to increase the quality of early foreign language teaching (EFLT) will be discussed and thus the necessary changes in policy making and designing new curricular guidelines and national standards. 


\section{Abkürzungsverzeichnis}

\section{Abkürzungsverzeichnis der Bundesländer}

$\mathrm{BW}=$ Baden-Württemberg

$\mathrm{BY}=$ Bayern

$\mathrm{BE}=$ Berlin

$\mathrm{BB}=$ Brandenburg

$\mathrm{HB}=$ Bremen

$\mathrm{HH}=$ Hamburg

$\mathrm{HE}=$ Hessen

MV = Mecklenburg-Vorpommern

NS = Niedersachsen

NW $=$ Nordrhein-Westfalen

$\mathrm{RP}=$ Rheinland-Pfalz

$\mathrm{SL}=$ Saarland

$\mathrm{SN}=$ Sachsen

$\mathrm{SA}=$ Sachsen-Anhalt

$\mathrm{SH}=$ Schleswig-Holstein

$\mathrm{TH}=$ Thüringen

\section{Allgemeines Abkürzungsverzeichnis}

DaZ = Deutsch als Zweitsprache

DGFF $=$ Deutsche Gesellschaft für Fremdsprachenforschung ESP = Europäisches Sprachenportfolio

L1 = Erstsprache

FMKS = Verein für frühe Mehrsprachigkeit an Kitas und Schulen

$\mathrm{FU}=$ Fremdsprachenunterricht

$\mathrm{FS}=$ Fremdsprache

GER = Gemeinsamer europäischer Referenzrahmen 
$\mathrm{KiTa}=$ Kindertagesstätte

$\mathrm{KMK}=$ Kultusministerkonferenz

PS = Primarstufe

Sek. I = Sekundarstufe I 


\section{Inhaltsverzeichnis}

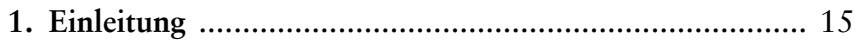

2. Didaktisch-methodische sowie bildungspolitische Themen des frühen Fremdsprachenunterrichts in den Bundesländern Deutschlands: aktueller Stand und Desiderata ....................................... 21

2.1 Immersion / Bilingualer Sachfachunterricht ............ 23

2.1.1 Zum Status quo von Immersion / Bilingualem Sachfachunterricht 23

2.1.2 Das Meinungsbild zur weiteren Handhabung von Immersion / Bilingualem Sachfachunterricht ................... 27

2.2 Lernende mit Migrationshintergrund 30

2.2.1 Zum Status quo des Themas Lernende mit Migrationshintergrund .......................... 30

2.2.2 Das Meinungsbild zur weiteren Handhabung des Themas Lernende mit Migrationshintergrund ............................... 33

2.3 Inklusion im frühen Fremdsprachenunterricht ....... 36 2.3.1 Zum Status quo von Inklusion im frühen Fremdsprachenunterricht ................. 36

2.3.2 Das Meinungsbild zur weiteren Handhabung von Inklusion im frühen Fremdsprachenunterricht ............................ 41

2.4 Schriftspracherwerb ................................................... 43

2.4.1 Zum Status quo von Schriftspracherwerb .... 43

2.4.2 Das Meinungsbild zur weiteren

Handhabung von Schriftspracherwerb ........ 44

2.5 Stellenwert der unterschiedlichen sprachlichen Kompetenzen 
2.5.1 Zum Status quo des Stellenwerts der unterschiedlichen sprachlichen Kompetenzen

2.5.2 Das Meinungsbild zur weiteren

Handhabung des Stellenwerts der unterschiedlichen sprachlichen

Kompetenzen

2.6 Grammatik, Sprachbewusstheit und sprachliche Mittel 54

2.6.1 Zum Status quo von Grammatik, Sprachbewusstheit und sprachlichen Mitteln 54

2.6.2 Das Meinungsbild zur weiteren Handhabung von Grammatik, Sprachbewusstheit und sprachlichen Mitteln ..................................... 56

2.7 Leistungsbewertung und Nutzung von Portfolios ... 60

2.7.1 Zum Status quo der Leistungsbewertung und der Nutzung von Portfolios ................... 60

2.7.2 Das Meinungsbild zur weiteren Handhabung von Leistungsbewertung und der Nutzung von Portfolios

2.8 Maßnahmen und Regelungen zum Übergang vom Fremdsprachenunterricht der Grundschule zu den weiterführenden Schulen 68

2.8.1 Zum Status quo von Maßnahmen und Regelungen zum Übergang vom

Fremdsprachenunterricht der Grundschule zu den weiterführenden Schulen 68

2.8.2 Das Meinungsbild zur weiteren Handhabung von Maßnahmen und Regelungen zum Übergang des Fremdsprachenunterrichts der Grundschule zu den weiterführenden Schulen 
2.9 Unterrichtsmethoden und Einsprachigkeit des Unterrichts .......................................................... 74

2.9.1 Zum Status quo von

Unterrichtsmethoden und

Einsprachigkeit des Unterrichts

2.9.2 Das Meinungsbild zur weiteren

Handhabung von Unterrichtsmethoden und Einsprachigkeit des Unterrichts

3. Resümee

4. Schlussfolgerungen

91

5. Literaturverzeichnis 99

6. Anhang

Anhang 1: Fragenkatalog zur Beantwortung durch die Experten (rev. Fassung)

Anhang 2: Exemplarischer Frage- und

Abstimmungsbogen 



\section{Einleitung}

Es dürfte wohl kaum ein unüberschaubareres bildungspolitisches Feld geben als das des frühen Fremdsprachenunterrichts (FU) in Deutschland. Die Gründe dafür sind in verschiedenen Umständen zu suchen: Hier ist zum einen die Bildungshoheit der 16 deutschen Bundesländer zu nennen, weil aufgrund dessen 16 individuelle Lehrpläne für das frühe Fremdsprachenlernen existieren, bzw. de facto eine noch viel höhere Zahl. Wenn man nämlich berücksichtigt, dass fast in jedem Bundesland mehrere Fremdsprachen in der Primarstufe unterrichtet werden, die je einem eigenen Lehrplan folgen, und wenn man ferner bedenkt, dass es in manchen Ländern zusätzlich Lehrpläne für Deutsch als Zweitsprache auf der Primarstufe gibt, so ist die Gesamtsumme der Lehrpläne fast doppelt so hoch wie die der Bundesländer. Zum anderen ist der FU der Primarstufe ein Gebiet, das sich auch mehr als zehn Jahre nach seiner flächendeckenden Einführung sowohl hinsichtlich seiner Grundlagenforschung als auch in didaktisch-methodischer Hinsicht bzw. in seinen organisatorischen Grundstrukturen kontinuierlich weiterentwickelt. Deutschland stellt damit keine Ausnahme dar, wie vergleichenden Überblicksstudien zu entnehmen ist, darunter die von Shelagh Rixon verfasste Studie British Council Survey of Policy and Practice in Primary English Language Teaching Worldwide (2013). Daher bezeichnet auch Gail Ellis im Vorwort zu diesem Überblick frühen Englischunterricht als „the biggest policy development in education and fastest growing area in ELT over the last 30 years" (Ellis in Rixon 2013, S. 2).

In Deutschland existiert der obligatorische FU in der Grundschule in den meisten Bundesländern seit 2004. Wie der Bericht der Kultusministerkonferenz (KMK) vom 17.10.2013 zeigt, gibt es jedoch noch immer kaum bundes- 
weit einheitliche Regelungen: Vielmehr bestehen sowohl hinsichtlich des Beginns, der wöchentlichen Stundenzahl, der Ausbildung der Lehrkräfte, der verwendeten Lehrmaterialien und des Umgangs mit der Schriftsprache als auch der Vorgaben zur Benotung bzw. Leistungsmessung teils erhebliche Unterschiede zwischen den Bundesländern (KMK 2013).

Es ist dieser Heterogenität der deutschen Bildungslandschaft sowie der schnellen Weiterentwicklung des frühen FU geschuldet, dass wir es uns Anfang des Jahres 2015 zum Ziel gesetzt hatten, durch Expertenbefragungen Informationen zu den einzelnen Bundesländern Deutschlands zu sammeln, um Gemeinsamkeiten bzw. Unterschiede sowie die Handhabung essenzieller Aspekte des FU in der Grundschule wie beispielsweise den zeitlichen Rahmen des Unterrichts, seine inhaltlichen Schwerpunktsetzungen, methodischen Ansätze etc. näher beleuchten zu können.

Im Unterschied zu Rixons internationaler Erhebung (2013) und zu dem Bericht der KMK (2013) geht unsere Überblicksstudie allerdings über eine reine Bestandsaufnahme hinaus. Es ging uns nämlich nicht nur darum, den Status quo zu erfassen, sondern auch darum zu erfahren, wie Experten ${ }^{1}$ jenseits der Lehrplankommissionen einerseits die aktuelle Ausgestaltung von Variablen wie beispielsweise der Zahl der wöchentlichen Unterrichtsstunden oder dem Zeitpunkt und der Methodik zur Einführung der Schriftsprache im FU der Primarstufe beurteilen, und wie andererseits potenziell zweckmäßigere Alternativen aussehen könnten.

Der Weg zu diesem Meinungsbild umfasste drei Schritte (vgl. Abb. 1): Zunächst ist hier eine Erhebung per Fragenkatalog zum Status quo in den 16 Bundesländern zu nennen,

1 In diesem Band werden die männlichen Formen als generisch verstanden. 
an der insgesamt rund zwei Dutzend Experten für frühes Fremdsprachenlernen teilnahmen. Dieser Expertenkreis setzte sich aus für die Primarstufe ausgewiesenen Fremdsprachendidaktikern an Hochschulen und Universitäten sowie an den Landesinstituten für Schule bzw. Schulentwicklung der einzelnen Bundesländer zusammen (vgl. auch die Danksagung zu Beginn des Bandes). Schritt 2 erfolgte während des 26. Kongresses für Fremdsprachendidaktik der Deutschen Gesellschaft für Fremdsprachenforschung (DGFF) 2015 in Ludwigsburg in Form von Working Sessions im Rahmen des zweitägigen Freien Formats „Fremdsprachenunterricht in der Grundschule in den Bundesländern Deutschlands“. Schritt 3 bestand aus dem Einholen begründeter Meinungsbilder, einer Erhebung per Frage- und Abstimmungsbögen, mit der wir während der Working Sessions begonnen hatten und die wir im Anschluss daran fortsetzten, um eine höhere Zahl an Primarstufenexperten einbeziehen zu können (vgl. hierzu auch Hempel, Kötter, Rymarczyk \& Steinlen 2017).

Der an die Experten geschickte Fragenkatalog enthielt 21 Fragen zu frühem FU (vgl. Anhang 1) und erlaubte es uns so, das Feld erst einmal sehr großflächig zu sondieren. Für die weitere Arbeit wählten wir aus diesem Fragenkatalog einzelne Fragen und die zu ihnen erhaltenen Informationen aus und fassten sie zu den folgenden neun Themenfeldern zusammen: „Immersion / Bilingualer Sachfachunterricht“, „Lernende mit Migrationshintergrund“, „Inklusion“, „Schriftspracherwerb“, „Kompetenzen“, „Language awareness / sprachliche Mittel“, „Leistungsbewertung / Portfolio“, „Übergang“ und „Unterrichtsmethodik“.

Während der Working Sessions wurden in mehreren Kurzvorträgen Schlaglichter auf die curricularen Brennpunkte unter diesen neun Themen geworfen, also auf jene Bereiche, die von einzelnen Bundesländern unterschiedlich gehandhabt bzw. teils sogar derartig gegensätzlich gesehen werden, 
dass die jeweilige schulische Praxis als diametrale Endpunkte einer Skala verstanden werden können. Es war unser Bestreben, über den Austausch und die Diskussionen zu diesen unterschiedlichen Umsetzungsformen in den Bundesländern gleichermaßen Urteile von Fachleuten für die Primarstufe einzuholen und herauszufinden, welche Vorgehensweisen bzw. Handhabungen einzelner fremdsprachendidaktischer Aspekte von der Mehrheit präferiert werden. $\mathrm{Zu}$ diesem Zweck hatten wir Frage- und Abstimmungsbögen zu den o.g. neun Einzelaspekten entwickelt, die versuchten die möglichen Spannbreiten in der Ausprägung bzw. im Umgang mit den Einzelaspekten des FU auf der Primarstufe wiederzugeben (vgl. den exemplarischen Bogen in Anhang 2).

Die Frage- und Abstimmungsbögen für diese zweite Erhebung (Schritt 3) basierten auf den Informationen zu dem Fragenkatalog aus der ersten Erhebungsphase. Damit entspricht ihr Inhalt dem Stand von 2015 bzw. dem, was uns zuvor von den Befragten zu ihrem jeweiligen Bundesland mitgeteilt worden war. Um sicherzustellen, dass alle Teilnehmer an dieser zweiten Erhebung über den aktuellen Kenntnisstand der Diskussion aus den DGFF-Working Sessions in Ludwigsburg verfügten, enthielten die Frage- und Abstimmungsbögen nicht nur die didaktisch-methodischen bzw. bildungspolitischen Alternativen, über die es abzustimmen galt, sondern zunächst einmal zusätzlich grundlegende Informationen zu den einzelnen Themen bezüglich ihrer Umsetzung in den einzelnen Bundesländern Deutschlands (vgl. Anhang 2). Weitere aktuelle Informationen zu den neun Themen, die wir während und nach den Working Sessions im Herbst 2015 erhielten bzw. recherchiert haben, sind den Auswertungen der Frage- und Abstimmungsbögen bzw. den Darstellungen der Meinungsbilder hinzugefügt.

Die Grundschulexperten erhielten somit die Möglichkeit, unabhängig von den bildungspolitischen Regelungen und den 
didaktisch-methodischen Handhabungen in ihrem jeweiligen Bundesland persönlich Stellung zu beziehen und für die von ihnen favorisierte Vorgehensweise in den verschiedenen Bereichen der Grundschulfremdsprachendidaktik zu votieren.

Abb. 1: Abfolge der Schritte der Überblicksstudie zum Status quo und der Weiterentwicklung des frühen $F U$

\begin{tabular}{|l|l|}
\hline Schritt 1 & $\begin{array}{l}\text { Erhebung per Fragenkatalog zum Status quo in den } \\
\text { 16 Bundesländern an ein bis zwei Experten für frühes } \\
\text { Fremdsprachenlernen, erste Jahreshälfte 2015 (N = 22) }\end{array}$ \\
\hline & \multicolumn{1}{|c|}{$\downarrow$} \\
\hline Schritt 2 & $\begin{array}{l}\text { Working Sessions „Fremdsprachenunterricht in der } \\
\text { Grundschule in den Bundesländern Deutschlands“ beim } \\
\text { DGFF-Kongress 2015 in Ludwigsburg: Schlaglichtartige } \\
\text { Vorstellung einzelner bildungspolitischer und } \\
\text { didaktisch-methodischer Aspekte und ihrer } \\
\text { idiosynkratischen Handhabung in verschiedenen } \\
\text { Bundesländern }\end{array}$ \\
\hline Schritt 3 & \multicolumn{1}{|c|}{$\downarrow$} \\
& $\begin{array}{l}\text { Votum per Frage- und Abstimmungsbogen } \\
\text { während der Working Sessions bzw. im Anschluss } \\
\text { daran zur Erstellung eines Meinungsbildes zu } \\
\text { optimalen bildungspolitischen Regelungen und } \\
\text { didaktisch-methodischen Handhabungen im Bereich des } \\
\text { frühen FU Ende 2015/ Anfang 2016 (N = max. 39) }\end{array}$ \\
\hline
\end{tabular}

Der Vergleich und die Diskussion der Resultate sollen Forscher, Lehrkräfte und nicht zuletzt Bildungspolitiker dazu anregen, konkrete Vorstellungen zur Vereinheitlichung einzelner Aspekte (z. B. zum Beginn des FU in der Grundschule) zu entwickeln und den Austausch zu noch offenen Fragestellungen zu fördern. Ziel dieser Bestandsaufnahme ist somit die qualitative Weiterentwicklung des FU in der Grundschule sowie letztlich die Entwicklung und Implementierung 
bundesländerübergreifender Bildungsstandards. Wir sind der Meinung, dass einzig Bildungsstandards einen einheitlichen, hohen Standard des FU der Primarstufe sichern und ihm zu dem Renommee verhelfen können, das er braucht, wenn die Forderung der europäischen Kommission, jeder Bürger Europas solle neben seiner Erstsprache zwei weitere Fremdsprachen beherrschen (Europäische Kommission 1996), eingelöst werden soll. 


\section{Didaktisch-methodische sowie bildungspolitische Themen des frühen Fremdsprachenunterrichts in den Bundesländern Deutschlands: aktueller Stand und Desiderata}

Zu Beginn des Jahres 2015 haben wir bundesweit einen Fragenkatalog (vgl. Anhang 1) zur Erhebung des Status quo an für die Grundschule ausgewiesene Experten (Fremdsprachendidaktiker für Englisch und/oder Französisch und Vertreter von Landesinstituten) verschickt. Da die gesamte Studie ursprünglich nur für den Englischunterricht der Primarstufe geplant war, sind in unserem Forscherteam nur Anglisten vertreten und auch die Mehrzahl der befragten Experten vertritt das Fach Englisch. Die Entscheidung auch den Französischunterricht zu betrachten, fiel erst spät, und zwar als es um die Abdeckung aller Bundesländer ging, denn das Saarland (SL) konnte nur über die Integration des Faches Französisch in die Umfrage aufgenommen werden. Auf die Ausweitung auf weitere Grundschulfremdsprachen wurde allerdings verzichtet, so dass weder die in den Grenzregionen unterrichteten Sprachen der jeweiligen Nachbarländer wie etwa Niederländisch oder Sorbisch/Wendisch einbezogen wurden noch weitere klassische Schulfremdsprachen wie beispielsweise Spanisch oder Russisch.

Der Fragenkatalog umfasste Fragen aus verschiedenen Bereichen wie z. B. die Organisation des Unterrichts (Beginn in welcher Jahrgangsstufe, Stundenumfang, welche Sprachen, Vorbereitung durch bilinguale Kindergärten, etc.), konkrete Inhalte (Schriftspracherwerb, Sprachbewusstheit, etc.) und die Frage nach Methoden (Bilingualer Sachfachunterricht, Inklusion, kooperatives Lernen, Einsatz von Lehrwerken, etc.). 
Er wurde von insgesamt 22 Experten für die 16 Bundesländer ausgefüllt (vgl. die dem Buch vorangestellten Danksagung).

Obwohl die Grundschulzeit in Berlin (BE) und Brandenburg (BB) erst mit der Jahrgangsstufe 6 endet, werden im Folgenden aus Gründen der Vergleichbarkeit nur die Jahrgangsstufen 1-4 berücksichtigt. Diese Beschränkung erfolgt vor dem Hintergrund unseres Fernziels, länderübergreifende Bildungsstandards für den FU auf der Primarstufe zu etablieren. Es soll mit der Klammer der Jahrgangsstufen 1-4 kein Bundesland ignoriert werden, aber wir können nur von diesen Jahrgangsstufen ausgehen, wenn wir zu einer brauchbaren, länderübergreifenden Basis gelangen wollen.

Aus den Ergebnissen dieser ersten Erhebung kristallisierten sich neun Themen als Hauptaspekte heraus: „Immersion / Bilingualer Sachfachunterricht“, „Lernende mit Migrationshintergrund“, „Inklusion“, „Schriftspracherwerb “, „sprachliche Kompetenzen“, „Language awareness / sprachliche Mittel“, „Leistungsbewertung / Portfolio“, „Übergang des FU der Primarstufe zur Sekundarstufe“ und „Unterrichtsmethodik". Zu jedem dieser Themen wurde in einem zweiten Schritt ein Frage- und Abstimmungsbogen entwickelt und im Bündel des Sets der insgesamt neun Bögen während des Kongresses der Deutschen Gesellschaft für Fremdsprachenforschung (DGFF) in Ludwigsburg im Jahr 2015 verteilt. Die Frage- und Abstimmungsbögen wurden fast ausschließlich von den Teilnehmern des zweitägigen sogenannten Freien Formats „Fremdsprachenunterricht in der Grundschule in den Bundesländern Deutschlands”, das von den Autoren dieses Bandes abgehaltenen worden war, ausgefüllt $(\mathrm{N}=\max$. 39). Im Folgenden wird auf diese Personengruppe als „Befragte" Bezug genommen, während die Gruppe derjenigen, die zu Beginn des Projekts den Fragenkatalog beantwortet hatten, als „Experten” bezeichnet wird. 
In den folgenden Unterkapiteln werden die erhobenen Daten sukzessive in jeweils zwei Teilen (X.1 und X.2) behandelt (vgl. 2.1.1 und 2.1.2-2.9.1 und 2.9.2). Teil 1 bezieht sich auf den aktuellen Stand bzw. die aktuelle Handhabung eines Aspekts in den einzelnen Bundesländern im Jahr 2015 und basiert hauptsächlich auf den Informationen der von uns mittels des Fragenkatalogs befragten Experten. Textstellen, an denen wir auf andere Quellen zurückgreifen, sind entsprechend gekennzeichnet; alle restlichen Informationen gehen jeweils auf die Aussagen der Experten zurück. Teil 2 gibt das Meinungsbild der beim DGFF-Kongress im Rahmen des Freien Formats „Fremdsprachenunterricht in der Grundschule in den Bundesländern Deutschlands" per Frage- und Abstimmungsbogen befragten Fachleute wieder. Die jeweils zur Abstimmung stehenden Fragen bzw. Thesen finden sich - einschließlich der erzielten Voten der von uns befragten Fachleute - in den sie betreffenden Kapiteln wieder. Ein kompletter Frage- und Abstimmungsbogen ist in Anhang 2 beigefügt, um exemplarisch aufzuzeigen, mit welchem Instrument die jeweils in Teil 2 der Kapitel referierten Daten erhoben wurden. Auf die komplette Darstellung aller Bögen wird verzichtet, da deren Inhalte im Fließtext der einzelnen Kapitel verschriftlicht werden.

\subsection{Immersion / Bilingualer Sachfachunterricht}

\subsubsection{Zum Status quo von Immersion / Bilingualem Sachfachunterricht}

Das Thema „Immersion / Bilingualer Sachfachunterricht“ ist das einzige Feld, bei dem unsere Erhebung auch den vorschulischen Bereich einschließt. Der Grund dafür liegt darin, dass uns die quantitative Relation zwischen bilingualen Kindertagesstätten (KiTas) und Grundschulen sowie die Frage interessiert, in wieweit es auf diesem Gebiet eine potenzielle Kontinuität gibt. 
Die Antworten der Experten für die einzelnen Bundesländer zeigen, dass die Zahl bilingualer KiTas in der Regel keine Rückschlüsse auf die Zahl der Grundschulen erlaubt. ${ }^{2}$ Tatsächlich gibt es eine Reihe von Ländern mit einer hohen Zahl an bilingualen vorschulischen Einrichtungen bei nur vergleichsweise wenigen bilingualen Grundschulen. Hier ist zuallererst das SL zu nennen, das mit $185 \mathrm{KiTas}$ (davon 184 französisch-deutsch, eine englisch-deutsch) als Spitzenreiter für bilinguale KiTas in Deutschland gilt, jedoch nur vier französisch-deutsche Grundschulen aufweist. Im Gegensatz dazu steht BW mit einer potentiell hohen Korrelation bilingualer Eirichtungen: 34 KiTas und 25 Grundschulen (davon 13 französisch-deutsch). Die meisten bilingualen Grundschulen (38, davon 17 englisch-deutsch) befinden sich in BE. Diesen 17 Grundschulen stehen 47 englisch-deutsche KiTas gegenüber. Das Schlusslicht bildet MV mit zwei bilingualen KiTas und einer Grundschule (englisch-deutsch).

Fremdsprachliche Schwerpunktsetzungen in KiTas finden sich nicht nur im SL mit der starken Dominanz des Französischen, sondern auch in anderen Bundesländern, die die Sprachen der Nachbarländer aufgreifen. Hier ist vor allem SN zu nennen mit 32 sorbisch-deutschen, vier tschechischdeutschen und drei polnisch-deutschen KiTas sowie $\mathrm{SH}$ mit 57 dänisch-deutschen Einrichtungen. Plattdeutsch-deutsche Kitas (18) sind das Alleinstellungsmerkmal von NI. Auch Herkunftssprachen werden unter den 20 Sprachen, die in den

2 Da die Angaben zu einzelnen Ländern entweder sehr unterschiedlich ausfielen oder auch gar nicht gemacht werden konnten, entstammen die folgenden Zahlen anders als die dem Abstimmungsbogen zu diesem Thema zugrunde liegenden den Berichten „Bilinguale Kitas in Deutschland” und „Bilinguale Grundschulen in Deutschland" des Vereins für frühe Mehrsprachigkeit an Kindertageseinrichtungen und Schulen (FMKS) (2014a, b). 
Programmen deutscher KiTas vorkommen, berücksichtigt. BE ist hier als das Bundesland mit der größten Sprachenvielfalt zu nennen. In den insgesamt 173 Berliner KiTas werden insgesamt 12 Herkunftssprachen gesprochen, davon 33 mal Türkisch, 23 mal Spanisch und 16 mal Russisch. Die meisten der insgesamt 1035 bilingualen vorschulischen Einrichtungen in Deutschland arbeiten jedoch mit Englisch (41 \%) oder Französisch (30 \%).

Der Anteil der englisch-deutschen KiTas an der Gesamtzahl bilingualer vorschulischer Einrichtungen ist dem der Grundschulen sehr ähnlich. Von den 287 bilingualen Grundschulen arbeiten $44 \%$ mit Englisch. Nach Auskunft des Vereins für frühe Mehrsprachigkeit an Kindertageseinrichtungen und Schulen (FMKS 2014b) bieten die bilingualen Grundschulen 17 Fremd- bzw. Herkunftssprachen an. Ergänzend ist hier jedoch durch die von uns erhobenen Daten das Angebot in HH herauszustellen, das bereits seit 2015 u. a. aktuelle Migrantensprachen berücksichtigt: Albanisch, Bosnisch, Dari, Farsi und Romanes.

Den Verbund von KiTa und Grundschule findet man nach wie vor nur sehr selten. In den meisten Fällen handelt es sich dabei um private Einrichtungen wie z.B. die International Schools, die in mehreren Bundesländern vertreten sind. Einige private Verbünde bieten mehr als ein Sprachprogramm an (maximal drei), wobei zumeist mit den Paaren englischdeutsch und französisch-deutsch gearbeitet wird. Auch staatliche Verbundprogramme sind äußerst rar; eine große Ausnahme, da hier auch noch eine weiterführende Schule angeschlossen ist, weist die Stadt Tübingen mit einem Verbund von bilingualer KiTa - bilingualer Grundschule und bilingualem Gymnasium auf (Umgangs- bzw. Unterrichtssprachen englisch-deutsch). Eine verpflichtende Kopplung bilingual arbeitender Grundschulen und weiterführender Schulen scheint in keinem Bundesland zu existieren. Es werden jedoch einzelne Verbünde von Grund- und Sekundarschulen genannt (z. B. HH mit drei Verbünden). 
Laut Angaben unserer Experten variiert die Kontaktzeit mit der Fremdsprache in den bilingualen Grundschulen sehr stark: Von 50 \% des gesamten Unterrichts in Immersionsprogrammen (wie z.B. an sechs Immersionsschulen in $\mathrm{HH}$ ) über unregelmäßig eingesetzte bilinguale Module (wie z. B. in BW) bis hin zu einzelnen Stunden Englisch (oder Französisch), Russisch und Spanisch, die ab Klasse 3 im 6-Wochen-Turnus zusätzlich zu den regulären Englisch- bzw. Französischstunden ab Klasse 1 in einem Thüringer Projekt angeboten werden. Dabei stehen das Kennenlernen der Sprachen und die Erziehung zur Mehrsprachigkeit im Vordergrund (Daten unserer Erhebung). Ein entscheidender Faktor bei der Kontaktzeit mit der Fremdsprache ist der Beginn der fremdsprachlichen Unterrichtsführung. Während der reguläre FU in den meisten Bundesländern nach wie vor ab Klasse 3 einsetzt, beginnen bilinguale Programme auch in diesen Ländern ab Klasse 1. In fast allen Ländern gibt es Schulversuche mit bilingualem FU ab Klasse 1 oder Unterricht in unregelmäßig eingesetzten bilingualen Modulen bzw. Schulen, die Ausnahmen von der Regelung FU ab Klasse 3 beantragt haben.

Während der Beginn bilingualen Sachfachunterrichts auf der Sekundarstufe häufig als grassroots Bewegung bezeichnet wird, scheint der Impetus zu bilingualem Unterrichten in der Primarstufe eher von den Hochschulen auszugehen. In BW weisen fast alle Pädagogischen Hochschulen einen Schwerpunkt in bilingualem Lehren und Lernen auf, aber die Grundschulen des Landes bieten nur selten durchgängigen bilingualen Unterricht an. Oftmals besteht - wie auch aus TH berichtet - eine nur geringe Verbreitung des Gedankens bilingualen Unterrichts unter den Lehrkräften. Eine Ausnahme stellt in diesem Kontext der bayerische Schulversuch „Lernen in zwei Sprachen - Bilinguale Grundschule Englisch“ dar. Die Stiftung Bildungspakt Bayern und das Bildungsministerium starteten 2015 den vierjährigen Schulversuch mit 21 Modellschulen, an denen Kunst, Musik 
und Sport (sowie ggf. weitere Fächer) auf Englisch unterrichtet werden (vgl. Stiftung Bildungspakt Bayern 2017).

\subsubsection{Das Meinungsbild zur weiteren Handhabung von Immersion / Bilingualem Sachfachunterricht}

Soll der FU der Grundschule durch Immersions- bzw. bilinguale Kindertagesstätten institutionell (d.h. mit Förderung durch das Land/Kultusministerium) vorbereitet werden? $(\mathrm{N}=38)$

\begin{tabular}{|l|l|l|l|l|}
\hline Stimme zu & $\begin{array}{l}\text { Stimme eher } \\
\text { zu }\end{array}$ & $\begin{array}{l}\text { Weder } \\
\text { noch }\end{array}$ & $\begin{array}{l}\text { Stimme eher } \\
\text { nicht zu }\end{array}$ & $\begin{array}{l}\text { Stimme } \\
\text { nicht zu }\end{array}$ \\
\hline $9(23,7 \%)$ & $15(39,5 \%)$ & $3(7,9 \%)$ & $4(10,5 \%)$ & $7(18,4 \%)$ \\
\hline
\end{tabular}

Das Ergebnis der Abstimmung zum möglichen Ausbau immersiver bzw. bilingualer KiTas ${ }^{3}$ zeigt, dass die Befragten dies mehrheitlich befürworten. Dieses Meinungsbild spiegelt sich nicht nur in den Zahlen wider (63\% der Befragten stimmten (eher) zu), sondern auch in den weiteren Anmerkungen. Es wurde deutlich zum Ausdruck gebracht, dass bilinguale KiTas nicht verpflichtend sein sollten, jedoch als Wahloption wünschenswert seien.

Diverse Teilnehmer der Abstimmung sprachen sich für ein professionelles Angebot aus, dessen Grundvoraussetzungen sie in einer guten Ausbildung und sehr guten Fremdsprachenkenntnissen der Erzieher sehen („muss professionell gemacht werden und verlangt größte Anstrengungen “). Zweifel an der Realisierbarkeit bestanden aber aufgrund der Kosten: „Das wäre schön, aber nicht finanzierbar. Es gibt zu wenig ausgebildetes Personal”.

3 Da der FMKS in seiner Auswertung nicht zwischen bilingualen und immersiv arbeitenden Einrichtungen unterscheidet, haben auch wir bei dieser Frage auf eine entsprechende Differenzierung verzichtet. 
Der Einsatz der Fremdsprache solle auf keinen Fall einer Lehrgangssystematik ähneln oder gar folgen, vielmehr wurden kleine Aktivitäten befürwortet, die die Fremdsprache auf spielerische Weise einbringen. Es wurde dezidiert darauf hingewiesen, dass bilinguale KiTas nicht auf den FU vorbereiten, da die Arbeitsweisen als zu unterschiedlich angesehen werden. Allerdings sprach man sich dafür aus, dass Programmverbünde entstehen: „Ich fände es wichtig, dass IM [= Immersions, die Autoren] -Kitas IM-Schulen vorgeschaltet sind".

Ein weiteres Argument dafür bilinguale KiTas als optionales Angebot statt als flächendeckenden, festen Bestandteil zu etablieren, ist der Hinweis auf Angebot und Nachfrage. Es wurde dafür plädiert, dass das Angebot den Initiativen von Eltern folgend weiter für verschiedene Sprachen ausgebaut werden solle. Andernfalls, so gaben einige in ihren Anmerkungen zu bedenken, könne die Vielfalt verlorengehen und eher Englisch als z. B. Herkunftssprachen angeboten werden.

Über ein Drittel der Befragten (35,1\%) zeigte sich der Ausweitung des Angebots immersiver und/oder bilingualer Kitas gegenüber skeptisch bzw. lehnte sie ab, führte aber in der Regel keine expliziten Begründungen dafür an.

Soll bilingualer Sachfachunterricht (Spektrum Immersion - bilinguale Module) fester, verpflichtender Bestandteil des Grundschulunterrichts werden? $(\mathrm{N}=37)$

\begin{tabular}{|c|c|c|c|c|}
\hline Stimme zu & $\begin{array}{l}\text { Stimme eher } \\
\mathbf{z u}\end{array}$ & $\begin{array}{l}\text { Weder } \\
\text { noch }\end{array}$ & $\begin{array}{l}\text { Stimme eher } \\
\text { nicht zu }\end{array}$ & $\begin{array}{l}\text { Stimme } \\
\text { nicht zu }\end{array}$ \\
\hline $13(35,1 \%)$ & $13(35,1 \%)$ & 0 & $4(10,8 \%)$ & $7(18,9 \%)$ \\
\hline \multicolumn{5}{|c|}{ Mit folgender Variante: } \\
\hline \multicolumn{2}{|c|}{ Immersions-Programme } & \multicolumn{2}{|c|}{$\begin{array}{l}\text { bilingualer } \\
\text { Sachfachunterricht }\end{array}$} & $\begin{array}{l}\text { bilinguale } \\
\text { Module }\end{array}$ \\
\hline \multicolumn{2}{|c|}{$2(5,4 \%)$} & \multicolumn{2}{|c|}{$4(10,8 \%)$} & $13(35,1 \%)$ \\
\hline
\end{tabular}




\begin{tabular}{|c|c|c|}
\hline $\begin{array}{l}\text { fächerübergreifender } \\
\text { Unterricht }\end{array}$ & $\begin{array}{l}\text { fächerübergreifende } \\
\text { Projekte }\end{array}$ & \\
\hline $8(21,6 \%)$ & $10(27,0 \%)$ & \\
\hline
\end{tabular}

Das Votum zur Einrichtung verpflichtender bilingualer Angebote an Grundschulen fiel mit einem Anteil von 70,2 \% der Befragten, die diesem Aspekt zustimmten, noch eindeutiger aus als jenes zu der Frage nach der Einrichtung immersiver und/oder bilingualer Angebote im Vorschulbereich. Von den möglichen Alternativen empfahlen die meisten Befragten die Arbeit mit bilingualen Modulen oder Projekten und somit von kürzeren Phasen bilingualen Unterrichts. Zwei Befragte kommentierten ihre uneingeschränkte Zustimmung („Stimme zu“) zu bilingualem Sachfachunterricht als festem, verpflichtendem Bestandteil des Grundschulunterrichts „als Idealziel".

Die Anmerkung eines Befragten, „je nach Kapazitäten und Kompetenzen”, vermag als Leitsatz zu dienen. In Bezug auf den erforderlichen Personalbedarf befürchteten einige nämlich trotz einer grundsätzlich sehr positiven eigenen Haltung zu bilingualem und immersivem Lernen, dass eine flächendeckende Realisierung solcher Angebote unmöglich sei und so Selektionsgefahr bestehe. Leistungsstarke Kinder besuchten dann u. U. die Schulen mit immersiven/bilingualen Angeboten, während die anderen Lernenden sich auf die Regelschulen verteilten. Dem steht der Vorschlag gegenüber, bilingualen Unterricht nicht für alle Grundschulen vorzusehen, sondern Schulen die Möglichkeit zur Schaffung bilingualer Profile sowie Eltern und Schülern zu einer entsprechenden Schulwahl zu eröffnen.

So oder so benötige man allerdings sehr gut ausgebildete Lehrkräfte, und zwar sowohl im Hinblick auf die Fremdspra- 
che und das Sachfach als auch auf die Didaktik und Methodik des bilingualen Sachfachunterrichts bzw. des immersiven Unterrichts: „Das Englischstudium allein bereitet darauf nicht ausreichend vor”. Die Herausforderungen an die Lehrkräfte wurden klar gesehen und die erfolgreiche Umsetzung der Methode teils angezweifelt: „Wenn in Immersionsklassen, wie man es gelegentlich erleben kann, nur die Lehrkraft Englisch spricht und es akzeptiert, dass die Kinder generell auf Deutsch antworten und sie weder zum Englischsprechen angehalten werden noch Unterstützung dafür erhalten, ist das eine vertane Chance“.

Der Grundtenor gegenüber der Ausweitung immersiver und/oder mit bilingualem Sachfachunterricht arbeitenden Einrichtungen ist jedoch ein positiver: Es wird für eine Art „bilinguale Propädeutik“, auch fächer- und lernbereichsverbindend plädiert, um über die sonst in den Grundschulen zumeist üblichen 2 x 45 Minuten hinaus Wissens- und Fertigkeitenerwerb in der Fremdsprache zu ermöglichen. Es scheint weitgehend Konsens zu sein, dass diese Art von Unterricht den Lehrkräften viel abverlangt, denn in mehreren Anmerkungen wurde darauf hingewiesen, dass die Lehrkräfte nicht nur entsprechend ausgebildet, sondern auch motiviert und engagiert sein müssten.

\subsection{Lernende mit Migrationshintergrund}

\subsubsection{Zum Status quo des Themas Lernende mit Migrationshintergrund}

Besonders in aktuelleren Debatten wird die Diskussion zu Lernenden mit Migrationshintergrund vielerorts unter dem Stichwort „Heterogenität“ als Teil des Diskurses zur Inklusion eingebunden. Hier wird sie dagegen bewusst gesondert behandelt, um dadurch die Besonderheiten dieser Schüler- 
gruppe ebenso wie auch das Potenzial von Mehrsprachigkeit deutlicher herausarbeiten zu können.

Der Mikrozensus von 2014 weist für HB die höchste Zahl an Kindern und Jugendlichen unter 15 Jahren mit Migrationshintergrund aus ${ }^{4}$ : Ihr Anteil an der altersgleichen Bevölkerung beträgt dort $80 \%$; es folgen urbane Gebiete Südhessens mit $70 \%$. Das andere Ende des Spektrums bilden MV, TH, SA mit weniger als $16 \%$. Insgesamt stellte sich bei der Zusammenfassung der Ergebnisse die Frage, wie die Deutschkenntnisse und/oder Mehrsprachigkeit von Schülern mit Migrationshintergrund zu berücksichtigen sind. Einerseits wurden z. B. in $\mathrm{HH}$ bereits beide Elternteile von fast zwei Drittel aller Schüler mit Migrationshintergrund (61,3\%) in Deutschland geboren, weshalb davon auszugehen ist, dass Deutsch bei den meisten dieser Schüler die dominante Sprache ist bzw. dass sie hier über erstsprachliche Kompetenzen verfügen. Andererseits waren durch die Flüchtlingssituation auch 2015 bereits sehr viele Schüler hinzugekommen, die noch überhaupt kein Deutsch sprachen.

Die diesbezüglichen Maßnahmen in den Lehrplänen einiger Länder fallen entsprechend disparat aus: NI und NW sehen eine konkrete Einbindung von Mehrsprachigkeit in den Englischunterricht vor. Dabei wird in NW die mehrsprachige und multikulturelle Lebenswelt von Kindern der Zielkulturräume für die Bewusstmachung der sprachlichen und kulturellen Vielgestaltigkeit des eigenen Umfelds herangezogen, während in NI die Herkunftssprachen zu Sprachbe-

4 Um die Ausgangslage für die Erhebung des Meinungsbildes nicht falsch darzustellen, müssen hier die Zahlen des Mikrozensus von 2014 (Destatis 2017 (2015)) wiedergegeben werden, auch wenn die aktuellen Zahlen durch die Flüchtlingsströme der letzten Jahre entschieden höher ausfallen. 
trachtungen und -vergleichen genutzt werden. Auch TH sieht Sprachvergleiche vor und entwickelt dafür Lehrmaterialien. Andernorts wird an die vorhandene (bzw. herauszubildende) Mehrsprachigkeit der Schüler curricular dagegen noch kaum angeknüpft, auch wenn Initiativen einzelner Schulen und schulübergreifend angelegte Kooperationen wie z.B. der Fachkongress „Die hundert Sprachen der Kinder“ (BW; vgl. MKJS BW 2014) oder das Projekt „Family Literacy“ (HH; vgl. LI Hamburg 2012) darauf hindeuten, dass die Dinge hier langsam in Fluss geraten. Zudem hat laut den Angaben unserer Befragten im Jahr 2015 etwa SA bereits auf die steigende Zahl an Flüchtlingskindern reagiert, indem ein spezielles Fortbildungsprojekt zu Mehrsprachigkeit auf den Weg gebracht wurde.

Auch die Berücksichtigung von Familiensprachen differiert stark. Während der Einbezug von Herkunftssprachen in manchen Ländern noch nicht bildungspolitisch verankert ist (z. B. BW, MV, TH), gibt es in anderen ein Curriculum bzw. einen Rahmenplan für herkunftssprachlichen Unterricht (NI, $\mathrm{HB}, \mathrm{SN}, \mathrm{RP})$. Vieles hängt von dem Engagement einzelner Lehrkräfte ab, ist fakultativ wie z. B. zweisprachige deutschtürkische Alphabetisierung und Erziehung (BE) oder liegt im Nachmittagsbereich (vgl. SN mit zwei bis vier Wochenstunden Herkunftssprachenunterricht unter regulärer Schulaufsicht in 14 Sprachen).

Die Anteile von Deutsch als Zweitsprache (DaZ) variieren ebenfalls über die Länder hinweg. Mal sind sie abhängig von einzelnen Lehrkräften (wie in SL), mal wurden die verpflichtenden DaZ-Anteile im Lehramtsstudium angehoben (in BW ab WS 2015/16 und in BE und NW ab WS 2016/17). In einigen Ländern sind verschiedene Maßnahmen bereits seit 2008/09 in Kraft: In NW existiert seitdem der Bereich „Deutsch für Schülerinnen und Schüler mit Zuwanderungs- 
geschichte" mit sechs Leistungspunkten verbindlich in allen lehramtsbezogenen Studiengängen. In BY gibt es das Vorkurskonzept „Deutsch 240“ (120 Std. in KiTas + 120 Std. in der Grundschule) als Maßnahme zur Verbesserung der Sprachkompetenzen von Vorschulkindern, insbesondere für Kinder mit Eltern nichtdeutschsprachiger Herkunft). Zweitsprachenunterricht in Deutsch findet in der Regel (u.a. in BW und in $\mathrm{TH}$ ) abgekoppelt von FU statt.

Schließlich wird Mehrsprachigkeit im Zusammenhang mit Differenzierung in den Englischunterricht einbezogen (BB) bzw. im Kontext von Fördermaßnahmen (zusätzliche Lehrerstundenzuweisungen) unterstützt, wenn mindestens vier Schüler mit besonderem Sprachförderbedarf in der Schule sind (RP).

\subsubsection{Das Meinungsbild zur weiteren \\ Handhabung des Themas Lernende mit Migrationshintergrund}

Die Anregung, aktiv auf die Mehrsprachigkeit der Kinder zurückzugreifen, um ihr Bewusstsein für die Mehrsprachigkeit und Multikulturalität ihrer Lebenswelt zu erhöhen, wurde mit je 38 Stimmen einstimmig befürwortet. Es wurde sogar vorgeschlagen, darüber hinauszugehen: „Nicht nur Bewusstmachung, sondern auch Einbezug”. Eine zweite Fremdsprache noch in der Primarstufe zu beginnen, wurde jedoch mit $84 \%$ vergleichsweise strikt abgelehnt, und zwar in erster Linie mit der Anmerkung, dass diese für Kinder mit einer anderen Erstsprache als Deutsch bereits die dritte Fremdsprache sei. Vielmehr solle hier der Schwerpunkt auf die Förderung der Herkunftssprache gelegt werden. Ferner wurde argumentiert, es müssten zunächst die Grundlagen in der ersten Fremdsprache gefestigt werden. Einigen Zuspruch bekam die Idee der zweiten Fremdsprache in der Grundschule 
allerdings unter der Prämisse, dass dieser FU optional und auf die Bedürfnisse der Schule und der Schüler ausgerichtet ist.

Sollen Familiensprachen durch folgende Maßnahmen stärker gefördert werden? $(\mathrm{N}=38)$

\begin{tabular}{|c|c|c|}
\hline $\begin{array}{l}\text { Nachmittags 2-4 } \\
\text { Stunden/Woche } \\
\text { als ein fakultatives } \\
\text { Unterstützungs- } \\
\text { angebot an den } \\
\text { Schulen }\end{array}$ & $\begin{array}{l}\text { Nachmittags 2-4 } \\
\text { Stunden/Woche (bei } \\
\text { dokumentierter Not- } \\
\text { wendigkeit) als ein } \\
\text { verpflichtendes Unter- } \\
\text { stützungsangebot an } \\
\text { den Schulen } \\
\end{array}$ & $\begin{array}{l}\text { Zweisprachige } \\
\text { Alphabetisierung und } \\
\text { herkunftssprachlicher } \\
\text { Unterricht der an der } \\
\text { GS am stärksten ver- } \\
\text { tretenen Sprache mit } \\
\text { je einem Zug } \\
\end{array}$ \\
\hline $30(78,9 \%)$ & $8(21,1 \%)$ & $16(42,2 \%)$ \\
\hline \multicolumn{2}{|c|}{$\begin{array}{l}\text { Herkunftssprachen als Brücke für die } \\
\text { Aneignung des Englischen/ Französischen, } \\
\text { auch für den Schriftspracherwerb }\end{array}$} & $\begin{array}{l}\text { Curricula für den } \\
\text { herkunftssprachlichen } \\
\text { Unterricht }\end{array}$ \\
\hline \multicolumn{2}{|c|}{$22(57,9 \%)$} & $16(42,2 \%)$ \\
\hline
\end{tabular}

Die Frage nach der Förderung der Familiensprache wurde von einer großen Mehrheit bejaht, wobei aber sehr deutlich wurde, dass man sich in diesem Kontext eine hohe Flexibilität und die Möglichkeit zu individuellen Vorgehensweisen wünschte. Diese Haltung ließ sich sowohl an der geringen Zahl der Befürworter eines verpflichtenden Unterstützungsangebots im Nachmittagsbereich $(21,1 \%)$ ablesen als auch an zusätzlichen Kommentaren, wie z. B. dem, dass den Schulen konkrete Vorgehensweisen nicht vorgeschrieben werden sollten.

Während Herkunftssprachen von den meisten Abstimmenden $(57,9 \%)$ für die Aneignung der ersten Schulfremdsprache einschließlich des Schriftspracherwerbs in dieser Sprache als wertvoll angesehen werden, ist die Resonanz auf die weiteren genannten Maßnahmen eher zurückhaltend. Auf die Optionen einer stärkeren Betonung der Herkunftssprachen 
und einer zweisprachigen Alphabetisierung wurde jeweils nur mit knapp $42 \%$ Zustimmung reagiert. Die letztgenannte Möglichkeit, an einer Grundschule einen Zug mit der am stärksten vertretenen Herkunftssprache einzurichten, in dem auch zweisprachig alphabetisiert wird, wurde entsprechend u. a. mit „nicht realisierbar!“ kommentiert; allerdings wurde auch darauf hingewiesen, dass hier letztlich viel von der Zahl der Schüler abhängen dürfte, die mit den entsprechenden Voraussetzungen an die Grundschule kommen. Die Möglichkeit, Curricula für den herkunftssprachlichen Unterricht zu entwickeln, wurde zum einen als unabdingbar angesehen („Wenn man unterrichtet, braucht man auch Curricula“), zum anderen aber auch mit einer gewissen Skepsis bewertet: "Stelle ich mir kompliziert vor - ist sicher auch abhängig von der jeweiligen Herkunftssprache“ und „Logistisch vermutlich kompliziert, aber aktuell wichtiger denn je!“.

Soll DaZ durch folgende Maßnahmen stärker gefördert werden? $(\mathrm{N}=38)$

\begin{tabular}{|l|c|}
\hline $\begin{array}{l}\text { Verpflichtende DaZ-Anteile im Lehramtsstudium } \\
\text { durch die Deutschdidaktik }\end{array}$ & $35(92,1 \%)$ \\
\hline Bei Bedarf Vorkurse (z. B. 120 Std.) in KiTas & $29(76,3 \%)$ \\
\hline $\begin{array}{l}\text { Bei Bedarf obligatorischer DaZ-Unterricht } \\
\text { (z. B. 120 Std.) gemäß Rahmenlehrplan }\end{array}$ & $29(76,3 \%)$ \\
\hline $\begin{array}{l}\text { Zusätzliche Lehrerstundenzuweisungen für } \\
\text { besondere Sprachfördermaßnahmen }\end{array}$ & $33(86,8 \%)$ \\
\hline
\end{tabular}

In Bezug auf die Förderung von Deutsch als Zweitsprache stimmten fast alle Befragten (92,1 \%) der Implementierung von verpflichtenden DaZ-Anteilen im Lehramtsstudium durch die Deutschdidaktik zu. Es gab allerdings auch die Information, dass es seitens einer Universität abgelehnt worden sei, eine DaZ-Ausbildung in das Studium zu integrieren. Infolgedessen 
gibt es nun an dem entsprechenden Landesinstitut eine rege genutzte Weiterbildung, um den durch die Flüchtlingswelle entstandenen Qualifikationsbedarf unter den Lehrkräften abzudecken. Schließlich schien es den Abstimmenden ein Anliegen zu sein, dass die DaZ-Anteile im Lehramtsstudium durch Fremdsprachendidaktiker (egal welcher sprachlichen Ausrichtung) abgedeckt werden und nicht etwa durch eine erstsprachlich ausgerichtete Deutschdidaktik.

Die Möglichkeiten, bei Bedarf Vorkurse bzw. obligatorischen DaZ-Unterricht gemäß Rahmenlehrplan im Umfang von z.B. 120 Stunden einzurichten, wurden von je 76,3\% der Befragten befürwortet. In diesem Kontext wurde u.a. angemerkt, dass ein obligatorischer KiTa-Besuch für alle Kinder ab dem 4. Lebensjahr sinnvoll sei und dass vielfältige Chancen und Anlässe, miteinander auf Deutsch zu kommunizieren sowie eine sprachsensible Unterstützung durch Erzieher wichtiger seien als Vorkurse. Zu der Maßnahme des obligatorischen DaZ-Unterrichts wurde ferner betont, dass er möglichst in gemischten Gruppen stattfinden solle. $\mathrm{Ob}$ hierbei eine Mischung von Kindern mit verschiedenen anderen Erstsprachen als Deutsch gemeint war oder aber auch Kinder mit Deutsch als Erstsprache miteinbezogen werden sollten, blieb offen.

\subsection{Inklusion im frühen Fremdsprachenunterricht}

\subsubsection{Zum Status quo von Inklusion im frühen Fremdsprachenunterricht}

Obwohl viele Bundesländer aufgrund der seit 26. März 2009 in Deutschland gültigen UN-Konvention über die Rechte von Menschen mit Behinderungen diesen teils schon seit Jahren das Recht auf inklusives Lernen eingeräumt haben, wird die Implementierung von Inklusionsprogrammen auf schulischer Ebene wie auf der Lehrerausbildungsebene organisatorisch, curricular 
und methodisch unterschiedlich realisiert. ${ }^{5}$ Dies wird schon in den unterschiedlichen Definitionen der Termini bzw. Konzepte für „Inklusion“ und „inklusives Lernen“ offensichtlich.

So betonen BE und BB explizit:

Das Unterrichtsprinzip Inklusion [...] bezieht sich nicht ausschließlich auf Schülerinnen und Schüler mit Behinderung, sondern ist im Gesamtzusammenhang der Individualisierung zu sehen. Auf Grundlage der UN-Konvention über die Rechte von Menschen mit Behinderungen hat der Berliner Senat 2011 das Gesamtkonzept „Inklusive Schule“ beschlossen. Das Konzept der Inklusion geht davon aus, dass eine Klassen- und Schulgemeinschaft ganz selbstverständlich Menschen mit unterschiedlichen Fähigkeiten, Bedürfnissen und eben auch Behinderungen umfasst. In einer Klassengemeinschaft, in der individualisiert gelernt wird, findet Inklusion selbstverständlich statt. (LISUM 2013, S. 3; Hervorhebung im Original)

Während man das hier propagierte Konzept der Inklusion unter „Umgang mit Heterogenität“ (vgl. auch Kapitel 2.2) subsumieren könnte, orientieren sich andere Länder (z.B. MV, RP: MBWJK RP 2013) enger an der UN-Konvention über die Rechte behinderter Menschen, indem sie stärker eine „chancengleiche Teilhabe für Menschen mit und ohne Behinderungen in Bildungssystemen “ fokussieren oder dass „so viele Kinder und Jugendliche mit besonderem Förderbedarf wie möglich an Regelschulen lernen“ (MBWK MV 2017, keine Seitenangabe).

5 An dieser Stelle sei noch einmal darauf hingewiesen, dass die im jeweils ersten Teil der Doppelkapitel referierten Daten aus dem Jahre 2015 stammen. Gerade im Bereich Inklusion hat es seitdem teils einschneidende Veränderungen gegeben. Daher liegt in diesem Kapitel der Fokus mehr auf der schulischen Ebene. Es braucht nämlich erhebliche Zeit, bis sich diese Veränderungen in der Schule manifestieren können. 
Manche Bundesländer haben die Inklusion in ihren Lehrplänen verankert (z.B. BW, NI), während diese in anderen nicht explizit vorkommt (HH, NW, RP), aber z. B. durch Erlasse verbindlichen Charakter erhält. Selbst in den Ländern, in denen das Konzept Inklusion verbindlich eingeführt wurde, gibt es sehr unterschiedliche Ausprägungen. Während in NS und SH fachspezifische Vorgaben für den FU gelten, bevorzugen andere Länder den fächerübergreifenden Ansatz oder erproben Mischformen. BY hat z.B. zwei fächerübergreifende Varianten: Regelschulen werden von mobilen sonderpädagogischen Diensten (MSD) betreut, die aber jeweils für mehrere Schulen zuständig und somit nur stundenweise vor Ort sind. Daneben gibt es auch 12 der insgesamt 2404 Grundschulen mit dem Schulprofil „Inklusion“, an denen die Förderschullehrkräfte fester Bestandteil des Kollegiums sind (vgl. Bayerisches Landesamt für Statistik 2015). In RP existiert zwar ein Landeskonzept für Inklusion für die Sekundarstufe, nicht aber für die Primarstufe (vgl. MBWJK RP 2013). In BB hat das LISUM ein fächerübergreifendes Fortbildungscurriculum „Inklusive Grundschule“ für Lehrkräfte entwickelt (vgl. LISUM 2012) und stellt fachspezifische Handreichungen für den Englischunterricht zur Verfügung (vgl. LISUM 2006b).

Aus diesen Beispielen wird ersichtlich, dass die Implementierung von Inklusion in den meisten Bundesländern oftmals Erprobungs- bzw. Modellcharakter hat und dass diverse Pilot- bzw. Modellprojekte zum inklusiven Lernen existieren (z. B. in BB das Pilotprojekt „Inklusive Grundschule“ (PInG; vgl. LISUM 2012; 2014) und in MV das Rügener Inklusionsmodell (vgl. MBWK MV 2017)). Aufgrund der Vielzahl der unterschiedlichen Ansätze herrscht auf schulischer Ebene Verunsicherung darüber, wie die neu eingeführten Anforderungen zu bewältigen sind. 
Der Grad der Verunsicherung der Lehrkräfte hängt u.a. mit ihrem Ausbildungsstand für den FU an Grundschulen und dem Mangel an erprobten Materialien für inklusives Lernen zusammen. Gerade für den inklusiven FU gilt in besonderem Maße, dass Lehrkräfte neben ausgezeichneten fremdsprachlichen Fertigkeiten über Methodenkompetenz und diagnostische Kompetenz verfügen müssen. Zwar werden Lehrkräften in einigen Bundesländern, wie z.B. BB und MV, Handreichungen mit Beispielen zur Differenzierung im Inklusionsunterricht an die Hand gegeben, in den meisten anderen Bundesländern (z. B. BW, HH) liegt die Umsetzung von Inklusion dagegen weitgehend im Ermessen der Lehrkräfte, die oftmals nur auf die Inklusionsmaterialien der Schulbuchverlage zurückgreifen können.

Wie massiv diese Unterschiede im Bereich des Aus- und Fortbildungsstands der Lehrkräfte sind, geht ebenfalls aus der Auswertung des Fragekatalogs aus der ersten Phase unserer Untersuchung hervor. Für $\mathrm{HH}$ wird beispielsweise angegeben, dass jede Grundschule mit 1-2 grundständig ausgebildeten Englischlehrkräften arbeitet. Obwohl es in BW und NW eine hohe Zahl an grundständig ausgebildeten Absolventen der Pädagogischen Hochschulen bzw. Universitäten gibt, müssen viele Grundschulen noch immer komplett ohne die Expertise einer Fremdsprachenlehrkraft auskommen. Bis zum Sommer 2013 hatte NW durch einen Runderlass vom 12.11.2001 (MSWF NW 2001) festgelegt, dass interessierte Lehrkräfte durch eine 60-stündige Fortbildungsmaßnahme und durch den Erwerb der sprachlichen C1-Qualifikation die Unterrichtserlaubnis für das Fach Englisch in der Grundschule erwerben konnten. Der 60-stündigen Fortbildungsmaßnahme mit C1-Qualifikation steht SN gegenüber mit einer Nachqualifizierung mit 360 Stunden Zertifikatskurs und einer Prüfung, deren Bestehen das B1-Niveau verlangt (vgl. KMK 2013, S. 59). Noch stärker weicht allerdings SA ab. 
Hier hatten Lehrkräfte im Rahmen einer Nachqualifizierung eine über mehrere Jahre dauernde Weiterbildung zu absolvieren. Im Jahr 2007 umfasste das betreffende Programm mindestens 450 Stunden - oder sogar 600 Stunden, falls ein fremdsprachlicher Vorkurs von 150 Stunden hinzukam (vgl. MBSA 2007b, Abs. 1.4). Selbst 2015 bot das Land SA noch immer an bereits im Beruf aktive Lehrkräfte gerichtete Kurse zwecks „Erwerb einer ,Unterrichtserlaubnis Englisch an Grundschulen“ oder einer ,Unterrichtserlaubnis Englisch an Förderschulen" mit dem Förderschwerpunkt Lernen“ im Umfang von „etwa 300 Stunden“ an (vgl. MBSA 2015, Abs. 1.1).

In Bezug auf die grundständige Lehrerausbildung hat es gravierende Veränderungen im Verglich zum Zeitpunkt (Stand 2015) der hier präsentierten Erhebung gegeben. Während 2015 lediglich in BE der thematische Baustein „Inklusion, Heterogenität, Differenzierung“ obligatorischer Bestandteil des Masters der Lehramtsstudiengänge Englisch war, sind zwischenzeitlich Module zur Inklusion auch in anderen Ländern in der universitären Lehrerausbildung verpflichtend eingeführt worden. In NW z. B. wurde 2016 die Lehramtszugangsvoraussetzung (LZV) so geändert, dass angehende Lehrkräfte künftig pro Unterrichtsfach „,inklusionsorientierte Fragestellungen" im Umfang von mindestens fünf Leistungspunkten studiert haben müssen (MSW NW 2016a, $\$ 1$, Abs. 2). In NS ist im Lehramtsstudium für Grund-, Haupt- und Realschulen ein Modul Inklusion Kernelement des MA-Studiengangs (vgl. CeLeB 2016).

Ähnliche Entwicklungen sind auch für den Vorbereitungsdienst selbst festzustellen. Wie in BE, wo das Thema Inklusion bereits einen Pflichtbaustein im Modul Unterrichten bildete (vgl. Senatsverwaltung 2014, S. 38), ist auch in anderen Ländern Inklusion obligatorischer Bestandteil des Vorbereitungsdienstes. 
In den meisten Bundesländern steht eine flächendeckende Fort- und Weiterbildung von Grundschullehrkräften für fachspezifische Inklusion im FU noch aus, während das Angebot für fächerübergreifende Maßnahmen größer ist.

\subsubsection{Das Meinungsbild zur weiteren Handhabung von Inklusion im frühen Fremdsprachenunterricht}

Das Ergebnis der Abstimmung zur verbindlichen Einführung von inklusivem Lernen im FU ist grundsätzlich positiv (69 \%), verzeichnet aber auch unentschlossene $(17 \%)$ bzw. ablehnende Stimmen von $14 \%$.

Soll inklusives Lernen verbindlich für den FU der Primarstufe eingeführt werden? $N=35$

\begin{tabular}{|l|l|l|c|c|}
\hline Stimme zu & $\begin{array}{l}\text { Stimme } \\
\text { eher zu }\end{array}$ & $\begin{array}{l}\text { Weder } \\
\text { noch }\end{array}$ & $\begin{array}{l}\text { Stimme eher } \\
\text { nicht zu }\end{array}$ & $\begin{array}{l}\text { Stimme } \\
\text { nicht zu }\end{array}$ \\
\hline $19(54,3 \%)$ & $5(14,3 \%)$ & $6(17,2 \%)$ & $4(11,4 \%)$ & $1(2,8 \%)$ \\
\hline
\end{tabular}

Aus den Kommentaren (z.B. „Dann muss eine fundierte Ausbildung vorausgehen!“ oder „Verbindliches inklusives Lernen nur, wenn alle notwendigen Voraussetzungen dafür geschaffen sind (geschultes (!) Betreuungspersonal), keine FSJ'ler“) geht hervor, dass die Ergebnisse dieses Meinungsbildes vor dem Hintergrund der sehr diversen und teilweise unzureichenden Ausbildungssituation der Lehrkräfte im FU (s. o.) zu sehen sind.

Auch die weiteren Ergebnisse zu den Fragen zur Ausbildung der Lehrkräfte untermauern die Forderung nach qualifizierten Lehrkräften. Eine deutliche Mehrheit der befragten Teilnehmer (89\%) sprach sich dafür aus, dass die Inklusion obligatorischer Bestandteil fremdsprachlicher Lehramtsstudiengänge, des Vorbereitungsdienstes und von Fortbildungen 
für den FU sein soll. 27 \% stimmten für Inklusion als fakultativen Bestandteil fremdsprachlicher Lehramtsstudiengänge, des Vorbereitungsdienstes und von Fortbildungen für den FU.

Die Frage danach, ob fachspezifische Materialien für den FU von Fachdidaktikern entwickelt werden sollen, die auch für inklusiven Unterricht ausgewiesen sind, wurde von $95 \%$ der Befragten bejaht. Niemand widersprach dieser Forderung. Zwei Befragte und damit knapp $5 \%$ konnten oder wollten sich in dieser Frage nicht festlegen.

Soll Material für inklusives Lernen von für Inklusion ausgewiesenen Fremdsprachendidaktikern entwickelt werden? $N=37$

\begin{tabular}{|l|l|c|c|c|}
\hline Stimme zu & $\begin{array}{l}\text { Stimme } \\
\text { eher zu }\end{array}$ & Weder noch & $\begin{array}{l}\text { Stimme eher } \\
\text { nicht zu }\end{array}$ & $\begin{array}{l}\text { Stimme } \\
\text { nicht zu }\end{array}$ \\
\hline $30(81,1 \%)$ & $5(13,5 \%)$ & $2(5,4 \%)$ & 0 & 0 \\
\hline
\end{tabular}

In den Kommentaren ist zu lesen, dass Inklusion und die damit zusammenhängende „gelungene Differenzierung [...] sehr zeit- und arbeitsintensiv“ sei und es hieß: „Lehrer brauchen, um das leisten zu können, Unterstützung “. Adäquate, von für Inklusion ausgewiesenen Fachdidaktikern entwickelte Materialien wurden als Unterstützung der Arbeit der Lehrkräfte und als wichtiges Element gesehen, damit „Qualität [...] gewährleistet“ werden könne. Zugleich wurde aber auch hervorgehoben, dass „der Erfolg von Inklusion [...] nicht von Materialien abhängig" sei, sondern primär von „fremdsprachendidaktisch ausgebildetem Fachpersonal“ und der Schaffung „notwendige[r] Voraussetzungen“. 


\subsection{Schriftspracherwerb}

\subsubsection{Zum Status quo von Schriftspracherwerb}

$\mathrm{Da}$ der FU in sechs Ländern (BB, BW $\left.{ }^{6}, \mathrm{MV}, \mathrm{NW}, \mathrm{RP}, \mathrm{SH}\right)$ in Klasse 1 beginnt, in allen anderen jedoch in Klasse 3, wird der Einsatz der Schriftsprache in den Bundesländern zwangsläufig unterschiedlich gehandhabt. Allen Ländern gemein ist hingegen, dass laut Vorgaben der Lehrpläne mit dem Lesen und Schreiben bereits im ersten Lernjahr Englisch begonnen wird. Explizite Bezüge zu Rechtschreibregeln werden dabei unterschiedlich früh hergestellt, in $\mathrm{HB}$, wo der FU in Klasse 3 beginnt, z. B. erst im zweiten Lernjahr in Klasse 4.

Als Konsequenz aus den unterschiedlichen Einstiegszeitpunkten in den FU variieren auch die beim Lesen und Schreiben zu erreichenden Ziele: Hier spannt sich der Bogen vom Abschreiben einzelner Wörter in Klasse 1 bis hin zu freien Schreibversuchen ganzer Sätze in Klasse 4. Somit wird auch die Bewertung der schriftlichen Schülertexte nur in einigen Ländern im Lehrplan thematisiert; dort wo sie aufgegriffen wird, werden meist auch Vorschläge für Lernzielkontrollen eingebracht (z. B. Französisch in TH).

Es kommen sowohl ganzheitliche als auch analytische Vermittlungsweisen zum Einsatz. In den meisten Ländern werden beide Vermittlungsweisen verknüpft, indem z. B. beim

6 BW stellt hier insofern eine Ausnahme dar, als laut dem Bildungsplan, der 2015 noch Gültigkeit besaß, Lesen und Schreiben erst ab Klasse 3 vorgesehen waren, obwohl der FU in Klasse 1 begann. Mit dem seit 2016 gültigen neuen Bildungsplan wurde der Beginn des Schriftspracherwerbs zwar in die Klasse 1 vorverlegt, jedoch beabsichtigt das baden-württembergische Ministerium für Kultus, Jugend und Sport laut Pressemitteilung vom 13.10.2017, den Beginn des FU insgesamt auf die Jahrgangsstufe 3 zurückzuverlegen (vgl. Staatsministerium Baden-Württemberg 2017). 
Lesen das ganzheitliche Erfassen der Wörter im Vordergrund steht, Unterschiede in den Laut-Buchstaben-Zuordnungen von Fremdsprache und der deutschen Sprache aber durchaus auch thematisiert werden (BB). BE ist eines der wenigen Länder, die selbst für die Lernanfänger in der Fremdsprache (hier in Klasse 3) für den Bereich des Schreibens ausschließlich analytische Vermittlungsweisen nennen: Es werden typische Buchstabenfolgen des Englischen sowie die Vermittlung einfacher Regeln der Wortbildung als Basisstrategie bzw. Schreibhilfe behandelt.

In allen Bundesländern wird der Schriftform eine stützende, lernstrategische Funktion zugeschrieben, die in der Regel implizit vermittelt wird. Leseverstehen und Schreiben dienen dem ganzheitlichen Wiedererkennen und Reproduzieren von im Klangbild vertrauten Wortbildern. Man macht sich die Unterstützung der Verstehens- und Behaltensprozesse durch das Schriftbild zunutze (z. B. NW, TH). Experten verweisen aber auch auf die Hilfe, die die mündliche Lehrersprache in einem konsequent auf Englisch geführten Unterricht für die schriftlichen Strukturen zu bieten vermag: Der mündliche fremdsprachliche Input wird als permanente Entlastung der einfachen, schriftlichen Strukturen des Englischen (A1 des GER) verstanden (SH).

\subsubsection{Das Meinungsbild zur weiteren Handhabung von Schriftspracherwerb}

Soll der Schriftspracherwerb ab Jgst. 1 beginnen? ( $N=35)$

\begin{tabular}{|l|l|l|l|l|}
\hline Stimme zu & $\begin{array}{l}\text { Stimme } \\
\text { eher zu }\end{array}$ & Weder noch & $\begin{array}{l}\text { Stimme eher } \\
\text { nicht zu }\end{array}$ & $\begin{array}{l}\text { Stimme } \\
\text { nicht zu }\end{array}$ \\
\hline $15(42,9 \%)$ & $8(22,9 \%)$ & $2(5,7 \%)$ & $7(20,0 \%)$ & $3(8,6 \%)$ \\
\hline
\end{tabular}


Mit insgesamt knapp $66 \%$ auf der (eher) zustimmenden Seite votierten die Befragten klar für einen Schriftspracherwerb ab Klasse 1. Als Begründung ihres Votums hoben sie die lernunterstützende Funktion der Schriftsprache sowie ihre Bedeutung in der Ausbildung von Sprachbewusstheit und Lernerautonomie hervor. Zudem wurde auf die Gefahr der Fossilisierung von Spontanschreibungen und die Aneignung idiosynkratischer Regeln verwiesen, wenn zwischen der Erstbegegnung mit gesprochenen Wortformen und dem Erstkontakt mit ihren jeweiligen orthographisch korrekten schriftsprachlichen Entsprechungen eine zu große Zeitspanne läge. Allerdings wurden ungeachtet der teils nachdrücklichen Befürwortung eines frühzeitigen Einbezugs der Schrift („Stimme selbstverständlich zu”, „Unbedingt!") auch Einschränkungen artikuliert bzw. es wurde auf erforderliche Gelingensbedingungen hingewiesen: „erst nach der Absicherung von Bedeutung und Lautbild”, „ohne Druck und ohne Zensuren”, „mit flexiblen Ausnahmen bei Inklusionskindern”, „der Altersstufe angemessen” und „zeitlich etwas versetzt, damit der deutsche Schriftspracherwerb Vorlauf hat".

Generell scheint der Zeitpunkt des Einsatzes der Schriftsprache in seiner Verknüpfung mit der gewählten Vermittlungsweise ein besonders sensibles Gebiet zu sein, für das sich die Befragten mehr Unterstützung wünschten. Diese Frage wurde nämlich als einziger Aspekt in der gesamten Umfrage mit dem Verweis kommentiert, dass entsprechende Bildungsstandards zu implementieren seien.

Unter den einen Schriftspracherwerb im FU der Klasse 1 tendenziell ablehnenden Stimmen (Stimme eher nicht zu) waren solche, die den simultanen Schriftspracherwerb in Erst- und Fremdsprache für problematisch hielten bzw. dies abhängig machten von der Stundenzahl: „Bei mehr Stunden in der Stundentafel würde ich eher zustimmen". Die völlige Ablehnung des Lesens und Schreibens in Klasse 1 (Stimme nicht $\mathrm{zu}$ ) basierte auf der Sorge, dass das Primat des Münd- 
lichen gefährdet sei. Die Schriftsprache solle frühestens ab Klasse 2 behandelt werden.

Sollen am Ende der Jgst. 4 ganze Sätze abgeschrieben sowie frei geschrieben und bewertet werden? $(N=30)$

\begin{tabular}{|l|l|l|l|l|}
\hline Stimme zu & $\begin{array}{l}\text { Stimme eher } \\
\mathbf{z u}\end{array}$ & Weder noch & $\begin{array}{l}\text { Stimme eher } \\
\text { nicht zu }\end{array}$ & $\begin{array}{l}\text { Stimme } \\
\text { nicht zu }\end{array}$ \\
\hline $13(43,3 \%)$ & $10(33,3 \%)$ & $3(10,0 \%)$ & $2(6,7 \%)$ & $2(6,7 \%)$ \\
\hline
\end{tabular}

Hinsichtlich der Frage, ob die Lernenden am Ende der Grundschulzeit im FU nicht nur dazu in der Lage sein sollten, ganze Sätze abzuschreiben, sondern auch frei schreiben zu können, und ob dies auch in die Leistungsbewertung einfließen solle (vgl. zu diesem Aspekt auch Kapitel 2.7), ergab sich ein sehr klares Votum, nämlich eine breite Akzeptanz eines hohen Anspruchsniveaus beim Schreiben. Die Produktion von Schriftsprache wurde nicht als etwas gesehen, das die Schüler überfordert, sondern als etwas, wodurch die „Schüler ernst genommen [werden]". Über drei Viertel der Befragten stimmten mindestens tendenziell der These zu, dass die Schüler beim Übergang auf die Sekundarstufe freies Schreiben in der Fremdsprache zumindest bereits in Ansätzen erprobt haben sollten, und dass dies auch in die Notenfindung eingehen solle. Einige unterstrichen jedoch, dass sie zwar die ersten Teile der These begrüßten, einer Berücksichtigung des hier Geleisteten bei der Notenfindung aber skeptisch gegenüber stünden. Manche sprachen sich entweder klar gegen eine Bewertung aus („Schreiben ja, aber nicht zur Kontrolle”) oder sie votierten für eine verbale Bewertung statt Ziffernoten („Anerkennung, kritische Würdigung, feedback [handschriftlich unterstrichen] sind wichtig”). In Bezug auf mögliche Vorgehensweisen bei der Bewertung wünschte man sich konkrete Anleitungen wie die Frage „Wie?” in den Kommentaren zeigte. 
Mehrere der hier geäußerten Meinungen spiegeln sich auch in den Daten zum in Kapitel 2.7 behandelten Themenkomplex „Leistungsbewertung und Portfolionutzung “ wider. Auch hier ist wiederum festzuhalten, dass die Frage nach der Vorgehensweise bei keinem anderen Thema im Rahmen der Kommentare gestellt wurde. Interessanterweise wurde aber auch genau diese Frage durch andere Kommentare beantwortet: (hier u.a.) „Bewertung für Abgeschriebenes aber nicht für frei Geschriebenes". Dabei fällt besonders auf, dass es offensichtlich unter den Befragten teils sehr unterschiedliche Auffassungen darüber gab, was Kinder in den Klassen 3 und 4 zu leisten im Stande sind bzw. zu leisten im Stande sein sollten. Die folgenden drei Sätze illustrieren das Spektrum der Haltungen zur schriftlichen Textproduktion der von uns befragten Klientel: ${ }^{7}$

- „Nach Mustern und mit Unterstützung eigene Texte schreiben.”

- „Das Abschreiben von ganzen Sätzen ist auch schon problemlos in Klasse 3 möglich, z. T. auch freies Schreiben.”

- „Freies Schreiben ist bei 2 Wochenstunden ab Klasse 3 [...] unrealistisch.“

Sollen die Lernenden auf einzelne Laut-Buchstaben-Korrespondenzen der Fremdsprache, die vom Deutschen abweichen, aufmerksam gemacht werden? $(\mathrm{N}=34)$

\begin{tabular}{|l|l|c|c|l|}
\hline Stimme zu & $\begin{array}{l}\text { Stimme eher } \\
\mathbf{z u}\end{array}$ & Weder noch & $\begin{array}{l}\text { Stimme eher } \\
\text { nicht zu }\end{array}$ & $\begin{array}{l}\text { Stimme } \\
\text { nicht zu }\end{array}$ \\
\hline $19(55,9 \%)$ & $11(32,3 \%)$ & $1(2,9 \%)$ & $2(5,9 \%)$ & $1(2,9 \%)$ \\
\hline
\end{tabular}

7 Da einige Befragte von der Möglichkeit, ihre Antworten anonym einzureichen, Gebrauch gemacht hatten, ließ sich nicht ablesen, ob diese unterschiedlichen Haltungen auf verschiedenen Einstiegszeitpunkten in den FU beruhen. 
Mit einem Ergebnis von über $88 \%$ wurde dieser Frage am deutlichsten (eher) zugestimmt. Diese hohe Befürwortung des Eingehens auf vom Deutschen abweichende PhonemGraphem-Korrespondenzen im FU weist daraufhin, dass nach Auffassung der Befragten die Behandlung des Schriftbildes nicht nur am Rande des Unterrichtsgeschehens, also ausschließlich implizit erfolgen soll, sondern dass eine explizite und analytische Vermittlung der Orthographie zu wählen sei. Damit wurde für eine Praxis votiert, die dem phonics-Ansatz des anglo-amerikanischen Sprachraums entspricht.

Die Notwendigkeit einer expliziten Handhabung der Phonem-Graphem-Korrespondenzen wurde von einigen mit Blick auf jene Lernende begründet, die Schwierigkeiten mit dem Schriftspracherwerb haben: „, $[\mathrm{M}]$ anche Kinder merken sonst die Besonderheiten nicht!”, „Phonics, punktuell und nach Bedarf eingesetzt, ist eine Unterstützung für vor allem schwächere Lernende!”.

Trotz der klaren Zustimmung zum hier zu bewertenden Aspekt wurden aber auch Befürchtungen dahingehend geäußert, dass die Lehrkräfte unter Umständen nicht genügend ausgebildet seien, um hier selbstständig zu zielführenden didaktisch-methodischen Entscheidungen zu gelangen: „Lehrkräfte müssen genau instruiert werden. Langatmige Erläuterungen auf der Metaebene sind sicher nicht zielführend. Es muss nach Klassenstufen differenziert werden" und "Wenn dadurch nicht Dinge zum Problem gemacht werden, die eigentlich keine sind!". Manche Befragten unterbreiteten konkrete Vorschläge zur Umsetzung eines bewusstmachenden Umgangs mit der Schrift, die klare Positionierungen erkennen lassen. So schrieb eine Person: „Die Schüler so viel wie möglich selbst entdecken lassen! Entsprechende Übungen einbauen”. Eine weitere befragte Person plädierte für „entdeckendes Lernen (statt 'Belehrung')". Eine dritte notierte: „Im Sinne von language awareness oder systematisch? 
Language awareness punktuell: Ja; systematisch: Nein". (Vgl. auch mehrere ähnlich lautende Anmerkungen zur Frage nach dem Status und dem Umgang mit Sprachbewusstheit in Kapitel 2.6.2.)

Die wenigen hinsichtlich eines bewusstmachenden Umgangs mit Laut-Buchstaben-Korrespondenzen skeptischen Voten bzw. die sie vertretenden Personen positionierten sich, wie ihre Kommentare illustrieren, teils diametral entgegengesetzt zur Mehrheit der Befragten. Die sich extrem widersprechenden Meinungen führten zu einem sehr weiten Spektrum. Selbst ein Votum der Gruppe „Stimme eher zu” war noch verknüpft mit einem Kommentar, der den Vergleich $\mathrm{zu}$ anderen Erstsprachen und damit zu einer analytischen und expliziten Vorgehensweise anführte („ggf. im Vergleich zu anderen L1, Nutzung der Muttersprachen!!”) und stand so in einem sehr klaren Gegensatz zu ablehnenden Kommentaren wie etwa „Ganz-Wort-Ansatz ist vorzuziehen”.

\subsection{Stellenwert der unterschiedlichen sprachlichen Kompetenzen}

\subsubsection{Zum Status quo des Stellenwerts der unterschiedlichen sprachlichen Kompetenzen}

Grundsätzlich hat die Aneignung sprachlicher Kompetenz in allen Bundesländern im FU der Grundschule einen hohen Stellenwert. Eine Durchsicht der aktuellen Vorgaben fördert jedoch Unterschiede sowohl hinsichtlich der Zahl der ausgewiesenen Kompetenzbereiche als auch ihres jeweiligen $\mathrm{Zu}$ schnitts zutage. In knapp der Hälfte der Bundesländer kommt den vier Kompetenzbereichen (1) Sprachlernkompetenz, (2) methodische Kompetenz, (3) funktional-kommunikative Kompetenz und (4) interkulturelle Kompetenz ein ähnlich hoher Stellenwert zu. Zudem wird dort meist ebenso betont, 
dass es (diese) unterschiedliche(n) Bereiche gibt, wie auch, dass sie sich gegenseitig ergänzen. In den meisten übrigen Ländern steht die Entwicklung funktional-kommunikativer Kompetenz im Zentrum, während die Förderung weiterer Kompetenzen teils implizit, teils aber auch explizit unterschiedlich gehandhabt und manchmal auch schlicht auf die Sek. I vertagt wird.

Vergleicht man die diversen Bildungs-, Lehr- oder Rahmenpläne der Länder miteinander, so kristallisiert sich eine insgesamt vergleichsweise große Schnittmenge an als besonders relevant erachteten Kernkompetenzen heraus. Hierzu zählt zentral das Hör(Seh-)verstehen, das in der Regel um produktive mündliche Kompetenzen und als weiteren Aspekt die zunehmende Fähigkeit ergänzt wird, Sprachlernprozesse durch den in wachsendem Maße erfolgreichen Einsatz von Methoden, Techniken und Strategien auch ohne stete Anleitung von außen bewältigen zu können. Überdies benennen viele Lehrpläne interkulturelle Kompetenzen als sukzessiv wichtiger werdenden Bereich. Gleichzeitig steht jeder, der schon einmal versucht hat, die Vielfalt der unterschiedlichen Kompetenzanforderungen in den Ländern auf einen gemeinsamen Nenner zu bringen, allerdings vor einer enormen terminologischen Vielfalt auf der Mesoebene.

So ist bei letztlich relativ ähnlicher Ausgestaltung der Konzepte mancherorts von „kommunikativer Kompetenz“ (BY) die Rede, woanders dagegen von „funktionalkommunikativer Kompetenz“ (SA) oder von „funktionaler kommunikativer Kompetenz" (MV). In HB vereint dieser letztgenannte Bereich zum einen die „kommunikativen Fertigkeiten“ und zum anderen „Verfügung über sprachliche Mittel“. In NW werden die Grundfertigkeiten unter dem Etikett „Kommunikation - sprachliches Handeln“ zusammengefasst, während die in ihrer Ausgestaltung mit den Angaben in HB praktisch identische „Verfügbarkeit 
von sprachlichen Mitteln“ zusammen mit „Methoden“ und „Interkulturelle[m] Lernen“ weitere Flügel des insgesamt vier Teilkompetenzen umfassenden sogenannten didaktischen Kreuzes bilden. Im in BE favorisierten Kompetenzmodell sind Sprachkompetenz, Methodenkompetenz und interkulturelle Kompetenz kreisförmig um das zentrale oberste Lernziel der interkulturellen fremdsprachigen Handlungsfähigkeit angeordnet. Im Fachlehrplan für Englisch in BY werden wiederum kommunikative Kompetenzen, interkulturelle Kompetenzen und methodische Kompetenzen als zentrale Lernbereiche ausgewiesen, wobei mit dem strukturell gleichwertigen Lernbereich „Themengebiete“ eine sonst in der Regel fehlende vierte Komponente ergänzt wird.

Was der Lehrplan in BE als „interkulturelle Kompetenz“ ausweist, heißt in SN „interkulturelle Handlungsfähigkeit“ und in NW ,interkulturelles Lernen“. Zugleich spezifiziert $\mathrm{BB}$ in seinem Lehrplan erstmals für das Ende des sechsten Lernjahres überhaupt konkrete „Anforderungen“, wobei der Kompetenzbegriff allerdings vermieden wird. SN nennt in seinem Lehrplan Englisch Anforderungen für die vier Grundfertigkeiten sowie für „,interkulturelle Handlungsfähigkeit“ und für „Sprachbewusstsein“. In MV fehlt dagegen der letztgenannte Bereich völlig (vgl. auch Kapitel 2.6). Dafür werden zusätzlich interkulturelle Kompetenz und, im Gegensatz zu $\mathrm{SN}$, methodische Kompetenz als eigene Lernbereiche ausgewiesen.

\subsubsection{Das Meinungsbild zur weiteren Handhabung des Stellenwerts der unterschiedlichen sprachlichen Kompetenzen}

Das Urteil der Teilnehmer unserer Befragung über die Ausweisung verschiedener Teilkompetenzen und ihrer Gewichtung zeigte eine klare Präferenz der Befragten: 
Sollen die vier Kompetenzbereiche Sprachlernkompetenz, methodische, funktional-kommunikative und interkulturelle Kompetenz in den Lehrplänen gleichwertig behandelt werden? $(N=38)$

\begin{tabular}{|l|l|l|l|l|}
\hline Stimme zu & $\begin{array}{l}\text { Stimme eher } \\
\mathbf{z u}\end{array}$ & Weder noch & $\begin{array}{l}\text { Stimme eher } \\
\text { nicht zu }\end{array}$ & $\begin{array}{l}\text { Stimme } \\
\text { nicht zu }\end{array}$ \\
\hline $13(34,2 \%)$ & $11(29,4 \%)$ & $1(2,6 \%)$ & $10(26,3 \%)$ & $3(7,9 \%)$ \\
\hline
\end{tabular}

Knapp zwei Drittel sprachen sich mindestens tendenziell für eine gleichrangige unterrichtliche Förderung der in der Frage benannten vier sprachlichen Teilkompetenzen aus. Nur weniger als ein Drittel stimmte dieser Option nicht zu. Weit mehr als bei der nachfolgenden Einschätzung zu Kompetenzbereichen sahen sich die Befragten damit offenbar dazu in der Lage, ein eindeutiges Votum abzugeben. Es wählte nämlich nur eine einzige befragte Person die Möglichkeit „weder - noch“.

Das Meinungsbild zur Relevanz einzelner Kompetenzbereiche dürfte allerdings zumindest auf den ersten Blick erstaunen.

Falls nicht alle Kompetenzbereiche berücksichtigt werden sollen, welche sollen dann in die Lehrpläne einfließen? $(N=38)$

\begin{tabular}{|l|c|c|}
\hline & Stimme zu & Stimme nicht zu \\
\hline Sprachlernkompetenz & $18(47,4 \%)$ & $20(52,6 \%)$ \\
\hline Methodische Kompetenz & $13(34,2 \%)$ & $25(65,8 \%)$ \\
\hline $\begin{array}{l}\text { Funktional-kommunikative } \\
\text { Kompetenz }\end{array}$ & $19(50,0 \%)$ & $19(50,0 \%)$ \\
\hline Interkulturelle Kompetenz & $15(39,5 \%)$ & $23(60,5 \%)$ \\
\hline
\end{tabular}

Schließlich ist für keine einzige zur Abstimmung stehende Kompetenz die Zahl derer, die sie lieber im Lehrplan berücksichtigt wissen wollen, größer als die Summe jener, die nicht zustimmen, dass eine bestimmte Kompetenz bei gleichzeitigem Verzicht auf andere Kompetenzen in jedem Fall im Lehrplan vertreten sein 
sollte. Wie die von vielen hinzugefügten Kommentare und Erläuterungen zeigen, fiel es einigen jedoch offenbar schwer, sich dezidiert für eine und gegen eine andere Kompetenz auszusprechen. Zudem bekundeten mehrere Befragte, dass sie zwar eine Gewichtung durchaus für sinnvoll hielten, dass es ihnen aber nicht leicht fiel, die Entscheidung gemäß der Frage vorzunehmen. Ein Grund dafür mag darin liegen, dass hinter den hier genutzten Etiketten, wie soeben in Kapitel 2.5.1. exemplarisch dargelegt, inhaltlich durchaus nicht so klar umrissene und eindeutige Vorgaben stehen können, wie dies durch identische Begrifflichkeiten immerhin auf den ersten Blick suggeriert werden mag. Ein Befragter notierte dementsprechend:

Was heißt „gleichwertig“ berücksichtigen? Es handelt sich um unterschiedliche Kompetenzen, die im Zusammenspiel zu einer „rundum“ kompetenten Sprachnutzung führen, zusammen mit wichtigen überfachlichen Kompetenzen (z.B. sozial-kommunikative Kompetenzen).

Zugleich ermunterte diese Frage manche dazu, ihre teils auch schon an anderer Stelle artikulierten Bedenken gegen die Ausweisung des einen oder anderen Bereiches als bereits im FU der Grundschule essenzielle Kompetenz oder gegen die Überbetonung eines bestimmten Teilaspektes vorzubringen. Zwei in diese Richtung gehende Kommentare lauteten:

Bei der funktional-kommunikativen Kompetenz muss dann betont werden, dass es nicht um das sture Lernen von Vokabellisten/Grammatikregeln gehen kann. [Stattdessen braucht es ein] stärkeres Gewicht auf Ausspracheschulung (altersgemäße Methodik).

M.E. gehören alle Kompetenzbereiche dazu, die kommunikative Kompetenz hat aber im Fremdsprachenunterricht das größte Gewicht. Die anderen Kompetenzen werden auch in anderen Fächern entwickelt. 
Eine weitere Person schrieb:

Meine Auswahl wirkt widersprüchlich, ist sie aber nicht. Ich denke, die drei angekreuzten Kompetenzen [Sprachlernkompetenz, funktional-kommunikative Kompetenz, interkulturelle Kompetenz] sollten berücksichtigt werden, die sprachliche Kompetenz aber sollte im Vordergrund stehen; sie ist die Grundlage für alle weiteren Kompetenzen. Interkulturelle Kompetenz ist $\mathrm{m}$. E. ohne die erforderliche Sprachkompetenz nicht möglich.

Besonders zur Entwicklung interkultureller Kompetenz fanden sich allerdings auch erneut teils sehr kritische Stimmen. Ein Befragter monierte: „In der Grundschule beinhaltet IKK oft reine Klischees“. Ein anderer ergänzte: „Interkulturelle Kompetenz ist eher schwierig in der GS, aber evtl. über literarische Texte anzubahnen (Bilderbücher) “. Damit besteht offenbar sowohl hinsichtlich der Zahl und der begrifflichen Präzisierung der Kompetenzen als auch hinsichtlich ihrer jeweils konkreten inhaltlichen Ausgestaltung und Abgrenzung voneinander noch einiges an Handlungsbedarf.

\subsection{Grammatik, Sprachbewusstheit und sprachliche Mittel}

\subsubsection{Zum Status quo von Grammatik, Sprachbewusstheit und sprachlichen Mitteln}

Die Vorgaben dazu, wie im Frühbeginn mit den Parametern Grammatik, Sprachbewusstheit (bzw. ihrem englischsprachigen Pendant language awareness) und (vorgegebene) sprachliche Mittel zu verfahren sei, unterscheiden sich erheblich voneinander. Zwar besteht breites Einvernehmen darüber, dass Sprachbewusstheit prinzipiell lernförderlich ist. Dahingehend, welche Rolle ihre Entwicklung im FU der Grundschule spielen soll, d. h. ob sie eher en passant angebahnt oder proaktiv entwickelt werden soll, herrscht jedoch Uneinigkeit. 
In MV und in RP werden die Begriffe Sprachbewusstheit bzw. language awareness gar nicht im Lehrplan erwähnt. In HB hingegen wird die „behutsam[e]“ Anbahnung von "Sprachbewusstheit (language awareness) mit ihren unterschiedlichen Facetten“ (SBW 2013, S. 5; Hervorhebung im Original) als Lernziel ausgewiesen, das über die Verknüpfung von „kindgemäße[r] Reflexion über Sprache“ mit der „Auseinandersetzung mit basalen grammatischen Elementen“ (ebd.) realisiert werden könne. „Damit Schülerinnen und Schüler Sprachbewusstsein entwickeln können, muss ihnen die Gelegenheit gegeben werden, Hypothesen zu entwickeln und zu verifizieren“ (MBK SL 2011: 5), so der Lehrplan des SL, wobei jene idealerweise als Reaktion auf einen reichhaltigen Input der Lehrkraft von den Schülern selbst ausgehen: „Häufig erkennen Kinder aus sich heraus gewisse sprachliche Regelmäßigkeiten. Ihre Beobachtungen können aufgegriffen werden und zum Anlass genommen werden, über die Funktionsweise von Sprache nachzudenken und somit ein grundlegendes Sprachbewusstsein zu entwickeln" (ebd., S. 7).

Mehrere Lehrpläne betonen darüber hinaus die „dienende Funktion “, welche Grammatik (BW, NW, SH) oder gar sämtliche sprachliche Mittel (BB, HE, NS) gegenüber der Entwicklung funktionaler kommunikativer Kompetenzen im FU der Grundschule einnehmen sollten. Auf das Vorgeben von Wortoder Strukturlisten wird jedoch überwiegend verzichtet. In BY gibt es zu jedem zu bearbeitenden Themenbereich Listen mit Redemitteln und Wortschatz, die laut Konkretisierung des Lehrplans „bis zum Ende der 4. Jgst. gelehrt und gelernt werden“ müssen, um „ein lernerfolgsorientiertes Unterrichten“ zu gewährleisten (BSUK 2004, S. 4). Der Lehrplan für MV enthält ähnlich wie der für SN eine Aufstellung „möglicher Sprachmittel“ als „relevante Beispiele“ für die Realisation ebenfalls aufgelisteter Sprachfunktionen (vgl. MBWK MV 2007, S. 22; SSK 2009a, S. 24-25). Auch die im Lehrplan für 
TH enthaltene Liste möglicher sprachlicher Mittel zur Versprachlichung der gelisteten Redeabsichten hat ausdrücklich „Empfehlungscharakter“ (TMBWK 2010, S. 14). Im Rahmenplan für BE finden sich „Hinweise zur Verfügbarkeit sprachlicher Mittel - Jahrgangsstufe 3/4" (SBJS BE 2006, S. 18), die mit folgendem erläuternden Zusatz versehen wurden: „Durch eigenständiges Entdecken und/oder Hinweise der Lehrenden werden einige für den Sprachgebrauch wichtige Strukturmerkmale bewusst gemacht" (ebd.). Alle übrigen Bundesländer verzichteten bis 2015 zumindest bis zum Ende von Klasse 4 auf entsprechende Listen. Im neuen Lehrplan Englisch von 2016 listet BW nun allerdings vierzehn Themenfelder auf, für die auch je eigene verbindliche Redemittel ausgewiesen werden (vgl. MKJS BW 2016, S. 22 ff.). In BB gibt es solches für die Doppeljahrgangsstufe 5 und 6.

\subsubsection{Das Meinungsbild zur weiteren Handhabung von Grammatik, Sprachbewusstheit und sprachlichen Mitteln}

Sollen bewusstmachende Verfahren in Bezug auf Grammatik, Aussprache, Wortschatz und Redemittel bereits von Anfang Bestandteil des FU sein? $(N=37)^{8}$

\begin{tabular}{|l|l|l|l|l|}
\hline Stimme zu & $\begin{array}{l}\text { Stimme eher } \\
\text { zu }\end{array}$ & Weder noch & $\begin{array}{l}\text { Stimme eher } \\
\text { nicht zu }\end{array}$ & $\begin{array}{l}\text { Stimme } \\
\text { nicht zu }\end{array}$ \\
\hline $16(43,2 \%)$ & $12(32,4 \%)$ & $2(5,4 \%)$ & $5(13,5 \%)$ & $2(5,4 \%)$ \\
\hline
\end{tabular}

8 Eine weitere Person hat den Fragebogen bearbeitet, indem sie inhaltliche Anmerkungen zu den Abstimmungen vornahm, sich jedoch der Abstimmung selbst enthielt. Sie fehlt daher zur sonst üblichen Zahl von 38 Personen, die die Bögen bearbeitet haben. Ihre Kommentare wurden ungeachtet ihres Abstimmungsverhalten aber mit berücksichtigt. 
Eine Mehrheit von über $75 \%$ votierte für den Einsatz von bewusstmachenden Verfahren in Bezug auf Grammatik, Aussprache und sprachlichen Mitteln im frühen FU. Dabei nutzte nahezu jeder zweite Teilnehmer an dieser Abstimmung und damit ein vergleichsweise besonders hoher Anteil der von uns konsultierten Fachleute die Gelegenheit, sein Votum näher zu erläutern. Dabei war gleich mehreren der Hinweis darauf wichtig, dass die Anbahnung von Sprachbewusstheit ,selbstverständlich nicht auf abfragbares Wissen abzielend”, sondern „nur als Lernunterstützung und im Sinne von language awareness-Entwicklung " erfolgen dürfe, und dass somit „language awareness nicht mit expliziter Grammatikvermittlung gleichgesetzt" werden dürfe, wie jemand anderes schrieb. Als Leitmotive wurden von einem dritten Befragten vielmehr die beiden Kriterien ,sinnvoll integriert [und] exemplarisch" vorgeschlagen. Zur Begründung dieser auch für ihn zutreffenden Sicht führte ein Vierter aus:

Bewusstmachende Verfahren einsetzen heißt ja nicht notwendigerweise, expliziten Grammatikunterricht durchführen. Ich bin für bewusstmachende Verfahren im Sinne der ,focal attention". Lerner sollten eine Sensibilität für bestimmte Formen entwickeln. Wenn sie in der Lage sind, z. B. Past-Formen (regel- und unregelmäßige) zu erkennen oder bestimmte Wortbildungsregeln (rain-rainy), dann ist schon viel erreicht, denn diese Kompetenz, Formen zu erkennen und zu klassifizieren, macht es überflüssig für die Lehrkraft, immer wieder selbst explizit auf Formen hinzuweisen.

Auch in den weiteren Anmerkungen wurde mehrfach darauf verwiesen, dass der Impetus zur Anbahnung von Sprachbewusstheit möglichst von einer konkreten Sprachhandlung ausgehen solle. Ergänzend zum bereits genannten Motto sollte daher "zulassen und anregen, aber nicht aufzwingen” als Maxime gelten, „vor allem, wenn die Kinder danach fra- 
gen” - wobei hier als Zusatz „und die Lehrkraft die nötige Kompetenz besitzt" hinzugefügt wurde. Damit wird der Blick erneut auch auf die im Urteil der Befragten zwingend nötige hohe Qualifikation der Lehrkräfte gelenkt. Ein Befragter notierte diesbezüglich:

Lehrkräfte können u.U. nicht genau einschätzen, wieviel Grammatik / LA sinnvoll ist und in einen konventionellen Grammatikunterricht abgleiten. Fortbildung von Lehrkräften ist hier vonnöten.

Gleich fünf Fachleute, die allesamt für die Nutzung bewusstmachender Verfahren votierten, betonten unabhängig voneinander, dass bewusstmachende Verfahren nach ihrer Überzeugung nicht schon in Klasse 1 eingesetzt werden sollten, sondern frühestens in Klasse 2, in den Augen mancher auch erst in Klasse 3. Dabei sei es wichtig, „kindgemäß“ bzw. „kindgerecht“ vorzugehen. Ein Befragter notierte: „Nicht in Jgst. 1./2., nach Bedarf und langsam zunehmend, Grammatik nachgeordnet”. Ein weiterer führte aus: „ja, wenn im Sinne von language awareness, entdeckendem Lernen entsprechend der individuellen sprachlichen Voraussetzungen der Kinder. Zulassen und anregen, aber nicht aufzwingen".

Ein weiterer Befragter erachtete es zudem als wichtig darauf hinzuweisen, dass bewusstmachende Verfahren „auch beim Lesen und Schreiben zum Einsatz kommen" sollten. Seiner Ansicht nach brauchten „vor allem schwächere Lernende $[. .$.$] diese Form der Unterstützung”, und das sei „kein$ Widerspruch zum Aufbau der funktional-kommunikativen Kompetenz". In bemerkenswertem Kontrast zu diesen Stimmen hat niemand derer, die in der Abstimmung gegen den Einsatz bewusstmachender Verfahren votierten, sein Urteil durch einen Textkommentar erläutert. Was die immerhin beinahe $20 \%$ der Befragten, die in dieser Form abstimmten, zu 
ihrem Urteil bewogen hat, muss daher zumindest hier unbeantwortet bleiben.

Auch bei der zweiten im Rahmen des Themenkomplexes Grammatik, Sprachbewusstheit und sprachliche Mittel zur Abstimmung gestellten Frage begründeten vor allem jene ihr Votum, die der generellen Tendenz der Frage zustimmten. Die Abstimmung darüber, ob ein Lehrplan mindestens exemplarische Listen mit zu erarbeitendem Wortschatz und zu erwerbenden Redemitteln enthalten solle oder nicht, fiel mit einer Zustimmungsrate von knapp $53 \%$ gegenüber rund $47 \%$ moderater oder völliger Ablehnung allerdings deutlich knapper aus.

Soll es im Lehrplan mindestens exemplarische Listen mit zu erarbeitendem Wortschatz und zu erwerbenden Redemitteln geben? ( $N=38)$

\begin{tabular}{|l|l|l|l|l|}
\hline Stimme zu & $\begin{array}{l}\text { Stimme eher } \\
\text { zu }\end{array}$ & $\begin{array}{l}\text { Weder } \\
\text { noch }\end{array}$ & $\begin{array}{l}\text { Stimme eher } \\
\text { nicht zu }\end{array}$ & $\begin{array}{l}\text { Stimme } \\
\text { nicht zu }\end{array}$ \\
\hline $6(15,8 \%)$ & $14(36,8 \%)$ & $0(0 \%)$ & $8(21,1 \%)$ & $10(26,3 \%)$ \\
\hline
\end{tabular}

Als Kernargument für Listen mit zu erarbeitendem Wortschatz und zu erwerbenden Redemitteln führten mehrere Befragte an, dass dies vor allem ,im Hinblick auf den Übergang [...] überlegt werden" solle. Sie könnten nämlich, wie andere schrieben, „der Orientierung dienen”, besonders wenn jemand die Fremdsprache fachfremd unterrichte. Ähnlich äußerte sich auch der Verfasser des folgenden Kommentars:

Stimme zu, wenn das Adj. „exemplarisch“ [Hervorhebung im Kommentar] ernst genommen wird. Das Argument [...], besonders Fachfremden eine Hilfe zu geben, leuchtet ein. Besser wäre: Statt Listen nur noch (grundständig) ausgebildete L[ehrerinnen und] L[ehrer]!

Auch hier wurde somit kritisiert, dass FU auf der Primarstufe oftmals nicht von Lehrkräften erteilt wird, die dafür 
auch grundständig ausgebildet worden sind. Fast die Hälfte aller Kommentatoren insistierte teils mit enormer Vehemenz darauf, dass solche Listen nicht nur exemplarisch sein könnten, sondern auch nur exemplarisch sein dürften, denn vorgegebene „Listen würden Gestaltungsmöglichkeiten für den EU einschränken“, so ein Befragter. Vor allem bestünde aber die Gefahr, dass besonders wenig erfahrene Lehrkräfte solche Listen selbst dann als verbindlich ansähen, wenn sie es gar nicht wären, sodass dann schon Exemplarisches „als Lernvoraussetzungen interpretiert” würde. „Listen sind“, wie ein Befragter pointiert formulierte,

für unsichere/unerfahrene LK wichtig und sind von Sek I sehr gewünscht. Ich empfinde diese als Einschränkung der sprachlichen Handlungsfreiheit. Wenn es sein muss, dann ja. Für den Erwerbsprozess völlig unnötig. Wie wird denn am Ende der Klasse 4 sichergestellt, ob die Kinder alles können?

"[W]enn dies unbedingt sein muss", so sollten im Urteil vieler eher Themenfelder vorgegeben werden als Strukturlisten:

Es sollte jedoch [aber auch] darauf geachtet werden, dass diese Listen „stimmig“ sind und die Vorkenntnisse der Kinder (cornflakes, mountain bike...) nicht noch einmal abbilden.

\subsection{Leistungsbewertung und Nutzung von Portfolios}

\subsubsection{Zum Status quo der Leistungsbewertung und der Nutzung von Portfolios}

In allen Bundesländern werden die im frühen FU gezeigten Leistungen im Zeugnis dokumentiert. Dies geschieht allerdings in unterschiedlicher Weise. Während mancherorts das Geleistete bis zum Ende der Grundschulzeit ausschließlich in Wortgutachten beschrieben wird, werden in anderen Bundesländern ab Klasse 3 bzw. Klasse 4 Ziffernoten vergeben. 
Dabei differieren sowohl die Vorgaben für Wortgutachten als auch jene für die Erteilung von Ziffernoten teils erheblich zwischen den Ländern. Zudem können teilweise die Eltern mitbestimmen, ob Kinder ein Berichts- oder ein Ziffernzeugnis erhalten, während dies andernorts nicht möglich ist.

In den Flächenländern BW und NW wird ab Klasse 3 benotet. Dabei schränkt BW (vgl. MKJS BW 2004) aber ein, dass anfangs nur mündliche Leistungen in die Benotung eingehen dürfen, während produktives schriftliches Können bis zum Ende der Primarstufe nicht in die Noten einfließen darf. NW (vgl. MSW NW 2008) betont hingegen ebenso explizit, dass alle erbrachten Leistungen Grundlage der Leistungsbewertung sein müssen (vgl. dazu auch weiter unten). SH nutzt wiederum eine Mischform: Hier sind Noten für das Ende der Grundschulzeit vorgeschrieben. Nach Klasse 3 sollen die Schüler dagegen zunächst einmal per Lernentwicklungsbericht beurteilt werden. Zwar ist auch jetzt schon die Vergabe von Ziffernoten möglich, dies muss jedoch ausdrücklich durch die Schulkonferenz beschlossen werden.

In keinem der 16 Länder sind die im Frühbeginn vergebenen Noten versetzungsrelevant. Sie können nach Auskunft des jüngsten Sachstandsberichts der KMK aber „[f]ür eine (bindende oder nicht bindende) Übertrittsempfehlung " hinzugezogen werden (KMK 2013, S. 7). Dessen ungeachtet verzichten einige Länder trotzdem gleich ganz auf die Notengebung. In TH etwa werden die Leistungen der Schüler im FU bis zum Ende der Grundschulzeit ausschließlich in verbaler Form erfasst und das überdies einzig bezogen auf die mündlichen Fertigkeiten. In RP, wo es ebenfalls keine Ziffernoten gibt, soll wiederum das rheinland-pfälzische Sprachenportfolio als Basis der Leistungsbewertung dienen. Insgesamt raten sogar mehr als die Hälfte der Länder dazu, bei der Leistungserfassung und/oder bei der Förderung von Sprach(Lern)bewusstheit auf Portfolios, insbesondere auf kindgerechte Varianten des Europäischen 
Sprachenportfolios (ESP) zurückzugreifen. Ein derart enges diesbezügliches Junktim wie in RP ist aber singulär.

Als - alleinige - Basis dessen, was bewertet werden soll, identifizieren gleich mehrere Länder spezifische fremdsprachliche Fähigkeiten der Schüler, während andere Kompetenzbereiche dezidiert ausgenommen werden. Neben BW, auf das oben schon eingegangen wurde, schreibt etwa SA vor, dass ein besonderer Schwerpunkt auf dem Hörverstehen liegen müsse, während - wie auch in vielen anderen Ländern - weder Diktate noch Klassenarbeiten geschrieben werden dürfen und auch schriftliche Vokabeltests untersagt sind. In NS sollen pro Halbjahr vier bis sechs Lernkontrollen im Umfang von je maximal zehn Minuten Dauer zu den im Unterricht erworbenen rezeptiven Kompetenzen durchgeführt werden. Speziell bezüglich der Notenfindung wird überdies Folgendes vorgegeben: „Das wiedererkennende Lesen von Wörtern und einzelnen Sätzen ist für die Ermittlung der Zeugnisnote am wenigsten bedeutsam. Das Schreiben nach Vorlage geht nicht in die Zeugnisnote ein“ (NKM 2006, S. 18). Damit unterscheidet sich NS nicht nur von NW, wo die Schüler bereits am Ende von Jgst. 2 dazu in der Lage sein sollen, einzelne Wörter korrekt abzuschreiben, sondern auch von HB, wo im Lehrplan für Englisch als schriftlicher Bewertungsbereich ausdrücklich nicht nur „Korrektes Abschreiben von Wörtern und Sätzen " [sic] ausgewiesen ist, sondern auch „Eigene kurze Textproduktionen“ und „Leseverstehen“ (SBW 2013, S. 15).

\subsubsection{Das Meinungsbild zur weiteren Handhabung von Leistungsbewertung und der Nutzung von Portfolios}

In gleich sechs Abstimmungen und damit mehr als zu jedem anderen Bereich wurden die befragten Fachleute darum gebeten, uns ihr Urteil über die aktuelle Praxis der Leistungs- 
bewertung im FU der Grundschule und die Nutzung von Portfolios mitzuteilen. In der ersten Abstimmung ging es dabei darum, generell zu beurteilen, ob Leistungen im FU der Grundschule per Ziffernote bewertet werden sollen und wenn ja, ab wann (Jgst. 1, 2, 3 oder 4) dies geschehen soll. Nur eine einzige Person votierte für die Vergabe von Ziffernoten von Anfang an. Zwei weitere befürworteten eine solche Praxis ab Jgst. 2. Exakt die Hälfte der Befragten (19 von 38 ) votierten demgegenüber für Noten ab Klasse 3 und zwei Personen, also weitere rund $5 \%$, hielten dies für das Ende der Grundschulzeit für eine gute Idee. Das bedeutet, dass insgesamt etwas mehr als $60 \%$ dafür plädierten, spätestens am Übergang auf die Sekundarstufe das Geleistete nicht nur per Wortgutachten, sondern auch per Ziffernote auszudrücken. Zugleich lehnten aber auch fast $39 \%$ der Befragten, nämlich alle, die keine der vier genannten Möglichkeiten angekreuzt bzw. stets die Option „Stimme nicht zu“ gewählt hatten, die Notengebung für Leistungen im FU der Grundschule ab. Eine Person begründete dies durch den Zusatz „Alternative Formen der Leistungsbewertung sind wesentlich hilfreicher". Drei Befragte merkten an, dass vor allem die Notengebungspraxis in allen Fächern einheitlich sein solle, und dass es daher weniger darauf ankomme, ab wann benotet werde, sondern vielmehr, dass die Fremdsprachen hier keine Sonderbehandlung erfahren sollten. Wichtig war drei weiteren Befragten aber auch, darauf hinzuweisen, dass Ziffernoten durchaus in Ordnung seien, aber dass sie (wie dies auch mehrere Lehrpläne empfehlen) unbedingt durch individuelle verbale Rückmeldungen ergänzt werden sollten.

Die zweite den Teilnehmern zum Thema Leistungsbewertung vorgelegte Frage lautete:

Sollen die schriftlichen Fähigkeiten in die Leistungsbewertung einfließen? $(\mathrm{N}=38)$ 
Auch hier wurde bei den möglichen Antworten zwischen den Jahrgangsstufen unterschieden, wenn auch diesmal nur zwischen den Alternativen „Ab Jgst. 1“ und „Ab Jgst. 3 “. Zudem konnten die Befragten entscheiden, ob sie dem Vorschlag zustimmen oder nicht zustimmen, dass dies einerseits für „Zuordnungs-, multiple choice-Aufgaben o. ä.“ und/oder andererseits für „Vokabeltests, Grammatikaufgaben, Diktate o. ä.“ gelten soll.

Eine Person empfahl, die schriftlichen Fähigkeiten bereits in die Beurteilung der Schüler am Ende der Jgst. 1 einfließen zu lassen. Verschiebt man die Zielmarke ans Ende von Jgst. 3, so hielten dies dagegen mehr als $75 \%$ der Befragten (29 von 38) für eine gute Idee. Auch hinsichtlich dessen, welche schriftlichen Leistungen in die Beurteilung eingehen sollten und welche nicht - ergibt sich ein klares Bild. Mehr als drei Viertel der Fachleute (30 von 38) stimmten der These zu, dass Zuordnungsaufgaben, multiple choice-Aufgaben und ähnliche Formate probate Mittel auf diesem Feld sind. Grammatikaufgaben, Diktate oder auch Vokabeltests, die in vielen Ländern im FU aktuell als Mittel zur Leistungsmessung ohnehin verboten sind, wurden auch von den Befragten fast ebenso stark abgelehnt (nur 10 von 38 stimmten hier zu), wie es im obigen Fall befürwortende Urteile gab.

Ein Befragter verlangte in der Begründung seines Votums, dass es strikt dabei bleiben müsse, dass nur „schriftliche Fähigkeiten wie im Lehrplan definiert" bewertet werden dürften, „also Abschreiben, Zusammenfügen von Wörtern, chunks, Sätzen mit geringer Gewichtung ab Klasse 3“. Eine weitere Person sekundierte: „Gerne auch etwas mehr Wert auf Orthographie, damit der Schock zur Sek I nicht zu groß ist". Eine dritte Stimme vereinigte in gewissem Sinne beide Positionen, indem sie schrieb: 
Alles, was positiv ist, sollte einfließen. Kinder zum Schreiben $\mathrm{zu}$ ermuntern, ist wichtig und motivierend, die Ahndung von Fehlern dagegen demotivierend. Im Bewusstsein um die Schwierigkeiten der englischen Orthographie sollte die Rechtschreibung in keinem Fall in die Bewertung einfließen.

Zudem komme es, wie ein Befragter schrieb, sowohl bei Zuordnungs- und multiple choice-Aufgaben als auch bei Vokabeltests, Grammatikaufgaben und Diktaten immer natürlich auch „auf die Ausgestaltung an“.

Die dritte Frage, die es zum Thema Leistungsmessung und -dokumentation zu beantworten galt, lautete:

Soll das sprachliche Können der Schüler in gleichem Maße in die Leistungsbewertung einfließen wie Faktoren wie Lernbereitschaft, Motivation oder Bereitschaft zur Mitarbeit? ( $N=39)$

\begin{tabular}{|l|l|l|l|l|}
\hline Stimme zu & $\begin{array}{l}\text { Stimme eher } \\
\text { zu }\end{array}$ & $\begin{array}{l}\text { Weder } \\
\text { noch }\end{array}$ & $\begin{array}{l}\text { Stimme eher } \\
\text { nicht zu }\end{array}$ & $\begin{array}{l}\text { Stimme } \\
\text { nicht zu }\end{array}$ \\
\hline $9(23,1 \%)$ & $13(33,3 \%)$ & $7(17,9 \%)$ & $4(10,3 \%)$ & $6(15,4 \%)$ \\
\hline
\end{tabular}

Die am Ende des Kastens zusammengestellten Daten zeigen, dass insgesamt eine Mehrheit der Befragten zustimmte, dass das sprachliche Können in gleichem Maße in die Bewertung der im FU gezeigten Leistung einfließen solle wie eher weichere Faktoren. Immerhin ein Viertel votierte jedoch auch mindestens tendenziell dagegen; und wenn man nun noch hinzunimmt, dass nahezu jeder Fünfte es vermied, sich bezüglich dieser Frage festzulegen, so ergibt sich insgesamt ein doch eher uneinheitliches Bild.

Besonders jene, welche die in der Frage angelegte Proposition ablehnten, ergänzten ihr Votum um erläuternde Kommentare. Einer lautete: „Dafür gab es früher die „Kopfnoten“". Andere versuchten eher eine Differenzierung und/ oder Relativierung vorzunehmen: Eine Person schrieb: 
„Klasse 1/2 - individuelle und gesellschaftspolitische, anforderungsbezogene Leistungsbegriffe: Hier würde ich eher zustimmen; Klasse 3/4 - stärker anforderungsbezogener Leistungsbegriff“. Ein weiterer Teilnehmer an der Befragung argumentierte: „Wenn Englisch ein Fach ist, dann sollte auch fachliches Können im Zentrum der Bewertung stehen“. Noch jemand anders gab an: „Vielleicht nicht in gleichem Maße, aber im Prozentanteil von 30 oder 33 \% “. Vier weitere Befragte und damit insgesamt acht derer, die eine gleichrangige Bewertung von sprachlichem Können und weiteren Faktoren eher ablehnten, formulierten ähnliche Einwände oder Bedenken. Im Gegensatz dazu ergänzte ein Befürworter seine Position um folgenden Kommentar: „Eine sehr schwierige Frage. Motiviertheit, soziales Engagement etc. sind Leistungen, die in die Bewertung einbezogen werden sollten ".

Den Abschluss des Themenblocks bildeten schließlich drei Fragen, die wieder dezidiert die Nutzung von Portfolios betrafen. Sie lauteten:

Soll die Arbeit mit dem Europäischen Portfolio der Sprachen im FU der Grundschule verpflichtend sein? $(N=39)$

\begin{tabular}{|l|l|l|l|l|}
\hline Stimme zu & $\begin{array}{l}\text { Stimme eher } \\
\text { zu }\end{array}$ & Weder noch & $\begin{array}{l}\text { Stimme eher } \\
\text { nicht zu }\end{array}$ & $\begin{array}{l}\text { Stimme } \\
\text { nicht zu }\end{array}$ \\
\hline $5(12,8 \%)$ & $16(41,0 \%)$ & $7(17,9 \%)$ & $4(10,3 \%)$ & $7(17,9 \%)$ \\
\hline
\end{tabular}

Soll die Arbeit mit dem Europäischen Portfolio der Sprachen auf der Sekundarstufe weitergeführt werden? $(N=39)$

\begin{tabular}{|l|l|l|l|l|}
\hline Stimme zu & $\begin{array}{l}\text { Stimme eher } \\
\text { zu }\end{array}$ & Weder noch & $\begin{array}{l}\text { Stimme eher } \\
\text { nicht zu }\end{array}$ & $\begin{array}{l}\text { Stimme } \\
\text { nicht zu }\end{array}$ \\
\hline $17(43,6 \%)$ & $11(28,2 \%)$ & $5(12,8 \%)$ & $3(7,7 \%)$ & $2(5,1 \%)$ \\
\hline
\end{tabular}


Soll die Sprache der Portfolios in den entsprechenden Lerngruppen (z. B. Schüler mit hohem Migrationsanteil; Klassen mit hoher englischer Sprachkompetenz) Englisch sein? $(\mathrm{N}=39)$

\begin{tabular}{|l|l|l|l|l|}
\hline Stimme zu & $\begin{array}{l}\text { Stimme eher } \\
\text { zu }\end{array}$ & Weder noch & $\begin{array}{l}\text { Stimme eher } \\
\text { nicht zu }\end{array}$ & $\begin{array}{l}\text { Stimme } \\
\text { nicht zu }\end{array}$ \\
\hline $8(20,5 \%)$ & $12(30,8 \%)$ & $7(17,9 \%)$ & $5(12,8 \%)$ & $7(17,9 \%)$ \\
\hline
\end{tabular}

Nicht ganz zwei Drittel der Befragten waren grundsätzlich eher dafür, die Arbeit mit dem ESP im FU der Grundschule verpflichtend $\mathrm{zu}$ machen. Fast $30 \%$ sprachen sich jedoch auch mindestens moderat dagegen aus, während sich erneut fast ein Fünftel auch bei dieser Frage nicht festlegen mochte. Gleich sechs Befragte wiesen in ihren Kommentaren darauf hin, dass es ihrer Ansicht nach klüger sei, Lehrkräfte mit guten Argumenten von den Vorteilen der Arbeit mit dem Portfolio $\mathrm{zu}$ überzeugen, statt sie dazu $\mathrm{zu}$ verpflichten (,,Wünschenswert' ja, nicht verpflichtend. Das P. sollte überzeugend empfohlen werden“), auch weil noch zu wenige Lehrkräfte überhaupt ausreichend kompetent seien, um adäquat mit ihm zu arbeiten („Schwierig zu realisieren, leider erhebliche Zweifel an der Portfolioarbeit bei Lehrkräften“). Zudem gab jemand zu bedenken, dass „es rechtlich nicht überall gelöst ist, wer das Portfolio einsehen kann “.

Über zwei Drittel, nämlich fast $70 \%$, votierten gleichzeitig dafür, die Arbeit mit dem ESP auf der Sekundarstufe fortzuführen. Zudem plädierte insgesamt eine Mehrheit der Befragten dafür, z. B. in Klassen mit hohem Migrationsanteil und/oder hoher englischer Sprachkompetenz das Portfolio im FU auf der Sekundarstufe fortzuführen. Bei manchen schien aber auch recht unverhohlen eine grundsätzliche Ablehnung der Arbeit mit Portfolios oder zumindest eine starke Skepsis unter den gegebenen Bedingungen durch. Ein Befragter notierte: „Viiiel zu viel Deutsch und viel zu wenig zur Verfügung stehende 
Unterrichtszeit“. Jemand anderes bekannte freimütig: „Ich bin ja [ohnehin] nicht der große Portfolio-Fan“. Und schließlich waren immerhin einige mittlerweile auch einfach ernüchtert darüber, wie gering die Akzeptanz von Portfolioarbeit in der Praxis (noch immer) ist: „Natürlich wäre das sinnvoll. Aber de facto wird das Grundschulportfolio so gut wie nicht verwendet, daher kann es auch nicht fortgeführt werden“.

\subsection{Maßnahmen und Regelungen zum Übergang vom Fremdsprachenunterricht der Grundschule zu den weiterführenden Schulen}

\subsubsection{Zum Status quo von Maßnahmen und Regelungen zum Übergang vom Fremdsprachenunterricht der Grundschule $z u$ den weiterführenden Schulen}

Laut KMK „, [schafft] der Fremdsprachenunterricht der Grundschule $[. .$.$] die Basis für die Fortsetzung des Sprachenlernens$ im Sekundarbereich“ und „[knüpft] beim Übergang in den Sekundarbereich an die Kompetenzen [an], die im Primarbereich verlässlich erworben wurden" (Hervorhebung durch die Autoren). Ein gelungener Übergang wird als essenziell wichtig für das erfolgreiche Fortführen der Fremdsprache gesehen (KMK 2013, S. 7). Dennoch existieren in den Bundesländern bis heute keine verbindlichen Vorgaben für die Gestaltung des FU für den Übergang von der Primar- zur Sekundarstufe. In den Lehrplänen gibt es allenfalls sehr allgemein gehaltene Verweise bzw. Empfehlungen, wie z.B., dass die Grundschule für den Erwerb grundlegender elementarer sprachlicher Mittel sowie konkreter kommunikativer Fähigkeiten und Fertigkeiten verantwortlich ist und dass die weiterführenden Schulen „[a]uf diesem verlässlichen Sockel sprachlicher Kompetenzen [...] mit ihrem Englischunterricht ab Klasse 5 [aufsetzen sollen]“ (MSW NW 2008, S. 5). 
In den meisten Bundesländern gibt es lediglich Handreichungen (z. B. für BB LISUM o.D.) und Empfehlungen zur Kooperation zwischen abgebenden und aufnehmenden Schulen, womit die Länder nicht die von der KMK geforderte „institutionell abgesicherte Kooperation von Primar- und Sekundarbereich“ (KMK 2013, S. 4) bieten. Empfohlen wurden gemeinsame schulformübergreifende Projekte, gegenseitige Hospitationen, gegenseitige Teilnahme an Fachkonferenzen und die Bildung von regionalen Netzwerken. Diese wurden oftmals durch Projekte wie das „Kleeblatt-Projekt“ (vgl. Schulanzeiger 2007) in BY oder "Schule im Team: Unterricht gemeinsam entwickeln“ (vgl. Stadt Dortmund 2013) in NW initiiert. Meistens wurden die Initiativen aber an die individuellen Schulen delegiert (z. B. BW, MV, NW, RP, TH). Dabei gestaltet es sich schwierig, stabile Strukturen zu entwickeln, weil die Schüler der Jahrgangstufe 5 der fortführenden Schulen meistens aus vielen unterschiedlichen Grundschulen stammen und die Zusammensetzung der neu zu bildenden Klassen jedes Jahr variiert.

Weitere Maßnahmen wie schulformübergreifende Fortbildungen und Regionalkonferenzen werden in SN, HB, SA durch Sprachbildungs- bzw. Fortbildungskonzepte gefördert. In BE, $\mathrm{HH}$, NS und NW werden externe Fortbildungen von Schulaufsichtsdezernenten bzw. Fachleitern veranlasst. Diese bieten dann auch eine Plattform für die empfohlene Entwicklung von gemeinsamen Lernaufgaben und diagnostischen Instrumenten. Nicht zuletzt wegen dieser Unverbindlichkeit variieren die Regelungen zum Übergang und der curricularen Anschlussfähigkeit sowie die Organisationsstrukturen in den 16 Ländern jedoch erheblich.

Besonders evident wird dies bei den zeitlichen Rahmenvorgaben zur Dauer der Grundschulzeit und zum Einsetzen der Fremdsprachen. In BE und BB umfasst die Grundschule sechs Jahre, sodass der Übergang später stattfindet als in allen anderen Bundesländern, in denen man von einer vierjährigen Grundschulzeit ausgeht. Zwar nehmen in BE knapp 
vier Dutzend Oberschulen sogenannte Schnellläufer auf, das heißt Schüler, die schon zu Klasse 5 auf eine weiterführende Schule wechseln. Dies ist jedoch typischerweise bei weniger als $10 \%$ der Schülerschaft der Fall. Ein weiterer Unterschied zwischen den Bundesländern, der eklatante Auswirkungen auf die von der KMK geforderten ,verlässlich erworbenen und vereinbarten Kompetenzen" (KMK 2013, S. 7) hat, ist das unterschiedliche Einsetzen des frühen FU. Während in $\mathrm{BW}^{9}, \mathrm{HH}, \mathrm{NW}$ und RP der FU in der Regel in Klasse 1 beginnt und bis zur vierten Klasse fortgeführt wird, setzt er in $\mathrm{BB}, \mathrm{BE}, \mathrm{HB}, \mathrm{HE}, \mathrm{MV}, \mathrm{NS}, \mathrm{SA}, \mathrm{SH}, \mathrm{SL}, \mathrm{SN}$ und TH erst in der dritten Klasse ein. ${ }^{10}$ Unabhängig davon, ob die Schüler zwei oder vier Jahre FU erteilt bekommen, streben fast alle Bundesländer in Bezug auf die Fertigkeiten die Niveaustufe A1 des Gemeinsamen Europäischen Referenzrahmens für Sprachen (GER) an. Lediglich in Bezug auf Schreiben setzen manche Länder ein Niveau unterhalb von A1 an (siehe auch Kapitel 2.4), während $\mathrm{HH}$ sowie einige Länder, in denen der FU in der Grundschule schon in Klasse 1 beginnt, besonders in Bezug auf Hör- und Hör-/Sehverstehen als Zielmarke das Niveau A2 oder immerhin Anteile davon benennen. Dennoch klaffen die Leistungserwartungen am Ende der Grundschulzeit, die in einigen Bundesländern (z. B. BE, BW, HB, HH, NW) in den Lehrplänen explizit formuliert sind, in den Ländern erheblich auseinander. Es stellt sich folglich die Frage

9 Für BW läuft diese Regelung allerdings aus, denn ab dem Schuljahr 2018/19 beginnen die Grundschulen mit dem FU erst ab Klasse 3 (vgl. Staatsministerium Baden-Württemberg 2017).

10 In BB kann die erste Fremdsprache allerdings schon in den Jahrgangstufen 1 und 2 im Rahmen des Ansatzes „Begegnung mit Fremdsprachen " unterrichtet werden. Im SL findet früher Französischunterricht ggf. in bilingualen Klassen ab Jahrgangstufe 1 statt. 
nach einer länderübergreifenden Vergleichbarkeit (vgl. auch Kapitel 2.7).

Während in BE und BB ein verbindlicher Lehrplan für den FU der Jahrgangstufe 1-10 gilt, bestehen in den anderen Bundesländern jeweils separate Lehrpläne für Primarstufe und Sekundarstufe I. In BB, NW und TH geben die Lehrpläne der Grundschulen verbindliche Abschluss- bzw. Übergangsprofile für die Kompetenzen in Bezug auf die Fertigkeiten vor, die aber in den Lehrplänen der weiterführenden Schulen nicht explizit aufgegriffen werden. In BE werden beim Wechsel zur weiterführenden Schule zu Beginn von Klasse 7 Lernausgangslagetests durchgeführt. Laut der befragten Experten werden in $\mathrm{HH}$ „Regelanforderungen “ und „verbindliche Inhalte" definiert, während HB kein Abschlussprofil hat.

\subsubsection{Das Meinungsbild zur weiteren \\ Handhabung von Maßnahmen und \\ Regelungen zum Übergang des \\ Fremdsprachenunterrichts der \\ Grundschule zu den \\ weiterführenden Schulen}

Wie das Ergebnis der Abstimmung zeigt, sprach sich eine deutliche Mehrheit von 85,8 \% für die Einführung bundesländer- und schulformübergreifender Regelungen zum Übergang aus.

Sollen Regelungen für den Übergang bundesländerübergreifend und schulformübergreifend bildungspolitisch verankert werden (z.B. stufenübergreifender Rahmenlehrplan, dezidierte Kompetenzerwartungen in Übergangsprofilen)? $(\mathrm{N}=35)$

\begin{tabular}{|l|l|c|c|l|}
\hline Stimme zu & $\begin{array}{l}\text { Stimme } \\
\text { eher zu }\end{array}$ & Weder noch & $\begin{array}{l}\text { Stimme eher } \\
\text { nicht zu }\end{array}$ & $\begin{array}{l}\text { Stimme } \\
\text { nicht zu }\end{array}$ \\
\hline $14(40,0 \%)$ & $6(45,8 \%)$ & $1(2,8 \%)$ & $2(5,7 \%)$ & $2(5,7 \%)$ \\
\hline
\end{tabular}


Gleich mehrere Befragte setzten ihrem Votum wörtlich oder zumindest dem Sinn nach hinzu, dass „dringend verbindliche Mindeststandards für Englisch in der Grundschule benötigt “ werden. Um zu gewährleisten, dass die weiterführenden Schulen bei den am Ende der Klasse 4 (respektive Klasse 6 in $\mathrm{BB}$ und in BE) erworbenen Kompetenzen ansetzen, wurde von einigen ein „durchgängiger Rahmenlehrplan von Schule zu Schule und Stufe zu Stufe“ als „ideal“ angesehen, denn derzeit sei, darin waren sich Befürworter wie Kritiker der bildungspolitischen Verankerung von Regelungen für den Übergang einig, „die Divergenz der einzelnen Bundesländer noch zu hoch“. Die Beurteilung der einzelnen Maßnahmen zeigte hingegen ein eher uneinheitliches Bild:

Sollen folgende Maßnahmen verpflichtend schulformübergreifend angeboten werden? $(\mathrm{N}=38)$

\begin{tabular}{|l|c|c|}
\hline & Stimme zu & $\begin{array}{l}\text { Stimme } \\
\text { nicht zu }\end{array}$ \\
\hline $\begin{array}{l}\text { Kooperation von Primar- und } \\
\text { Sekundarschulen }\end{array}$ & $30(79,4 \%)$ & $8(20,6 \%)$ \\
\hline Schulformübergreifende Projekte & $17(44,1 \%)$ & $21(55,9 \%)$ \\
\hline Fortführung des Grundschulportfolios & $19(50,0 \%)$ & $19(50,0 \%)$ \\
\hline Gegenseitige Hospitation & $29(76,3 \%)$ & $9(23,7 \%)$ \\
\hline $\begin{array}{l}\text { Gegenseitige Teilnahme an } \\
\text { Fachkonferenzen }\end{array}$ & $21(55,9 \%)$ & $17(44,1 \%)$ \\
\hline $\begin{array}{l}\text { Schulformübergreifende } \\
\text { Regionalkonferenzen }\end{array}$ & $24(63,2 \%)$ & $14(36,8 \%)$ \\
\hline $\begin{array}{l}\text { Schulformübergreifende } \\
\text { Fortbildungen }\end{array}$ & $28(73,6 \%)$ & $10(26,4 \%)$ \\
\hline $\begin{array}{l}\text { Entwicklung von gemeinsamen } \\
\text { Lernaufgaben/diagnostischen } \\
\text { Instrumenten }\end{array}$ & $24(63,2 \%)$ & $14(36,8 \%)$ \\
\hline
\end{tabular}


Zwar votierte eine Mehrheit (79,4\%) für die Kooperation von Primar- und Sekundarschulen, aber bei den konkreten Umsetzungsformen zeigten sich Divergenzen: 76,3\% befürworteten gegenseitige Hospitationen, aber nur $44 \%$ plädierten für schulformübergreifende Projekte. Geteilter Meinung waren die Befragten auch in Bezug auf die Fortführung des Grundschulportfolios in den Sekundarschulen, und zwar zum einen, weil „bisher das Führen einen GS-Portfolios nicht verpflichtend [ist], [und] von daher auch nicht fortgeführt werden [kann] “ und zum anderen, weil Einsatz, Bedeutung, Funktion von Grundschulportfolios in den jeweiligen Bundesländern so stark variierten (vgl. auch Kapitel 2.7).

Die Qualifizierung der Lehrkräfte bzw. die Lehrerbildung hatten bei den Befragten einen hohen Stellenwert. So wurden schulformübergreifende Fortbildungen und Regionalkonferenzen mehrheitlich positiv beurteilt und als probate Maßnahmen angesehen, um dem mangelnden Kenntnisstand der Lehrkräfte in Bezug auf die jeweils andere Schulform entgegen zu wirken. Aus den Kommentaren der Befragten ging auch hervor, dass in der grundständigen Lehrerausbildung schulformübergreifende Elemente gefordert wurden: „Gemeinsame LA-Ausbildung in der Uni, zumindest schultypübergreifende Kurse“. Weiterhin erachteten einige Befragte die „Entwicklung von Lehrwerken/ Materialien" als wichtig, bei denen Primar- und Sekundarstufe aufeinander abgestimmt sind.

Befürworter wie auch Kritiker von verbindlichen Maßnahmen und Regelungen sahen das Fehlen von Bildungsstandards als das grundlegende Problem:

[Regelungen sind] zukünftig sicher wünschenswert, aber solange die Rahmenbedingungen für FSU in den Ländern noch so stark variieren (z. B. Beginn in Jahr 1 vs. 3, Frz. vs. Englisch etc.), sehe ich eher dort die ,Baustellen'. Wenn diese Dinge mehr vereinheitlicht sind, sollte die Vereinheitlichung des Übergangs angegangen werden. 


\subsection{Unterrichtsmethoden und Einsprachigkeit des Unterrichts}

\subsubsection{Zum Status quo von Unterrichtsmethoden und Einsprachigkeit des Unterrichts}

Das Thema „Unterrichtsmethoden und Einsprachigkeit des Unterrichts" ist das einzige Feld, in dem - im Gegensatz zu den erheblichen Divergenzen in den anderen Bereichen - eine grundlegende bundesländerübergreifende Übereinstimmung in der didaktisch-methodischen Gestaltung des FU zu finden ist. So herrscht in allen Bundesländern Einigkeit über den Vorrang des mündlichen Sprachhandelns. Dies manifestiert sich auch in den Lehrplänen, die alle eine kommunikativhandlungsorientierte Unterrichtsmethodik fordern, den spielerisch-entdeckenden Umgang mit Sprache sowie ganzheitliches und multisensorisches Lernen erlauben und somit den FU an den allgemeinen didaktisch-methodischen Grundsätzen der Grundschule ausrichten (vgl. KMK 2013, S. 5).

Neben den allgemeinen Grundschulgrundsätzen kommen fremdsprachenspezifische Prinzipien zum Tragen. Der FU folgt einer kommunikativen Progression, die auf den Erwerb von funktional-kommunikativen Kompetenzen in den Bereichen Hör/Hör-Sehverstehen, Sprechen, Leseverstehen, Schreiben und Sprachmittlung abzielen (vgl. auch Kapitel 2.5). Doch auch wenn Mündlichkeit bundesweit als vorrangig angesehen wird und für die Fertigkeiten des Hör/ Hör-Sehverstehens und des Sprechens mit Ausnahme von $\mathrm{HH}^{11}$ am Ende der Klassenstufe 4 überall das Niveau A1 (GER) angestrebt wird, gibt es sehr unterschiedliche Einstellungen und Vorgaben zum Einsatz von Schreiben und Lesen (vgl. auch Kapitel 2.4).

11 HH strebt das Niveau A2 an (vgl. KMK 2013, S. 4). 
Auch darüber, den FU weitgehend einsprachig zu gestalten, besteht ein breiter Konsens. Bei der Sprachmittlung, bei der Bewusstmachung von Sprache durch Vergleiche oder um Verstehen zu sichern kann bzw. soll auf die deutsche Sprache - respektive auf die Herkunftssprachen - zurückgegriffen werden (vgl. SBJS 2006, S. 51). Dennoch wird die „funktionale Einsprachigkeit“ (SSK 2009a, S. 3; MSW NW 2012, S. 7) als Grundlage der Unterrichtsführung angestrebt, weshalb der Unterricht "überwiegend einsprachig geführt“ (MSW NW 2008, S. 6) werden soll. Es liegen noch keine empirisch fundierten Aussagen dazu vor, inwieweit die Lehrkräfte diese Vorgaben zur funktionalen Einsprachigkeit konkret im FU umsetzen; aber es wird darauf hingewiesen, dass die Umsetzung u.a. von der Qualifikation der Lehrkräfte abhängt.

Der Fokus auf Mündlichkeit und Methodenvielfalt wird bei den im FU verwendeten Methoden besonders offensichtlich. Explizit benannt werden der Einsatz von Storytelling (BW, NI, RP); Liedern / musischem Lernen und Reimen (BW, NI); Hörtexten (BW); Spielen (BW, NI, SA, TH); interaktivem Sprechen / Rollenspiel / dramapädagogischen Methoden (NI, BW, SA) und Total Physical Response (NI, RP). Trotz des übereinstimmenden Rufes nach Methodenvielfalt gibt es bei der konkreten Umsetzung allerdings erhebliche Unterschiede. Schon die Vorgaben - (je nach Bundesland in Form von diesbezüglichen Handreichungen, Leitfäden und Fachbriefen, z. B. BB, LISUM 2006a, 2008) sowie der Grad der Verbindlichkeit variieren von Bundesland zu Bundesland erheblich. Einig sind sich fast alle Länder hingegen im Empfehlen der Nutzung von offenen Lernarrangements wie kooperativem Lernen (HH, NW), Stationenarbeit (HE, NW, SA, SH), Werkstattunterricht (SA), Wochenplanarbeit (NW, $\mathrm{BE})$, Freiarbeit (NW), Lernbüros (BE), Lerntheken (SA, SH) und Projektarbeit (HE, NW, SA, TH). 


\subsubsection{Das Meinungsbild zur weiteren Handhabung von Unterrichtsmethoden und Einsprachigkeit des Unterrichts}

Wie das Ergebnis der Abstimmung zu diesem Thema zeigt, sprach sich eine deutliche Mehrheit von $76 \%$ der Befragten dafür aus, funktionale Einsprachigkeit verbindlich in den Lehrplänen vorzuschreiben. Nur $18 \%$ standen dieser Idee mehr oder weniger ablehnend gegenüber. Gut $5 \%$ legten sich nicht fest.

Soll Einsprachigkeit verbindlich in den Lehrplänen vorgegeben werden? $(\mathrm{N}=38)$

\begin{tabular}{|l|l|l|l|l|}
\hline Stimme zu & $\begin{array}{l}\text { Stimme eher } \\
\mathbf{z u}\end{array}$ & Weder noch & $\begin{array}{l}\text { Stimme eher } \\
\text { nicht zu }\end{array}$ & $\begin{array}{l}\text { Stimme } \\
\text { nicht zu }\end{array}$ \\
\hline $16(42,1 \%)$ & $13(34,2 \%)$ & $2(5,3 \%)$ & $4(10,5 \%)$ & $3(7,9 \%)$ \\
\hline
\end{tabular}

Aus den Kommentaren wird ersichtlich, dass viele Befürworter sich auf eine „funktionale“ bzw. „aufgeklärte Einsprachigkeit" bezogen, welche den Gebrauch der deutschen Sprache, der sogenannten „Schulsprache“, für „interkulturelles Lernen, Sprachmittlung, Reflexionsphasen " und language awareness mit einbezieht. Ein Argument der Befragten für die weitgehende Einsprachigkeit war, dass Deutsch „nicht für alle L1 “ und der Umgang „mit den Herkunftssprachen“ weiterhin eine offene „brennende Frage“ sei. Zudem wurde darauf hingewiesen, dass die durch die Stundentafel bedingte „begrenzte Unterrichtszeit soweit wie möglich für die Zielsprache zu nutzen" und ein Höchstmaß an zielsprachlichem „Input“ erstrebenswert seien, dass dies aber „kein Dogma“ darstellen solle, da ja zugleich der Ausbildungsstand der Lehrkräfte eine Rolle spiele.

Jene, die einer verbindlichen Vorgabe skeptisch gegenüberstanden, verwiesen hingegen darauf, dass die 
„Qualifikation der Lehrkräfte oft nicht ausreichend für einsprachigen Englischunterricht" sei und somit erst einmal die Voraussetzungen für die Verpflichtung zur Einsprachigkeit auf der Ebene der Lehrerausbildung und für die „verbindlichen Mindeststandards für Englisch “ geschaffen werden müssten.

Das Meinungsbild zum verbindlichen Vorschreiben von Unterrichtsmethoden in den Lehrplänen war demgegenüber weniger eindeutig. Nicht nur an den Prozentwerten (39\% der Befragten befürworteten dies, $42 \%$ lehnten es ab), sondern auch in den weiteren Anmerkungen spiegelte sich wider, dass die individuelle, auf die Lerngruppe abgestimmte Gestaltung des FU einerseits befürwortet wurde, dass es aber auch einige Befürworter einer (qualitativen) Verbindlichkeit bestimmter Methoden gab.

Sollen bestimmte Unterrichtsmethoden verbindlich in den Lehrplänen vorgegeben werden? $(N=38)$

\begin{tabular}{|l|l|l|l|l|}
\hline Stimme zu & $\begin{array}{l}\text { Stimme eher } \\
\text { zu }\end{array}$ & $\begin{array}{l}\text { Weder } \\
\text { noch }\end{array}$ & $\begin{array}{l}\text { Stimme eher } \\
\text { nicht zu }\end{array}$ & $\begin{array}{l}\text { Stimme } \\
\text { nicht zu }\end{array}$ \\
\hline $5(13,2 \%)$ & $10(26,3 \%)$ & $7(18,4 \%)$ & $6(15,8 \%)$ & $10(26,3 \%)$ \\
\hline
\end{tabular}

Bei allen (auch bei den Nicht-Befürwortern) herrschte Konsens in Bezug auf die nötige Verbindlichkeit didaktischer Grundsätze und Prinzipien: „,[D]ie wichtigsten didaktischmethodischen Grundsätze [...] sollten verbindlich vorgegeben werden, z. B. Handlungsorientierung, Lernerorientierung, TBL, Differenzierung, Inklusion“, und ebenso solle „der themen- und situationsorientierte Ansatz verbindlich sein". Überdies plädierten Befürworter wie Skeptiker dafür, „statt Methoden Prinzipien“ verbindlich zu machen. Letztere betonten aber, dass lediglich „Beispiele“ für verwendete 
Methoden gegeben werden sollten, da „mehr der Kompetenzorientierung widersprechen [würde]".

Sowohl die Befürworter verbindlicher Methodik als auch die diesbezüglichen Skeptiker kamen zudem zu dem Schluss, dass verbindliche Vorgaben auf der Mikromethodenebene nicht nur hinderlich für die Kompetenzorientierung sind, sondern auch für die Lernerorientierung sowie deren situative, kontextuelle Einbindung: „Es sollte vorgegeben werden, dass unterschiedliche Methoden ständig zum Einsatz kommen sollten, [welche], das kommt auf die LK und die Schüler an“. Doch wurde ebenfalls betont, dass die Einstellung der Lehrkräfte und deren Qualifikation für die Methodenwahl zentral seien, denn es ergebe „wenig Sinn, verbindlich Methoden $\mathrm{zu}$ fordern, $\mathrm{zu}$ denen Unterrichtende (aus welchen Gründen auch immer) keinen Zugang finden.“

Somit lässt sich bilanzieren, dass die Mehrheit der Befragten sich für eine hohe Flexibilität und die Möglichkeit für individuelle Vorgehensweisen der Lehrkräfte aussprach. Zudem bestand Konsens darüber, dass die Methodenkompetenzen der Lehrkräfte durch die Bereitstellung von Materialien mit Beispielen für einen adäquaten Einsatz von Methoden in Form von Handreichungen und Fachbriefen und spezifischen Fortbildungen gestärkt werden sollte. 


\section{Resümee}

Auch mehr als zehn Jahre nach seiner verbindlichen flächendeckenden Einführung befinden sich sowohl die Theorie als auch die Praxis des frühen Fremdsprachenunterrichts im Zustand fortwährender Weiterentwicklung (vgl. auch Kapitel 1). Die Lehrpläne praktisch aller Bundesländer benennen als Zielmarke für das Ende der Grundschulzeit fremdsprachliche Kompetenzen der Schüler auf der Niveaustufe A1 des GER - wobei jene Länder, in denen der FU in Klasse 1 beginnt, optional teils auch bereits Anteile von A2 erwähnen (vgl. auch Kapitel 2.8). Unterhalb dieses kleinsten gemeinsamen Nenners herrscht jedoch, wie die je ersten Teile der Doppelabschnitte in Kapitel 2 des Buches zeigen, sehr häufig eine enorme Diversität der Vorgaben und Lernziele. Manchmal kann man sogar fast von einer antagonistischen Pluralität sprechen, wobei die Länder allerdings einen Punkt gemeinsam haben: Kein Land kommt mehr ohne einen Hinweis auf die Heterogenität der Schülerschaft aus. Welche Konsequenzen sich daraus für die Praxis z. B. in Bezug auf inklusionsorientierte Fragestellungen und, als sprachbezogener Teilbereich dessen, für die Arbeit mit Schülern mit Migrationshintergrund im FU ergeben, wird jedoch sehr unterschiedlich gesehen (vgl. auch Kapitel 2.3.1 und 2.9.1). Kompetenzen, deren Entwicklung im einen Land im Zentrum des Unterrichts stehen sollen, werden im anderen teils nicht einmal erwähnt (vgl. Kapitel 2.5.1); und auch die Leistungsfähigkeit in der Grundschule und daraus abgeleitet die Frage, was man von den Schülern (wann) verlangen sollte, wird von den von uns Befragten wie auch in den Lehrplänen durchaus nicht immer gleich beantwortet (vgl. auch Kapitel 2.4.1, 2.6.1, 2.7.1 und 2.8.1). 
Ein Grund für die Vielzahl an Unterschieden zwischen den Lehrplänen dürfte sein, dass um die Jahrtausendwende, als jene Beschlüsse gefasst wurden, auf denen die Vorverlegung des FU in die Primarstufe beruhte, zu wesentlich weniger Aspekten des Frühbeginns belastbare empirische Daten vorlagen als dies heute der Fall ist. Zweitens spielt es daher zumindest in einigen Punkten eine Rolle, wann ein Lehrplan geschrieben wurde und auf welchem Erkenntnisstand er somit fußt. Ein dritter Faktor, der zur fortgesetzten Zieldifferenz in vielen Curricula beigetragen haben dürfte, sind aber auch widerstreitende und sich gelegentlich komplett widersprechende (bildungs)politische Konzepte.

Es würde den Rahmen des Bandes sprengen, auch nur einen dieser drei Aspekte ausführlich aufzuarbeiten (vgl. aber z. B. Diehr \& Rymarczyk 2012; Kötter \& Rymarczyk 2011, 2015). Stattdessen soll der Blick auf jene Fachleute für frühes Fremdsprachenlernen und -lehren gelenkt werden, die sich bereits seit vielen Jahren professionell mit der Begleitung, Erforschung und Weiterentwicklung fremdsprachlicher Praxis befassen. Sie stellen eine - bislang zumeist vernachlässigte relevante Größe dar, die nach unserer Überzeugung dazu geeignet ist, dem frühen Fremdsprachenlernen neue Impulse zu geben. Knapp drei Dutzend von ihnen - und damit eine nicht gerade kleine Zahl - hat, wie im je zweiten Teil der vorstehenden Doppelkapitel dokumentiert, im Herbst 2015 schriftlich dargelegt, zu welchem Urteil sie über Kernaspekte des Frühbeginns und deren künftige Ausgestaltung kommen. Nachdem in Kapitel 2 das so entstandene Meinungsbild vorgestellt wurde, geht es nun darum, für die in der Auswertung der Lehrpläne und der Praxis erfassten und anschließend beurteilten Bereiche jeweils jene Aspekte zu benennen und zu bündeln, in denen die Vorgaben und die Urteile der befragten Fachleute nicht übereinstimmen, um so die jeweils zentralen Desiderata herauszuarbeiten - und dies sowohl mit Blick auf 
die fortlaufende Überarbeitung einzelner Lehrpläne als auch hinsichtlich der dringend nötigen Erarbeitung bundesweiter Mindeststandards für den FU (vgl. auch Kapitel 4).

Als Orientierung für die Auswertung von Kapitel 2 fungieren somit folgende Fragen:

1. $\mathrm{Zu}$ welchen Themenbereichen des frühen Fremdsprachenlernens und -lehrens herrscht Einigkeit bzw. Dissens, und welche Alternativen bestehen jeweils?

2. Welche Handlungsanleitungen lassen sich daher hinsichtlich der Konkretisierung, Erhöhung bzw. Reduzierung der Anforderungen in bestimmten Bereichen des FU auf der Primarstufe ableiten?

Zu dem Aspekt der Inklusion sei eine Prämisse vorangestellt, für die exemplarisch aus $\$ 1$ des Schulgesetzes für NW zitiert wird. Der Paragraph besagt, dass alle Schüler „ein Recht auf schulische Bildung, Erziehung und individuelle Förderung“" haben (MSW NW 2016b; Hervorhebung hinzugefügt). Dazu, wie dieses Anrecht in den einzelnen Bundesländern umgesetzt wird, d.h. im Rahmen welches Schulsystems mit welchen Schulformen und wie sehr dabei inklusionsorientiertes Lehren und Lernen praktiziert wird, gibt es jedoch nicht immer einheitliche Vorgaben (vgl. auch Kapitel 2.3.1). Im Lichte unserer Befragung ist eine knappe Mehrheit derer, die professionell mit der Fremdsprachendidaktik befasst sind, uneingeschränkt dafür, inklusives Lernen verbindlich im FU der Primarstufe einzuführen - allerdings unter der Prämisse, dass dafür auch grundständig ausgebildete Lehrkräfte verfügbar sind. Fast $90 \%$ der von uns Befragten sprachen sich dafür aus, inklusionsorientierte Fragestellungen als obligaten Bestandteil fremdsprachlicher Lehramtsstudiengänge wie auch der zweiten Ausbildungsphase zu verankern. Zudem votierten sie dafür, dass es für bereits praktizierende Lehrkräfte hochwertige Fort- und Weiterbildungsangebote geben müsse. 
In beiden Fällen ist somit Qualität das Schlüsselwort. Es besteht nämlich nicht nur aufseiten der Lehrkräfte im Urteil der Befragten ein diesbezüglicher Bedarf an (weiterer) Professionalisierung, sondern auch hinsichtlich der Materialien, mit denen sie arbeiten. Material für inklusives Fremdsprachenlernen soll nach Ansicht von erneut über $90 \%$ der Befragten nicht nur von didaktisch qualifiziertem Personal, sondern von für Inklusion ausgewiesenen Fremdsprachendidaktikern entwickelt werden.

Fokussiert man die Perspektive auf die sprachlichen Voraussetzungen der Schüler, so zeigen die Abstimmungen, dass die Befragten sich in hohem Maße darüber einig sind, dass sowohl solide Deutschkenntnisse als auch die Beherrschung der Herkunftssprache (sofern diese nicht Deutsch ist) einen zentralen Beitrag zum Schulerfolg leisten, und dass es daher die Aufgabe der Grundschule sein muss, substanziell am Abbau potenzieller Defizite der Schüler auf diesem Gebiet mitzuwirken (vgl. Kapitel 2.2.2). Mehr als drei Viertel befürworteten die Einrichtung wöchentlich zwei- bis vierstündiger fakultativer Nachmittagsangebote zur Verbesserung der herkunftssprachlichen Kompetenz der Schüler, wobei aber selbst bei dokumentiertem diesbezüglichen Förderbedarf ein Zwang zur Teilnahme an einer Maßnahme ebenso deutlich abgelehnt wird. Auch für die Option, Curricula für den herkunftssprachlichen Unterricht zu entwickeln, fand sich keine Mehrheit.

Über $90 \%$ der Befragten unterstützten jedoch die vielerorts bereits umgesetzte Forderung nach verpflichtenden DaZ-Anteilen angehender Grundschullehrkräfte im Studium, damit diese hier später professionell handeln können. Zudem sprachen sich über $80 \%$ für zusätzliche Lehrerstundenzuweisungen für besondere Sprachfördermaßnahmen aus, d. h. die genannten Nachmittagsangebote sollten - auch wenn dieses Junktim hier inferiert wird, da es nicht eigens erfragt wurde - offenbar durch Lehrkräfte aus den Schulen betreut 
werden und nicht etwa als Angebote von außen erfolgen. Damit stehen sowohl hinsichtlich des weiteren Umgangs mit inklusionsorientierten Fragen als auch der künftigen Arbeit mit Schülern mit Migrationshintergrund nicht nur die Schulen in der Pflicht, sondern auch die Hochschulen sowie die Bildungs- und die Finanzministerien der Länder.

Eine Möglichkeit, fremdsprachliche Fertigkeiten und so argumentieren zumindest deren Befürworter - damit auch konzeptionelles und sprachverbindendes Denken der Schüler schon frühzeitig in besonderem Maße zu fördern, sind Immersionsprogramme wie auch bereits die Wahrnehmung teilimmersiver bilingualer Angebote bzw. bilingualer Sachfachunterricht. Knapp $60 \%$ stimmten in der von uns durchgeführten Befragung der These zu, dass der FU in der Grundschule durch staatlich geförderte immersive oder bilingual arbeitende Kindertagesstätten vorbereitet werden soll. Immerhin ein Fünftel votierte jedoch auch dezidiert gegen eine solche Option. Diese Skepsis wurde teils damit begründet, dass auch hier Qualität vor Quantität gehen müsse, und dass man zunächst einmal über Fachkräfte in ausreichender Zahl verfügen müsse, bevor man diesen Plan weiterverfolgen könne. Zudem unterstrichen einige, dass trotz aller fachlichen Ziele das Spielerische im Vordergrund bleiben müsse und dass man Sorge dafür tragen müsse, dass speziell Englisch hier nicht letztlich wichtiger werde als - besonders bei Kindern mit Migrationshintergrund - die Förderung ihrer herkunftssprachlichen Kompetenz.

Dessen ungeachtet votierten rund zwei Drittel der Fachleute mindestens in der Tendenz dafür, bilinguale Angebote (im Spektrum von Immersion bis zu bilingualen Modulen) fest im Lehrplan für den FU auf der Primarstufe zu verankern. Ein Drittel sah hier das größte Potenzial in bilingualen Modulen, während sich weitere Befragte auch für fächerübergreifenden Unterricht aussprachen. 
Geht es hingegen darum, welche Kompetenzen in den Schulfremdsprachen wann in welchem Maße entwickelt werden sollen, so besteht, wie schon am Schluss von Kapitel 2.5.2 bilanziert, offenbar noch einiges an Handlungsbedarf, und dies sowohl hinsichtlich der Anzahl und der begrifflichen Präzisierung der fremdsprachlichen Teilkompetenzen, welche die Schüler erwerben sollen, als auch hinsichtlich ihrer inhaltlichen Ausgestaltung und Abgrenzung voneinander. Viele Lehrpläne legen ebenso wie die Fachwelt anfangs ein besonders hohes Gewicht auf die Entwicklung rezeptiver und hier besonders der auditiven - Fertigkeiten sowie im Verhältnis von mündlichem und schriftlichem Sprachgebrauch ein Primat auf die Mündlichkeit. Über diesen Kernkonsens hinaus wird die Entwicklung funktional-kommunikativer, methodischer und interkultureller Kompetenz sowie von Sprachlernkompetenz - möglichweise auch aufgrund fehlender breit akzeptierter Kompetenzmodelle - jedoch curricular wie auch im Urteil der Fachleute nicht einheitlich gesehen.

Nur ein knappes Drittel der Befragten votierte vorbehaltlos dafür, dass die genannten Kompetenzbereiche in den Lehrplänen gleichrangig behandelt werden sollten. Beinahe ebenso viele taten dies mit Einschränkungen („stimme eher zu“) bzw. waren tendenziell eher dagegen, alle vier Teilbereiche curricular gleich zu gewichten. Diese Unterschiede, eventuell aber auch Unsicherheit oder gar Unschlüssigkeit darüber, wie Teilkompetenzen zueinander gewichtet werden sollten, spiegeln sich auch in den Ergebnissen dazu wider, welche Kompetenzcluster in die Lehrpläne einfließen sollen, wenn nicht alle von ihnen berücksichtigt werden sollen. Bei einer Abstimmungsfrage, bei der man hinsichtlich des Einoder Ausschlusses einer Kompetenz nur mit „stimme zu“ oder mit „stimme nicht zu“ votieren konnte, erhielt kein Cluster mehr als zwei Drittel Zustimmung oder Ablehnung. Hier könnte es daher geboten sein, die in den letzten Jahren 
partiell stark ausgeuferte Aufspaltung von Teilbereichen von Sprache und Unterricht in immer mehr Subkompetenzen auch einmal wieder auf ein intersubjektiv gemeinsam vertretbares geringeres Maß zu reduzieren und klarere Standards zu entwickeln, als das die meisten Kompetenzforscher sowie in ihrem Gefolge die Autoren der Lehrpläne in den letzten Jahren häufig getan haben.

Ein Kernbereich sprachlicher Kompetenz, nämlich die Einführung und der Rückgriff auf die Schriftsprache, stand im Fokus des vierten Abstimmungsbogens. Besonders auf diesem Gebiet hat die jüngere Forschung nämlich Ergebnisse zutage gefördert, die dem teilweise recht deutlich widersprechen, was zum Zeitpunkt der flächendeckenden Einführung von FU in der Grundschule die herrschende Lehrmeinung war. Besonders der Umstand, dass es vielen jungen Schülern hilft, nicht nur Laut-, sondern auch Schriftbilder fremdsprachlicher Wörter und Sätze mehr oder weniger von Anfang an als Lernhilfe verfügbar zu haben, ist inzwischen empirisch gut belegt (vgl. Diehr \& Frisch 2008; Duscha 2007). Somit nimmt es nicht wunder, dass auch die von uns befragten Fachleute den Stellenwert von Schriftlichkeit teils deutlich höher ansetzten, als das manche (ältere) Lehrpläne und Praktiker tun.

Nahezu $80 \%$ stimmten tendenziell oder gar uneingeschränkt der These zu, dass die Lernenden auf einzelne vom Deutschen abweichende Laut-Buchstaben-Korrespondenzen der Fremdsprache im Unterricht aufmerksam gemacht werden sollten. Knapp zwei Drittel votierten darüber hinaus dafür, die Alphabetisierung der Schüler (auch) im FU bereits in Klasse $1 \mathrm{zu}$ beginnen (so dieser bereits im ersten Schuljahr einsetzt), wobei in beiden Fällen mehrere erläuternde Kommentare ausdrücklich auf den aktuelle(re)n Forschungsstand verwiesen. Zugleich spiegelt sich das veränderte Denken der Profession in den Positionen der Fachleute dazu wider, was man von den Schülern beim Wechsel auf die weiterführende 
Schule auf schriftsprachlichem Gebiet verlangen kann: Eine deutliche Mehrheit der Befragten votierte dafür zu verlangen, dass die Schüler am Ende der Klasse 4 ganze Sätze - und nicht nur einzelne Wörter - abschreiben können, dass sie immerhin in Ansätzen frei schreiben können sollten, und dass dieses Können auch in die Beurteilungen der Schüler einfließt.

Damit sich dies realisieren lässt, ist vielerorts nicht nur ein modifizierter Umgang mit der Schrift nötig, sondern auch eine geänderte Unterrichtsgestaltung sowie ein stärkerer Einbezug bewusstmachender Verfahren, und dies nicht nur bei Laut-Buchstaben-Zuordnungen. Wie bereits eingangs von Kapitel 2.9.2 ausgeführt, sprach sich eine deutliche Mehrheit von $76 \%$ der Fachleute dafür aus, funktionale Einsprachigkeit in den Lehrplänen verbindlich vorzuschreiben. Dies bedeutet konkret, dass wo sinnvoll und möglich in der Fremdsprache kommuniziert werden soll, auch weil Deutsch die Herkunftssprache eines prozentual immer geringeren Anteils aller Grundschüler ist, dass aber zudem, wie diverse Kommentare der Fachleute verdeutlichen, ausdrücklich auch - nicht nur im obigen Sinne - sprachvergleichend gearbeitet werden soll.

Auch darüber, dass die Vorgabe bestimmter weiterer Prinzipien (wie z. B. dem der Handlungsorientierung) vorteilhaft sei, herrscht ausweislich der Anmerkungen in den Kommentarspalten ein breiter Konsens. Hinsichtlich dessen, ob zugleich gar eine spezifische Unterrichtsmethodik vorgegeben werden sollte, halten sich Zustimmung und Ablehnung dagegen die Waage. Dies sollte, so argumentierten einige, letztlich dem Ermessen der Lehrkräfte vorbehalten bleiben. Schließlich waren aber einige durch die Hoffnung, dass sich gerade bei fachfremd erteiltem FU auf diese Weise zumindest ein Minimum an Grundstrukturen und Routinen etablieren lässt, motiviert, diese Option trotz aller Skepsis nicht gänzlich auszuschließen. 
Wie schwierig es werden könnte, eine einmal eingeführte Praxis nachträglich zu ändern, zeigte sich bereits in Ansätzen im Rahmen der Diskussion zum Umgang mit der Schrift. Noch deutlicher wird diese Problematik aber beim Thema Sprachbewusstheit und, als Teilaspekt davon, der Arbeit mit dem Europäischen Portfolio der Sprachen (ESP). Zwar war eine Mehrheit der Fachleute prinzipiell dafür, die Arbeit mit dem ESP curricular als verbindlichen Bestandteil von FU in der Grundschule zu verankern. Beinahe ein Drittel votierte aber auch zumindest moderat dagegen, während ein mit nahezu $20 \%$ ungewöhnlich hoher Anteil der Befragten weder für noch gegen die verbindliche Verankerung von Portfolioarbeit im Lehrplan stimmte, sondern die Option „weder/ noch" wählte.

Gerade solch komplexe Prozesse wie die gegenstandsadäquate Arbeit mit Portfolios, die nicht nur viel Zeit, sondern auch eine sorgfältige Begleitung und individuelle Rückmeldungen an jeden einzelnen Lernenden verlangt, lassen sich zwar natürlich ebenso von außen verordnen, wie man auch auf anderen Gebieten Vorschriften erlassen kann. Sind die Lehrkräfte aber nicht willens oder nicht dazu in der Lage, die Anforderungen an eine gelingende Praxis auch zu erfüllen, so helfen selbst die besten Vorgaben nur begrenzt weiter. Angesichts dieses Vorbehalts drängt sich die Frage auf, ob die Zahl der Skeptiker hinsichtlich der verbindlichen Verankerung von Portfolioarbeit nicht zu hoch ausgefallen ist, um Portfolios im frühen FU beizubehalten. Andererseits plädierten allerdings mehr als zwei Drittel dafür, die Arbeit mit dem ESP auf der Sekundarstufe fortzuführen.

Zur Frage der Leistungsmessung und -dokumentation in einem größeren Rahmen befanden drei Viertel der Befragten, dass sowohl mündliche als auch schriftliche Leistungen ab Klasse 3 Eingang in die Notengebung finden sollen, während weniger als die Hälfte dies auch schon zu einem 
früheren Zeitpunkt für sinnvoll hielt. Ebenso einig war man sich jedoch darüber, dass Grammatikaufgaben, Diktate und auch Vokabeltests allesamt keine geeigneten Mittel seien, um zu irgendeinem Zeitpunkt während der Grundschulzeit das Leistungsvermögen der Schüler zu erfassen. Vielmehr seien auf diesem Niveau noch vor allem Zuordnungs- und Antwort-Auswahl-Verfahren die Instrumente der Wahl. Hinsichtlich dessen, ob das Geleistete eher per Ziffernote oder in einem Berichtszeugnis dokumentiert werden sollte, mochten die Befragten sich nicht festlegen. Eine frühe Notengebung (also bereits in Klasse 1 und 2) wurde jedoch fast einstimmig abgelehnt, während exakt die Hälfte der Befragten eine Notengebung ab Klasse 3 präferierte. Die Option, erst ein Jahr vor dem Übergang auf die Sekundarstufe mit Ziffernoten zu beginnen, ergab kaum einen Stimmenzuwachs gegenüber einer zur Mitte der Grundschulzeit einsetzenden Notengebung.

Ungeachtet dieses in Bezug auf die Notengebung uneinheitlichen Bildes waren sich die Fachleute im Rahmen eines weiteren Fragenkomplexes, bei dem es ausschließlich um den Übergang von der Primar- auf die Sekundarstufe ging, zu über $80 \%$ darin einig, dass es hierfür baldmöglichst über alle Bundesländer und auch Schulformen hinweg übergreifende, curricular fest verankerte Regelungen geben müsse. In den diese Voten begleitenden Kommentaren kulminierte entsprechend die Forderung nach einheitlichen (Mindest)Standards nicht nur für Deutsch und Mathematik, sondern auch für den FU der Grundschule. Hinsichtlich der Frage, ob und, wenn ja, welche weiteren Einzelmaßnahmen künftig verpflichtend schulformübergreifend eingeführt werden sollten, erhielten besonders die Optionen „Kooperation von Primar- und Sekundarschulen“, „Gegenseitige Hospitation“ und „Schulformübergreifende Kooperation", die ja auch inhaltlich alle eng miteinander verzahnt sind, hohe Zustimmungswerte 
(von jeweils knapp unter oder sogar oberhalb von $75 \%$ ). Doch auch schulformübergreifende Regionalkonferenzen und die Entwicklung von gemeinsamen Lernaufgaben sowie diagnostischen Instrumenten hielten mit je knapp $63 \%$ fast zwei Drittel der befragten Fachleute nicht nur für eine gute Idee, sondern gemäß der Fragestellung auch für etwas, das künftig verpflichtend gemacht werden sollte.

Zieht man an dieser Stelle Bilanz und ruft sich noch einmal die eingangs des Kapitels gestellten beiden Leitfragen ins Gedächtnis, so lassen sich unseres Erachtens folgende Trends in den Antworten der befragten Fachleute erkennen:

- Angesichts einer herkunftssprachlich immer heterogeneren Schülerschaft scheint es dringend geboten, einerseits den Schülern schulisch angebundene, jedoch trotz alledem fakultativ bleibende Angebote zur Verbesserung ihrer herkunftssprachlichen Kompetenz wie auch ihrer Deutschkenntnisse zu unterbreiten, andererseits aber auch sowohl die bereits aktive als auch die künftige Lehrerschaft weit stärker als dies aktuell der Fall ist durch DaZ-Module und weitere Maßnahmen dazu in die Lage zu versetzen, mit der sprachlichen Diversität der Schüler professionell umzugehen.

- (Teil)Immersive vorschulische Angebote werden grundsätzlich begrüßt. In welchem Verhältnis die Relevanz des Ausbaus teilimmersiver Angebote $\mathrm{zu}$ anderen aktuell benötigten bildungspolitischen Maßnahmen wie z. B. der Förderung von Familiensprachen/DaZ steht, bleibt an dieser Stelle allerdings noch offen. Hier könnten Vergleichsstudien wertvolle Einblicke liefern.

- Auf der Primarstufe haben bilinguale Angebote in Form von Immersion und bilingualem Sachfachunterricht bzw. bilingualen Modulen durchaus ihren Platz. Auch fächerverbindende Projekte können dazu beitragen, sprachver- 
netzendes Denken anzustoßen und die Sprach(lern)bewusstheit der Schüler zu erhöhen. Bilinguale Angebote ermöglichen es ferner Schülern mit erst geringen Deutschkenntnissen, dem Unterrichtsgeschehen auf demselben Niveau wie ihre Mitschüler zu folgen. Auf diese Weise können sie im Urteil vieler befragter Fachleute wesentlich dazu beitragen, die Herausforderungen einer herkunftssprachlich immer heterogeneren Schülerschaft zu mindern.

- Lehrpläne sollten weniger in die Breite gehen und stattdessen fokussierter vorgeben, welche konkreten Ziele bis zum Übergang auf die Sekundarstufe erreicht worden sein müssen. Damit würde eine Basis für verbindliche Abschluss- bzw. Übergangsprofile geschaffen, die von den weiterführenden Schulen aufgegriffen werden könnte. Dies erfordert zum einen die Entschlackung der in den letzten Jahren ausgeuferten und terminologisch wie konzeptuell immer weniger miteinander in Übereinstimmung zu bringenden konkurrierenden Kompetenzen und zum anderen eine länderübergreifende Verständigung auf die Rolle u. a. der Schrift, bewusstmachender Verfahren und des Stellenwertes von Sprach(lern)bewusstheit.

- Es sollte deutlich mehr Kooperation sowohl zwischen dem Primar- und Sekundarbereich als auch unter den sie jeweils regelnden Ministerien, Behörden und deren (Unter-)Abteilungen geben, um unnötige Reibungsverluste auf ein absolutes Minimum zu reduzieren. 


\section{Schlussfolgerungen}

Die in Kapitel 3 diskutierten Meinungsbilder bieten im $\mathrm{Zu}$ sammenspiel mit der Darstellung des jeweiligen Status quo der untersuchten Themenkomplexe einen höchst aufschlussreichen Einblick in die Entwicklung des frühen FU über die Grenzen der Bundesländer hinweg. Sie zeigen auf, dass sich auch ein Jahrzehnt nach der flächendeckenden Einführung des frühen FU in der Bundesrepublik in den 16 Bundesländern ein eher disparater Gesamteindruck ergibt:

1. Wie bereits in Kapitel 2 dargelegt, weichen die ministeriellen Vorgaben in den einzelnen Bundesländern immer wieder voneinander ab (vgl. dazu insbesondere die Themenbereiche Inklusion (Kapitel 2.3) und Kompetenzen (Kapitel 2.5)). Aufgrund der fehlenden gemeinsamen Voraussetzungen können einschlägige fremdsprachendidaktische Forschung und insbesondere Anschlussforschung zur Qualitätssicherung bzw. Qualitätsverbesserung von FU nur beschränkt überregional verankert und ihre Resultate nur bedingt verallgemeinert bzw. abgeleitete Maßnahmen nur mit Vorsicht implementiert werden. Die erkenntnistheoretischen aber auch die finanziellen Nachteile dieser Situation liegen auf der Hand. Die größten Probleme manifestieren sich jedoch in der konkreten Praxis von Familien mit Grundschulkindern, die durch einen Umzug in ein anderes Bundesland mit u.U. völlig anderen Regelungen konfrontiert $\operatorname{sind}^{12}$.

12 Der gravierendste Einschnitt dürfte in den Spezifika der hier ansonsten nicht weiter diskutierten Rheinschiene (westliches BW) liegen, in der ausschließlich Französisch als erste Fremd- 
2. Die Meinungsbilder der von uns befragten Fachleute entsprechen häufig nicht den in den Lehrplänen beschriebenen Vorgaben; die Befragten votierten vielmehr in einer ganzen Reihe von Punkten mehrheitlich für Regelungen, die von den Vorgaben der Lehrpläne abweichen (vgl. dazu in erster Linie die Themenbereiche Grammatik, Sprachbewusstheit und sprachliche Mittel (Kapitel 2.6) sowie Schriftspracherwerb (Kapitel 2.4)). Wann immer dies der Fall ist, muss aber geklärt werden, warum es zu diesen Abweichungen kommt und wo eine forschungsbzw. evidenzbasierte Überarbeitung der Lehrpläne nicht nur sinnvoll wäre, sondern auch geboten ist. Den sich hier manifestierenden Widersprüchen muss teils durch Aufgreifen der jüngeren Forschung, teils durch weitere Untersuchungen auf den Grund gegangen werden. Diese Anschlussforschung sollte jedoch vor dem unter Punkt 1 dargelegten, disparaten Gesamtbild länderübergreifend angelegt sein, sodass die Ergebnisse bundesweit gelten und somit die empirisch ermittelte Basis für bundesweite Mindeststandards darstellen können.

3. Die Notwendigkeit einer Überarbeitung der Lehrpläne ergibt sich ferner aus der in Kapitel 2 dokumentierten Widersprüchlichkeit respektive Unvereinbarkeit mehrerer Vorgaben und Ziele, die die Lehrpläne zu zwar unterschiedlichen Themenkomplexen vorgeben, die aber nichtsdestotrotz in enger Verbindung zueinander stehen. Immer wieder schließen sich nämlich Vorgaben gegenseitig aus; und dies gilt nicht nur für die in dieser Studie explizit in Form eines Themenfeldes behandelten Be-

sprache angeboten wird. Ein Umzug in ein anderes Bundesland kann hier im Extremfall bedeuten, dass ein Kind beim Übergang in die Klasse 4 drei Jahre Englischunterricht nachzuholen hat. 
reiche, sondern beispielsweise auch für die Regelungen zum Medieneinsatz in der Grundschule. Dies wird im Folgenden mit Beispielen illustriert und näher erläutert.

Ein besonders deutlicher, sich aus Querverbindungen zwischen einzelnen Themenkomplexen ergebender Widerspruch betrifft die disparaten Vorgaben zum Schriftspracherwerb. Die Forderungen aller Länder nach Methodenvielfalt, kooperativen Lernformen, Differenzierung, der Förderung von Sprachbewusstheit, dem Einsatz des Grundschul-Portfolios und von Medien sowie nach bilingualen Programmen sind ohne den frühen Schriftspracherwerb nicht zu erfüllen. So zeigen Ministerien zahlreicher Bundesländer beispielsweise ein großes Interesse an bilingualen Programmen, wie u.a. das Beispiel Bayerns mit 21 Grundschulen im Schulversuch belegt (vgl. Kapitel 2.1). Sie lassen aber gleichzeitig auch eine eher zurückhaltende Position erkennen, wenn es um frühen Schriftspracherwerb geht. Hier stellt sich daher die Frage, wie die Sachfächer ohne Zuhilfenahme der Schriftform so bilingual unterrichtet werden sollen, dass die Schüler ein sachfachliches Niveau erreichen können, das dem des traditionellen Unterrichts gleichkommt. Die Sachfachlehrer sollten den Kindern Materialien wie Sachtexte und auszufüllende Arbeitsblätter bereitstellen dürfen, auch wenn es sich zunächst nur um Beschriftungen von Abbildungen u. ä. handeln kann, die dem Einwortstadium der Kinder im mündlichen Bereich der Fremdsprache entsprechen. Zudem sei zu diesem Punkt angemerkt, dass die von uns befragten Fachleute aus der fremdsprachendidaktischen Forschung und Schulpraxis sich zu über $70 \%$ für bilingualen Unterricht als festen, verpflichtenden Bestandteil des Grundschulunterrichts ausgesprochen haben und dass $66 \%$ für die Einführung der Schriftsprache ab Klasse 1 votierten. Folgte man diesem Meinungsbild der Fachleute (Implementierung bilingualen 
Unterrichts bei gleichzeitiger Einführung des Schriftbilds ab Lernjahr 1), so löste sich der z.Zt. noch bestehende Widerspruch in den Lehrplänen (Ermutigung zu bilingualem Unterricht bei gleichzeitiger Zurückhaltung in Bezug auf eine frühe Einbindung des Schriftbildes) auf.

Ein weiterer Widerspruch findet sich in den Vorgaben für BW zu Mediennutzung und Schriftspracherwerb. Nach dem zum Zeitpunkt unserer Studie dort aktuelle Lehrplan sollen Zweitklässler dazu in der Lage sein, vertraute Medien für autonomes Lernen zu nutzen (MKJS BW 2004, S. 74), während aber das Abschreiben einzelner Wörter, Wendungen sowie kurzer, einfacher Texte erst für die Klasse 4 vorgesehen ist (a.a.O. S. 78). Sofern Lehrkräfte sich nach dem hier in Rede stehenden Lehrplan richten, wird die tatsächliche Nutzbarkeit der Medien für autonomes Lernen in den Klassen 2 und 4 sehr stark eingeschränkt bzw. auf das Lesen und ein Behalten reduziert, das nicht durch das Notieren des Gelesenen unterstützt werden kann. Es wäre folglich an dieser Stelle entschieden sinnvoller, dem Meinungsbild der Befragten zu folgen und mit dem Schriftspracherwerb ab Klasse 1 zu beginnen. Lernende der Klassenstufe 2 wären somit u.U. tatsächlich in der Lage, die Medien ohne weitere Hilfe der Lehrkraft zu nutzen. Ohne die Hinführung der Kinder an ein sinnvolles Abschreiben bzw. Anfertigen von Notizen ab der Klasse 1 dürfte autonomes medial-unterstütztes Lernen dagegen eine Überforderung der Kinder darstellen.

Der Schriftspracherwerb scheint in den engen Verflechtungen vieler Lernbereiche mit anderen Aspekten der Curricula und mit den organisatorischen Gegebenheiten in den verschiedenen Bundesländern ein besonders sensibler Themenkomplex zu sein. Neben den inhaltlichen Spezifika des Themas fußt dieser Umstand vermutlich auch darauf, dass es zum Zeitpunkt unserer Erhebung drei Varianten gab: den Start in Klasse 1, in Klasse $3(=1$. Lernjahr Englisch) 
und in Klasse 3 (= 3. Lernjahr Englisch). Aufgrund dieser heterogenen Basis differieren auch die Herangehensweisen an die Vermittlung der Schrift (ganzheitlich vs. analytisch), da sie u. a. von dem Stand der Alphabetisierung in der Schulsprache Deutsch abhängen. Zugleich klaffen die Fertigkeiten auseinander, deren Erreichen man am Ende der Klasse 4 nach zwei oder vier Jahren Auseinandersetzung mit der Schriftsprache des Englischen von den Kindern erwarten kann ${ }^{13}$. Da die Sekundarschulen einen stärkeren Fokus auf Schriftlichkeit legen, wären klar definierte Mindeststandards für die Fertigkeit Schreiben am Ende der Klasse 4 für einen reibungsloseren Übergang wichtig.

Elementare Aspekte des frühen FU wie z. B. sein Beginn sollten folglich nicht länger in den Händen der einzelnen Bundesländer liegen, (die ihre Entscheidungen nicht selten an politisch opportun erscheinenden Optionen ausrichten, die sich lediglich auf bildungswissenschaftliche Überzeugungen stützen statt auf fremdsprachendidaktisch-evidenzbasierte Forschung), sondern bundesweit einheitlich geregelt werden müssen. So könnte u. U. sichergestellt werden, dass nicht einzelne Bundesländer den Beginn des FU ohne Blick auf die Forschungsergebnisse der Fremdsprachendidaktik aus dem

13 Die zahlenmäßig deutlich geringere Beantwortung der Fragen zum Schriftspracherwerb als zu denen anderer Themenkomplexe lässt darauf schließen, dass die von uns befragten Fachleute sich sehr stark an den Gegebenheiten ihres Bundeslandes orientiert haben. Fragen wie „Sollen am Ende der Jgst. 4 ganze Sätze abgeschrieben sowie frei geschrieben und bewertet werden?" oder die nach der Behandlung einzelner, vom Deutschen abweichender Laut-Buchstaben-Korrespondenzen der Fremdsprache sind für Didaktiker aus Bundesländern, in denen Englisch bzw. die Schriftsprache erst ab Klasse 3 eingeführt wird, oftmals von nur geringem Belang (mündliche Kommunikation, J.R.). 
ersten Lernjahr streichen und auf einen entschieden späteren Zeitpunkt verlegen. ${ }^{14}$

Aus dem hier Dargestellten folgt, dass die Abweichungen in den einzelnen Lehrplänen der Länder untereinander und deren immanente Widersprüche einer gelingenden und effizienten Umsetzung der Erkenntnisse fremdsprachendidaktischer Forschung sowie von best practice Erfahrungen in den täglichen FU auf der Primarstufe im Wege stehen und somit eine positive Weiterentwicklung von Unterricht und seinen Grundlagen erschweren, wenn nicht gar verhindern. Die Notwendigkeit der Implementierung von nationalen Bildungsstandards geht auch eindeutig aus den Übereinstimmungen in den Meinungsbildern der befragten Fachleute hervor. Bezüglich des Übergangs von der Primar- auf die Sekundarstufe sind sich über $80 \%$ der Befragten darin einig, dass es hierfür baldmöglichst über alle Bundesländer und auch Schulformen hinweg übergreifende, curricular fest verankerte Regelungen geben müsse (vgl. Kapitel 2.8). Die aktuell überarbeitete Version des GER bietet an dieser Stelle keine Unterstützung, obwohl sie „Young Learners“ mitaufgenommen und für sie das Referenzniveau „Pre-A1“ neu geschaffen hat, da die Altersgruppe mit sieben bis zehn Jahren festgelegt wurde (vgl.

14 An dieser Stelle sei auf das Beispiel des Landes BW verwiesen, wo Englisch und Französisch ab dem Schuljahr 2018/19 statt in Klasse 1 wieder erst in Klasse 3 unterrichtet werden. Die Kostspieligkeit dieses Unterfangens wird wiederum im Kontext des Schriftspracherwerbs besonders deutlich: Mit dem neuen Lehrplan im Jahr 2016 wurde der Beginn des Schriftspracherwerbs aus dem dritten Lernjahr der Fremdsprachen Englisch bzw. Französisch in das erste Lernjahr verlegt, nur um mit der Rückverlegung des Beginns des gesamten frühen FU bereits ein Jahr später wieder in die Klasse 3 geschoben zu werden (Staatsministerium Baden-Württemberg 2017). 
Council of Europe 2017, S. 49). Siebenjährige sind in der Regel in der zweiten Klasse, der FU beginnt in Deutschland aber in Klasse 1 oder 3 und betrifft somit Sechs- bzw. Achtjährige.

Ein weiteres augenfälliges Ergebnis unserer Arbeit ist die hohe Übereinstimmung der Fachleute dahingehend, dass zu den primären Gelingensbedingungen des frühen FU unabdingbar eine sehr gute Ausbildung der Lehrkräfte gehört. Dies wurde vor allem zu den Bereichen Immersion / Bilingualer Sachfachunterricht (vgl. Kapitel 2.1), Umgang mit Lernenden mit Migrationshintergrund (Kapitel 2.2), Inklusion (Kapitel 2.3) und Unterrichtsmethodik und Einsprachigkeit (Kapitel 2.9) geäußert ${ }^{15}$. An dieser Stelle ist die Einstellungspolitik der Länder gefragt, denn wie die letzte BIG-Studie von 2016 gezeigt hat, lag der Anteil der vollausgebildeten Lehrkräfte für das Fach Englisch unter den für diese Studie Befragten bei unter 50 \% (Börner, Böttger, Müller, Kierepka, Kronisch, Legutke, Lohmann \& Schlüter 2016). Die Schulministerien müssen die Relevanz der fremdsprachlichen Fächer auf der Primarstufe erkennen und eine

15 Vgl. hierzu auch die Prämisse der Frühjahrkonferenz 2018 zu Rolle und Professionalität der Fremdsprachenlehrpersonen, nämlich dass die konkrete Gestaltung von Fremd- und Zweitsprachenunterricht in hohem Maße von der Lehrperson und damit von deren Professionalität und Rollenverständnis abhängt (Burwitz-Melzer; Königs; Riemer \& Schmelter erscheint). Auch Frisch (2017, S. 60) kommt in ihrem Forschungsüberblick zur Ausbildung der Englischlehrkräfte für die Grundschule zu dem Schluss, dass nur gut ausgebildete Lehrkräfte den Spracherwerbsprozess der Kinder mit all seinen Facetten angemessen unterstützen können. Damit ist die Aussage der von uns befragten Fachleute bestätigt, aber auch auf eine noch breitere Basis an Fachdidaktikern in Deutschland gestellt. 
entsprechende Einstellungspolitik verfolgen, denn selbst mit bundesweiten Bildungs- bzw. Mindeststandards lässt sich ein Ausbildungsdefizit der Lehrkräfte im fremdsprachlichen Klassenzimmer nicht wettmachen.

Sowohl die detaillierte Betrachtung spezifischer oftmals miteinander in Wechselbeziehung stehender Einzelaspekte wie auch die Gesamtbetrachtung aller in dieser Studie untersuchten Bereiche führen zu dem Ergebnis, dass es über alle Bundesländer und auch Schulformen hinweg übergreifende, curricular fest verankerte Regelungen und einheitliche (Mindest)Standards für den FU in der Grundschule geben muss. Wie auch in den Fächern Deutsch und Mathematik könnten diese nicht nur die Basis für den FU der Grundschule bilden, sondern auch für die Lehreraus- und -fortbildung in diesem Bereich. 


\section{Literaturverzeichnis}

Bayerisches Landesamt für Statistik (2015): Amtliche Schulstatistik. Tabelle 1: Eckdaten der amtlichen Schulstatistik in Bayern im Herbst 2015 nach kreisfreien Städten und Landkreisen, abgerufen am 05.06.2017 von https://www. statistik.bayern.de/medien/statistik/bildungsoziales/schu_ eckdaten_bayern_2015.pdf.

(BSBKWK) Bayrisches Staatsministerium für Bildung und Kultus, Wissenschaft und Kunst (Hrsg.) (2002): Lehrplan Deutsch als Zweitsprache. Grundschule. Lernfelder Grundkurs. Würzburg: Stürzt.

(BSBKWK) Bayrisches Staatsministerium für Bildung und Kultus, Wissenschaft und Kunst (Hrsg.) (2015): Lehrplanauszüge. Fachlehrpläne. Würzburg: Stürzt.

(BSUK) Bayerisches Staatsministerium für Unterricht und Kultus (2004): Konkretisierung des Lehrplans Fremdsprachen in der Grundschule - Englisch [zu KMS IV.1-5S 7402.17-4.31735]. München: J. Maiß.

Behörde für Schule und Berufsbildung Hamburg (Hrsg.) (2011a): Bildungsplan Grundschule. Englisch. Hamburg: Behörde für Schule und Berufsbildung.

Behörde für Schule und Berufsbildung Hamburg (Hrsg.) (2011b): Bildungsplan Grundschule. Deutsch als Zweitsprache in Vorbereitungsklassen. Hamburg: Behörde für Schule und Berufsbildung.

Börner, Otfried; Böttger, Heiner; Müller, Tanja; Kierepka, Adelheid; Kronisch, Inge; Legutke, Michael; Lohmann, Christa \& Schlüter, Norbert (2016): „Der Lernstand im Englischunterricht am Ende von Klasse 4 - Erste Ergebnisse der BIG-Studie “. In: Böttger, Heiner \& Schlüter, Norbert (Hrsg.), Fortschritte im Frühen Fremdsprachenlernen. 
Tagungsband zur 4. FFF-Konferenz. Braunschweig: Westermann 8-44.

Burwitz-Melzer, Eva; Königs Frank G.; Riemer, Claudia; Schmelter, Lars (Hrsg.) (erscheint): Rolle und Professionalität der Fremdsprachenlehrpersonen (Arbeitstitel). Arbeitspapiere der 38. Frühjahrskonferenz zur Erforschung des Fremdsprachenunterrichts. Tübingen: Narr.

(CeLeB) Centrum für Lehrerbildung und Bildungsforschung der Stiftung Universität Hildesheim (2016): Informationen zum Master of Education „GHR 300“, abgerufen am 22.09.2017 von https://www.uni-hildesheim.de/ media/celeb/Koordinierungsstelle_Lehramt/Dokumente/ Einfuehrung_MasterGHR_300_WS1617.pdf.

Council of Europe (2017): Common Framework of References for Languages: Learning, Teaching, Assessment. Companion Volume with New Descriptors. Provisional Edition September 2017, abgerufen am 25.10.2017 von http://www.coe.int/en/web/common-european-frameworkreference-languages.

Diehr, Bärbel; Frisch, Stefanie (2008): Goodbye Hungry Caterpillar. Ein forschungsgestütztes Plädoyer für produktiven Sprachgebrauch im Englischunterricht der Grundschule. In: Grau, Maike; Legutke, Michael K. (Hrsg.): Fremdsprachen in der Grundschule. Auf dem Weg zu einer neuen Lern- und Leistungskultur. Frankfurt: Grundschulverband. 142-167.

Diehr, Bärbel; Rymarczyk, Jutta (2012): Current developments in Teaching English as a Foreign Language in German Primary Schools. In: Anglistik, Volume 23, Issue 1, 13-23.

Duscha, Michael (2007): Der Einfluss der Schrift auf das Fremdsprachenlernen in der Grundschule. Dargestellt am Beispiel des Englischunterrichts in Niedersachsen, abge- 
rufen am 22.09.2017 von https://publikationsserver.tubraunschweig.de/receive/dbbs_mods_00021088.

Europäische Kommission (1996): Weißbuch Lehren und Lernen - Auf dem Weg zur kognitiven Gesellschaft. Luxemburg: Amt für amtliche Veröffentlichungen der Europäischen Gemeinschaften.

Frisch, Stefanie (2017): Eckpfeiler des kommunikativen Englischunterrichts in der Grundschule. In: Fremdsprachen Lebren und Lernen 46, Heft 2, 55-69.

Hempel, Margit; Kötter, Markus; Rymarczyk, Jutta \& Steinlen, Anja (2017): Fremdsprachenunterricht in der Grundschule in den Bundesländern Deutschlands: Eine Bestandsaufnahme. In: Appel, J.; Jeuk, S. und J. Mertens (Hrsg.): Sprachen lehren. Dokumentation zum 26. Kongress für Fremdsprachendidaktik der Deutschen Gesellschaft für Fremdsprachenforschung (DGFF). Ludwigsburg, 30.9.-3.10.2015, Baltmannsweiler: Schneider Verlag Hohengehren, 313-315.

Hessisches Kultusministerium (Hrsg.) (2011): Bildungsstandards und Inhaltsfelder. Das neue Kerncurriculum für Hessen. Primarstufe. Moderne Fremdsprachen. Wiesbaden: Hessisches Kultusministerium.

Kötter, Markus; Rymarczyk, Jutta (Hrsg.) (2011): Fremdsprachenunterricht in der Grundschule: Forschungsergebnisse und Vorschläge zu seiner weiteren Entwicklung. Frankfurt a.M. u. a.: Peter Lang.

Kötter, Markus; Rymarczyk, Jutta (Hrsg.) (2015): Englischunterricht auf der Primarstufe. Neue Forschungen - weitere Entwicklungen. Frankfurt a.M. u. a.: Peter Lang.

(KMK) Kultusministerkonferenz (2011): Empfehlungen der Kultusministerkonferenz zur Stärkung der Fremdsprachenkompetenz. Beschluss der Kultusministerkonferenz vom 08.12.2011, abgerufen am 22.09.2017 von https:// 
www.kmk.org/fileadmin/Dateien/veroeffentlichungen beschluesse/2011/2011_12_08-Fremdsprachenkompetenz. pdf.

(KMK) Kultusministerkonferenz (2013): Bericht „Fremdsprachen in der Grundschule - Sachstand und Konzeptionen 2013 “. Beschluss der Kultusministerkonferenz vom 17.10.2013, abgerufen am 22.09.2017 von https:// www.kmk.org/fileadmin/Dateien/veroeffentlichungen beschluesse/2013/2013_10_17-Fremdsprachen-in-derGrundschule.pdf.

(LI Hamburg) Landesinstitut für Lehrerbildung und Schulentwicklung (Hrsg) (2012): Family Literacy. Good PracticeBeispiele aus elf Hamburger FLY-Schulen. LI Hamburg, abgerufen am 22.09.2017 von http://li.hamburg.de/ family-literacy/.

(MBSA) Ministerium für Bildung des Landes Sachsen-Anhalt (Hrsg.) (2007a): Fachlehrplan Grundschule. Englisch. Magdeburg: Ministerium für Bildung.

(MBSA) Ministerium für Bildung des Landes Sachsen-Anhalt (Hrsg.) (2007b): Berufsbegleitende Weiterbildungskurse für Lehrkräfte allgemein bildender und berufsbildender Schulen. Bek. des MK vom 30.04.2007-22-84.300, abgerufen am 22.09.2017 von http://www.mk.bildung-lsa.de/ bildung/be-berufsbegleit_weiterbildungskurse.pdf.

(MBSA) Ministerium für Bildung des Landes Sachsen-Anhalt (Hrsg.) (2015): Berufsbegleitende Weiterbildungskurse für Lehrkräfte allgemeinbildender und berufsbildender Schulen im Schuljahr 2015/2016. Bek. des MK vom 25.2.2015-31-84300, abgerufen am 22.09.2017 von http://www.mk.bildung-lsa.de/bildung/be-weiterbildung lehrkraefte_2015.pdf. 
(MBFJ RP) Ministerium für Bildung, Frauen und Jugend Rheinland-Pfalz (Hrsg.) (2004): Rahmenplan Grundschule. Teilrahmenplan Fremdsprache. Grünstadt: Sommer.

(MBJS BB) Ministerium für Bildung, Jugend und Sport des Landes Brandenburg (Hrsg.) (2012): Verbindliche curriculare Vorgaben für den Englischunterricht in den Jahrgangsstufen 1-6. Berlin: Hermann Schlesener.

(MBK SL) Ministerium für Bildung und Kultur des Saarlandes (Hrsg.) (2011): Kernlehrplan Französisch. Grundschule. Klassenstufen 3/4. Ministerium für Bildung: Saarbrücken 2011.

(MBWJK RP) Ministerium für Bildung, Wissenschaft, Jugend und Kultur Rheinland-Pfalz (Hrsg.) (2006): Rabmenplan Deutsch als Zweitsprache. Grünstadt: Sommer.

(MBWJK RP) Ministerium für Bildung, Wissenschaft, Jugend und Kultur Rheinland-Pfalz (Hrsg.) (2013): Weiterentwicklung der Inklusion im schulischen Bereich, abgerufen am 22.09.2017 unter https://bm.rlp.de/fileadmin/ mbwwk/1_Bildung/Inklusion/Landeskonzept_Inklusion. pdf.

(MBWK MV) Ministerium für Bildung, Wissenschaft und Kultur des Landes Mecklenburg-Vorpommern (Hrsg.) (2007): Rahmenplan. Grundschule. Fremdsprachen. Schwerin: Adiant.

(MBWK MV) Ministerium für Bildung, Wissenschaft und Kultur des Landes Mecklenburg-Vorpommern (2017): Bildungsserver Mecklenburg-Vorpommern, abgerufen am 22.09.2017 unter http://www.bildung-mv.de/ fruehkindliche-bildung/inklusion/.

(MBWK SH) Ministerium für Bildung, Wissenschaft und Kultur Schleswig-Holstein (Hrsg.) (2007): Rabmenplan Englisch in der Grundschule. Kiel: Ministerium für Bildung, Wissenschaft und Kultur. 
(MKJS BW) Ministerium für Kultus, Jugend und Sport des Landes Baden-Württemberg (Hrsg.) (2004): Bildungsplan 2004. Grundschule. Ditzingen: Philipp Reclam Jun.

(MKJS BW) Ministerium für Kultus, Jugend und Sport Baden-Württemberg (2014): Die Hundert Sprachen der Kinder. Internationaler Kongress vom 9.-10. Oktober 2014. Liederhalle Stuttgart, abgerufen am 18.10.2017 von http://www.hundert-sprachen.de/.

(MKJS BW) Ministerium für Kultus, Jugend und Sport Baden-Württemberg (Hrsg.) (2016): Bildungsplan der Grundschule. Englisch. Stuttgart: Neckar-Verlag.

(MSFW NW) Ministeriums für Schule, Wissenschaft und Forschung des Landes Nordrhein-Westfalen (2001). Runderlass des MSWF vom 12.11.2001 (BASS 20-22 Nr. 57). Düsseldorf: MSWF.

(MSW NW) Ministerium für Schule und Weiterbildung des Landes Nordrhein-Westfalen (Hrsg.) (2008): Lebrplan Englisch für die Grundschulen des Landes NordrheinWestfalen. Frechen: Ritterbach.

(MSW NW) Ministerium für Schule und Wissenschaft Nordrhein-Westfalen (Hrsg.) (2012): Englisch als Kontinuum. Von der Grundschule zur weiterführenden Schule [Heft 9048]. Düsseldorf: Ministerium für Schule und Weiterbildung.

(MSW NW) Ministerium für Schule und Weiterbildung (2016a): Verordnung über den Zugang zum nordrheinwestfälischen Vorbereitungsdienst für Lehrämter an Schulen und Voraussetzungen bundesweiter Mobilität (Lehramtszugangsverordnung - LZV) vom 25. April 2016. In: Ders. (Hrsg.): Gesetz- und Verordnungsblatt (GV. NRW.) Ausgabe 2016 Nr. 12 vom 6.5.2016. Düsseldorf: Ministerium für Schule und Weiterbildung. 
(MSW NW) Ministerium für Schule und Weiterbildung (2016b): Schulgesetz für das Land Nordrhein-Westfalen (Schulgesetz NRW - SchulG). Zuletzt geändert durch Gesetz vom 6. Dezember 2016 (GV. NRW. S. 1052). Düsseldorf: Ritterbach.

(NKM) Niedersächsisches Kultusministerium (Hrsg.) (1995): Didaktisch-methodische Empfehlungen für das Fremdsprachenlernen in der Grundschule. Hannover: Schroedel.

(NKM) Niedersächsisches Kultusministerium (Hrsg.) (2006): Kerncurriculum für die Grundschule. Schuljahrgänge 3-4. Englisch. Hannover: Unidruck.

Rixon, Shelagh (2013): British Council Survey of Policy and Practice in Primary English Language Teaching Worldwide. London: British Council.

(Schulanzeiger) Regierung von Oberfranken (Hrsg.) (2007): Amtlicher Schulanzeiger für den Regierungsbezirk Oberfranken, Nr. 6, 118. Jahrgang Bayreuth, 1. Juni 2007, 171-175, abgerufen am 22.09.2017 von https://www.regierung. oberfranken.bayern.de/imperia/md/content/regofr/schulen/ schulanzeiger/pdf/schulanzeiger_2007_06.pdf.

(SSK) Sächsisches Staatsministerium für Kultus (Hrsg.) (2004): Lehrplan Grundschule. Sorbisch. Dresden: Saxoprint.

(SSK) Sächsisches Staatsministerium für Kultus (Hrsg.) (2009a): Lehrplan Grundschule. Englisch. 2004/2009. Dresden: Saxoprint.

(SSK) Sächsisches Staatministerium für Kultus (Hrsg.) (2009b): Deutsch als Zweitsprache. Lehrplan für Vorbereitungsgruppen, Vorbereitungsklassen und Vorbereitungsklassen mit berufspraktischen Aspekten. Dresden: Sächsisches Staatministerium für Kultus. 
(SSK) Sächsisches Staatsministerium für Kultus (Hrsg.) (2010): Lehrplan Grundschule. Intensives Sprachenlernen - Sorbisch als Fremdsprache. 2006/2010. Dresden: Saxoprint.

(SBW) Die Senatorin für Bildung und Wissenschaft (Hrsg.) (2013): Englisch. Bildungsplan für die Grundschule. Bremen: Landesinstitut für Schule.

(LISUM o.D.) Senatsverwaltung für Bildung, Jugend und Sport; Landesinstitut für Schule und Medien (Hrsg.): Materialien zum selbstständigen standortorientierten Lernen für den Übergang von der Grundschule in die weiterführenden Schulen, ohne Datum, abgerufen am 22.09.2017 von http://bildungsserver.berlin-brandenburg. de/fileadmin/bbb/unterricht/faecher/sprachen/englisch/ zusatzmaterial/uebergang_broschuere.pdf.

(LISUM) Senatsverwaltung für Bildung, Jugend und Sport; Landesinstitut für Schule und Medien (Hrsg.) (2006a): Anregungen und Entscheidungshilfen für die Methodenwahl im Fremdsprachenunterricht der Grundschule - Materialien zur Umsetzung des Rahmenlehrplans Grundschule Fremdsprachen, abgerufen am 22.09.2017 unter https://bildungsserver. berlin-brandenburg.de/fileadmin/bbb/unterricht/ rahmenlehrplaene/grundschule/implementationsmaterial/ fremdsprachen/Methoden_1_und_2_051207_01.pdf.

(LISUM) Senatsverwaltung für Bildung, Jugend und Sport; Landesinstitut für Schule und Medien (Hrsg.) (2006b): Die Arbeit mit Schülerinnen und Schülern mit großen Problemen beim Lernen-Beispiele zur Differenzierung im Fremdsprachenunterricht. Materialien zur Umsetzung des Rahmenlehrplans Grundschule Fremdsprachen, abgerufen am 22.09.2017 von http://lisum.berlinbrandenburg.de/aufgabenschwerpunkte/schulentwicklung/ unterrichtsentwicklung/inklusion/handreichungen-zumthema-inklusion/quick-guides-fuer-inklusion-teil-1/. 
(LISUM) Senatsverwaltung für Bildung, Jugend und Sport; Landesinstitut für Schule und Medien (Hrsg.) (2008): Geschichten erzählen - Storytelling. Materialien für den Fremdsprachenunterricht in der Grundschule mit Beispielen für Englisch und Polnisch, abgerufen am 22.09.2017 von https://bildungsserver.berlin-brandenburg.de/fileadmin/bbb/ unterricht/rahmenlehrplaene/grundschule/fachbezogenes/ englisch/Storytelling.pdf.

(LISUM) Senatsverwaltung für Bildung, Jugend und Sport; Landesinstitut für Schule und Medien (2012): Fortbildungscurriculum zum Pilotprojekt „Inklusive Grundschule" in Brandenburg, abgerufen am 22.09.2017 unter http://lisum.berlin-brandenburg.de/fileadmin/bbb/schule/ inklusion/2012/Curriculum_Inklusion.pdf.

(LISUM) Senatsverwaltung für Bildung, Jugend und Sport; Landesinstitut für Schule und Medien (2013): Fachbrief Nr. 5. Englisch. Grundschule. Differenziert unterrichten und individualisiert lernen, abgerufen am 22.09.2017 unter http://docplayer.org/docview/65/52517325/\#file=/ storage/65/52517325/52517325.pdf.

(LISUM) Senatsverwaltung für Bildung, Jugend und Sport; Landesinstitut für Schule und Medien (2014): Wissenschaftliche Begleitung des Pilotprojekts „Inklusive Grundschule" (PInG), abgerufen am 22.09.2017 unter http:// www.inklusion-brandenburg.de/fileadmin/daten/service/ publikationen/pressemitteilungen/LISUM_wissensch._ Begleitung_Pilotschulen.pdf.

(SBJS BE) Senatsverwaltung für Bildung, Jugend und Sport Berlin (2002): Rabmenplan für Unterricht und Erziehung in der Berliner Schule. Deutsch als Zweitsprache für Schüler und Schülerinnen im Alter von 6 bis 15 Jahren unterschiedlicher Niveaustufen in allen Schularten. Berlin: Senatsverwaltung für Bildung, Jugend und Sport. 
(SBJS BE) Senatsverwaltung für Bildung, Jugend und Sport Berlin (2006): Rahmenlehrplan für die Grundschule und die Sekundarstufe 1. Englisch 1./2. Fremdsprache. Oktoberdruck: Berlin 2006.

Senatsverwaltung für Bildung, Jugend und Wissenschaft Berlin (Hrsg.) (2014): Handbuch Vorbereitungsdienst. 4. überarb. Auflage. Berlin: Hermann Schlesener.

Staatsministerium Baden-Württemberg (2017): Bildungspolitische Konsequenzen aus dem IQB-Bildungstrend. Pressemitteilung vom 13.10.2017, abgerufen am 15.10.2017 von http://www.baden-wuerttemberg.de/de/service/presse/ pressemitteilung/pid/bildungspolitische-konsequenzenaus-dem-iqb-bildungstrend/

Stadt Dortmund, Fachbereich Schule, Regionales Bildungsbüro (Hrsg.) (2013): Schule im Team - Unterricht gemeinsam entwickeln: Dokumentation des Vernetzungsprojekts in Dortmund, S. 9-13, abgerufen am 22.09.2017 von https:// www.dortmund.de/media/p/regionales_bildungsbuero_3/ downloads_2/schulen_im_team/Schulen_im_Team_ Projektdokumentation.pdf.

(Destatis) Statistisches Bundesamt (2017): Bevölkerung und Erwerbstätigkeit. Bevölkerung mit Migrationshintergrund. Ergebnisse des Mikrozensus 2014. (Erschienen 2015, korrigiert 2017), abgerufen am 22.09.2017 von https://www.destatis.de/DE/Publikationen/Thematisch/ Bevoelkerung/AlteAusgaben/MigrationshintergrundAlt. html.

Stiftung Bildungspakt Bayern (2017): Lernen in zwei Sprachen - Bilinguale Grundschule Englisch, abgerufen am 18.10.2017 von http://bildungspakt-bayern.de/lernen-inzwei-sprachen-bilinguale-grundschule-englisch/.

(TKM) Thüringer Kultusministerium (Hrsg.) (2003): Lehrplan Deutsch als Zweitsprache. J. Maiß: Erfurt. 
(TMBWK) Thüringer Ministerium für Bildung, Wissenschaft und Kultur (Hrsg.) (2010): Lehrplan für die Grundschule und für die Förderschule mit dem Bildungsgang der Grundschule. Fremdsprache. Erfurt: Thüringer Ministerium für Bildung, Wissenschaft und Kultur.

(FMKS) Verein für frühe Mehrsprachigkeit an Kindertageseinrichtungen und Schulen (o.D.): Frühe Mehrsprachigkeit an Kitas und Schulen [=Ankerseite des FMKS], abgerufen am 22.09.2017 von http://www.fmks-online.de/bilikitas. html.

(FMKS) Verein für frühe Mehrsprachigkeit an Kindertageseinrichtungen und Schulen FMKS e. V. (2014a): Bilinguale Kitas in Deutschland, abgerufen am 5.6.2017 von www. fmks-online.de/_wd_showdoc.php?pic=1043.

(FMKS) Verein für frühe Mehrsprachigkeit an Kindertageseinrichtungen und Schulen FMKS e. V. (2014b): Bilinguale Grundschulen in Deutschland, abgerufen am 5.6.2017 von http://www.fmks-online.de. 



\section{Anhang}

\section{Anhang 1: Fragenkatalog zur Beantwortung durch die Experten (rev. Fassung)}

1. Welche Fremdsprachen?

2. Beginn des Fremdsprachenunterrichts (FU) in der Grundschule? Stundenzahl?

3. Vorbereitung durch Immersions- bzw. bilinguale Kindertagesstätten?

4. Gibt es Immersions-Programme / bilingualen Sachfachunterricht / bilinguale Module / fächerübergreifenden Unterricht / fächerübergreifende Projekte? In welcher Form werden diese Programme konkret umgesetzt?

5. Prozent der Kinder mit Migrationshintergrund?

6. Wie werden Mehrsprachigkeit / dezidierter Zweitsprachenunterricht / Familiensprachenunterricht berücksichtigt bzw. umgesetzt?

7. Rolle der Inklusion im frühen FU?

8. Wann beginnt der Einsatz der Schriftsprache? Wird die Schriftsprache nach den Richtlinien unterrichtet? Falls nicht, wo wird abgewichen?

9. Was ist der Stellenwert von Language Awareness (Grammatik)?

10. Welchen Stellenwert haben Sprachlernkompetenz, methodische, funktional-kommunikative und interkulturelle Kompetenz?

11. Welche sprachlichen Mittel (Wortschatz, Redemittel) werden in Lehrplänen am Ende von Klasse 4 erwartet? Welche werden gezielt eingeführt / vermittelt? Offenheit der Richtlinien (messbar z. B. durch vorgegebene Listen für rezeptiven und / oder produktiven Wortschatz)? 
12. Unterrichtsmethoden / Einsprachigkeit des Unterrichts / Verwendung von offenen Lernarrangements?

13. Lehrwerke

- Welche Lehrwerke werden benutzt?

- Häufigkeit ihrer Verwendung im Unterricht?

- Häufigkeit der Verwendung von auditiven/audio-visuellen Elementen der Lehrwerke?

14. Verwendung von authentischen Materialien?

15. Benoteter FU? Form der Leistungsbewertung: Was (Skills/ Wortschatz/Language Awareness/ Lernmethoden, ...), wie gemessen und bewertet?

16. Portfolio

- Ist ein Portfolio Teil der Leistungsbewertung?

- Sind die Selbstreflexionstools in englischer, deutscher oder einer sonstigen Sprache verfasst?

- Wie wird mit dem kreativen Teil des Portfolios umgegangen?

- Weiterführende Schulen: Wie wird das Portfolio der Grundschule genutzt?

17. Wird Englisch von FachlehrerInnen (Staatsexamen für Englisch Primarstufe) unterrichtet?

18. Wie sieht der Ausbildungshintergrund der Lehrkräfte aus? Gibt es Weiterbildungsangebote?

19. Wer ist bei der Mitgestaltung von Lehrplänen involviert?

20. Welche Übergangsregelungen und Maßnahmen gibt es? (z.B. Kooperation, gegenseitige Hospitationen, gegenseitige Teilnahme an Fachkonferenzen, schulinterne/ -externe Fortbildungen)

21. Forschungsergebnisse 


\section{Anhang 2: Exemplarischer Frage- und Abstimmungsbogen}

Name

Bundesland

Telefon/ E-Mail

Wie wird der Schriftspracherwerb gehandhabt?

- Der Beginn des Einsatzes der Schriftsprache variiert nach wie vor:

BB, NRW, RP, SH: ab Jgst. 1

BE, BY, HH, HE, MV, NI, SL, SN, ST, TH (in Ausnahmefällen auch ab Jgst. 1): ab Jgst. 3

HB: Je nach Lernvoraussetzung einer Klasse kann ab Jgst. 3 mit dem Schriftsprachenerwerb behutsam begonnen werden, sollte aber spätestens zu Beginn Jgst. 4 erfolgt sein.

BW: Behandlung der Schriftsprache wird vorverlegt (Bildungsplan 2004 ab Jgst. 3, 2016 ab Jgst. 1).

\section{Abstimmung:}

Soll der Schriftspracherwerb ab Jgst. 1 beginnen?

\begin{tabular}{|c|c|c|c|c|}
\hline Stimme zu & $\begin{array}{l}\text { Stimme } \\
\text { eher zu }\end{array}$ & $\begin{array}{l}\text { Weder } \\
\text { noch }\end{array}$ & $\begin{array}{l}\text { Stimme eher } \\
\text { nicht zu }\end{array}$ & $\begin{array}{l}\text { Stimme } \\
\text { nicht zu }\end{array}$ \\
\hline$\bigcirc$ & $\bigcirc$ & $\bigcirc$ & $\bigcirc$ & $\bigcirc$ \\
\hline
\end{tabular}

Für evtl. weitere Anmerkungen (bitte auch Rückseite benutzen): 
- Die beim Lesen und Schreiben zu erreichenden Ziele variieren in ihrem Anspruch.

BW: Widersprüchliche Ziele: Einerseits bereits in Jgst. 2: „Die Schülerinnen und Schüler [...] können bereits bekannte vorhandene Medien für selbstständiges Lernen nutzen“ (Ministerium für Kultus, Jugend und Sport 2004: 74); andererseits erfolgt das Abschreiben einzelner Wörter erst ab Jgst. 3 (ab 2016: Jgst. 2); Jgst. 4: „Die Schülerinnen und Schüler [...] besitzen auch durch die Arbeitsweise in anderen Fächern Lerntechniken, wie etwa die Verwendung von altersangemessenen einfachen Nachschlagewerken [...] und können auf individuelle Weise erste Notizen anfertigen“ (ebd., 77). RP: „Die SuS sollen im Verlauf der Grundschulzeit erste Erfahrungen mit dem Schriftbild sammeln (einzelne Wörter, kurze Sätze lesen und schreiben).“

HH: Ende Jgst. 4: A1 (GER): „Ich kann eine kurze einfache Postkarte schreiben, z. B. Feriengrüße. Ich kann auf Formularen, z. B. in Hotels, Namen, Adresse, Nationalität usw. eintragen “ - Bewertung ab Jgst. 3.

SH, ST: Mit Hilfe von Beispieltexten werden „eigene kleine Texte" - meist mit Bezug auf die eigene Person verfasst. Es wird nichts aus dem Gedächtnis geschrieben.

BE: freie Schreibversuche ganzer Sätze

TH: genaue Vorgaben zum Einsatz der Schrift; Anspruchsniveau ist Schreiben nach Vorlage, in sinnvollen Zusammenhängen und mit kommunikativer Funktion. Vorschläge für Lernzielkontrollen.

\section{Abstimmung:}

Sollen am Ende der Jgst. 4 ganze Sätze abgeschrieben sowie frei geschrieben und bewertet werden?

\begin{tabular}{|c|c|c|c|c|}
\hline Stimme zu & $\begin{array}{l}\text { Stimme } \\
\text { eher zu }\end{array}$ & $\begin{array}{l}\text { Weder } \\
\text { noch }\end{array}$ & $\begin{array}{l}\text { Stimme eher } \\
\text { nicht zu }\end{array}$ & $\begin{array}{l}\text { Stimme } \\
\text { nicht zu }\end{array}$ \\
\hline$\bigcirc$ & $\bigcirc$ & $\bigcirc$ & $\bigcirc$ & $\bigcirc$ \\
\hline
\end{tabular}


Für evtl. weitere Anmerkungen (bitte auch Rückseite benutzen):

- Es kommen unterschiedliche Vermittlungsweisen zum Einsatz.

\section{Analytische Vermittlungsweisen}

BE: Beim Schreiben werden typischer Buchstabenfolgen des Englischen, Vermittlung einfacher Regeln der Wortbildung als Basisstrategie behandelt.

BB: Beim Lesen werden Unterschiede in den Laut-BuchstabenZuordnungen von Fremdsprache und der deutschen Sprache wahrgenommen.

NRW: Das Schreiben hat [von Anfang an] unterstützende Funktion für einen ganzheitlichen Spracherwerb; Heranführung an Buchstabenfolgen des Englischen; beim Abschreiben von Wörtern/Texten wird zunehmend auf korrekte Schreibweise geachtet.

\section{Ganzheitliche Vermittlungsweisen}

BB: beim Lesen ganzheitliche Erfassung der Wörter

SH: Die S sollen Wortbilder ganzheitlich erfassen und ihnen eine Bedeutung zuordnen. Kleine Texte sollen nach Vorlage geschrieben werden.

Implizite Vermittlungsweisen für die stützende, lernstrategische Funktion der Schriftform

TH: Leseverstehen und Schreiben dienen dem ganzheitlichen Wiedererkennen und Reproduzieren von im Klangbild vertrauten Wortbildern.

HE, NRW, SH; SL: einfache Strukturen (A1) werden mündlich eingeführt und durch das Schriftbild unterstützt. Dabei wird erwartet, dass die Lehrkraft den Unterricht auf Englisch führt und somit permanent die einfachen, schriftlichen Strukturen mündlich entlastet. 
HB: ganzheitliche Mitleseverfahren; Wort-Bild-Zuordnungen, einfache Beschriftungen sollen das FS Lernen unterstützen; das Schriftbild wird als Lernhilfe und Gedächtnisstütze genutzt. ST: Schriftsprache wird erst nach ausreichender Festigung der semantischen und akustisch-artikulatorischen Komponente eingesetzt.

\section{Abstimmung:}

Sollen die Lernenden auf einzelne Laut-Buchstaben-Korrespondenzen der Fremdsprache, die vom Deutschen abweichen, aufmerksam gemacht werden?

\begin{tabular}{|c|c|c|c|c|}
\hline Stimme zu & $\begin{array}{l}\text { Stimme } \\
\text { eher zu }\end{array}$ & $\begin{array}{l}\text { Weder } \\
\text { noch }\end{array}$ & $\begin{array}{l}\text { Stimme eher } \\
\text { nicht zu }\end{array}$ & $\begin{array}{l}\text { Stimme } \\
\text { nicht zu }\end{array}$ \\
\hline$\bigcirc$ & $\bigcirc$ & $\bigcirc$ & $\bigcirc$ & $\bigcirc$ \\
\hline
\end{tabular}

Für evtl. weitere Anmerkungen (bitte auch Rückseite benutzen): 